\title{
Low Temperature Combustion Demonstrator for High Efficiency Clean Combustion
}

\author{
DE-FC26-05NT42413
}

Final Report

26 October 2010

\author{
Navistar \\ William de Ojeda, PhD, PE \\ Principal Investigator \\ Tel: (708) 865-4074 \\ Fax: (708) 865-4169 \\ 10400 W. North Avenue \\ Melrose Park, IL 60160
}




\section{Executive Summary}

The project which extended from November 2005 to May of 2010 demonstrated the application of Low Temperature Combustion (LTC) with engine out NOx levels of $0.2 \mathrm{~g} / \mathrm{bhp}$-hr throughout the program target load of 12.6bar BMEP. The project showed that the range of loads could be extended to 16.5bar BMEP, therefore matching the reference lug line of the base 2007 MY Navistar 6.4L V8 engine.

Results showed that the application of LTC provided a dramatic improvement over engine out emissions when compared to the base engine. Furthermore LTC improved thermal efficiency by over $5 \%$ from the base production engine when using the steady state 13 mode composite test as a benchmark.

The key enablers included improvements in the air, fuel injection, and cooling systems made in Phases I and II. The outcome was the product of a careful integration of each component under an intelligent control system. The engine hardware provided the conditions to support LTC and the controller provided the necessary robustness for a stable combustion.

Phase III provided a detailed account on the injection strategy used to meet the high load requirements. During this phase, the control strategy was implemented in a production automotive grade ECU to perform cycle-by-cycle combustion feedback on each of the engine cylinders. The control interacted on a cycle base with the injection system and with the Turbo-EGR systems according to their respective time constants. The result was a unique system that could, first, help optimize the combustion system and maintain high efficiency, and secondly, extend the steady state results to the transient mode of operation.

The engine was upgraded in Phase IV with a Variable Valve Actuation system and a hybrid EGR loop. The impact of the more versatile EGR loop did not provide significant advantages, however the application of VVA proved to be an enabler to further extend the operation of LTC and gain considerable benefits in fuel economy and soot reduction. Finally, the transient demonstration was performed in Phase IV.

The project demonstrated the achievement of meeting US10 emissions without NOx aftertreatment. The successful execution of the project has served to highlight the effectiveness of closely matched combustion predictive tools to engine testing. It has further served to highlight the importance of key technologies and future areas of research and development. In this regard, recommendations are made towards further improvements in the areas of engine hardware, fuel injection systems, controls and fuels. 


\section{Contributing Authors}

\section{Principal Investigator}

\section{Section Leads}

Multi-Cylinder Combustion Development

Controls Systems Development

Injector Development

VVA Engine

CFD Modeling

Engine Build

\section{Special Technical Assistance}

Program Managment

Single-Cylinder Combustion Testing

Engine Testing

CFD Modeling

Fuel formulation

Turbocharger design and procurement

Piston design and procurement

Variable Valve Actuation System

Fuel Injector design and procurement

Department of Energy, Development Manager

NETL, Project Manager
William de Ojeda, Navistar

Raj Kumar, Navistar

Tom Machamer, Navistar

Raul Espinosa, Navistar

Ilya Sagalovich, Navistar

Chunyi Xia, Navistar

Daniel Cornelius, Navistar

Phil Zoldak, Navistar

Kishore Kavuri, Navistar

Ning Lei, Navistar

Tytus Bulicz, Navistar

Yuyu Tan, University of Windsor

Prof. Ming Zheng, University of Windsor

Per Andersson, Ricardo

Daniel Flowers, LLNL Jonas Edman, LLNL

Fred Cornforth, ConocoPhillips

John Watson, BorgWarner

Luiz Perrone, Mahle

Ken Wirkkala, Mahle

Steve Ernest, Jacobs Vehicle Systems

Ulrich Augustin, Continental

Ken Howden

Sam Taylor 


\section{Table of Contents}

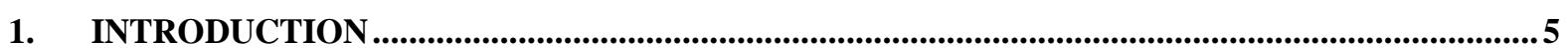

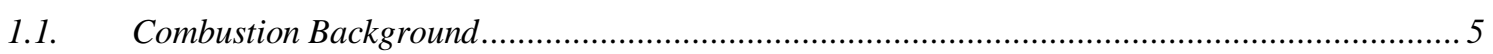

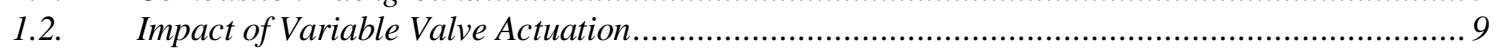

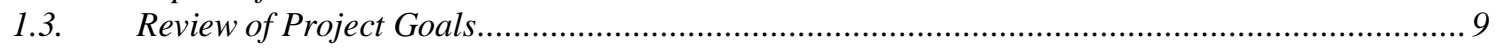

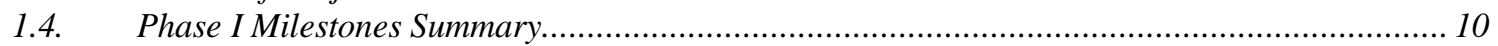

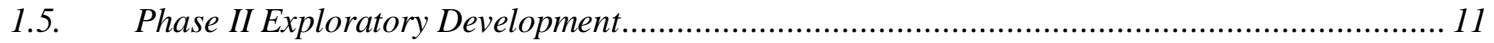

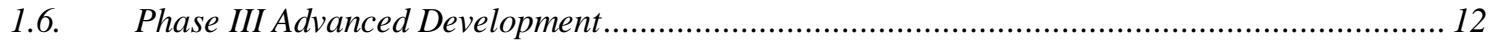

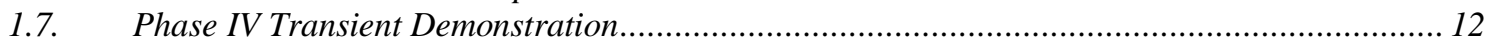

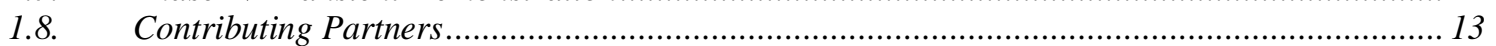

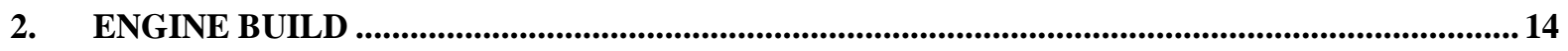

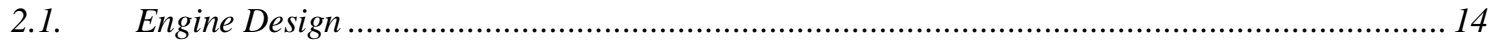

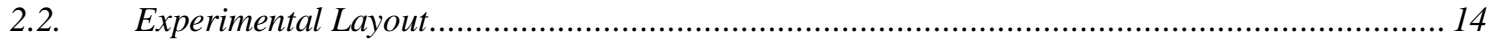

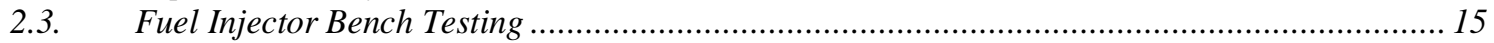

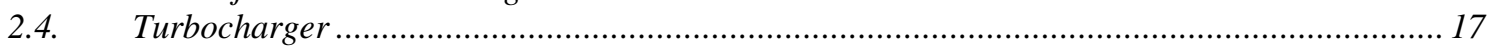

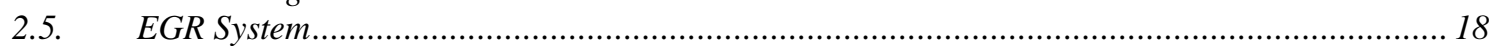

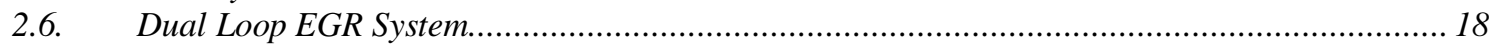

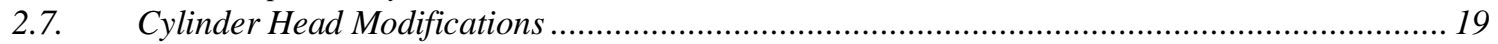

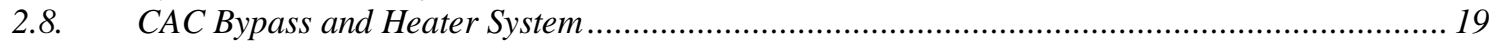

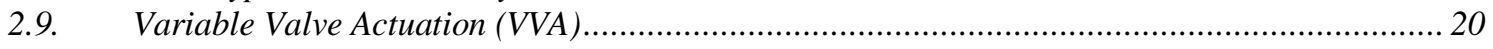

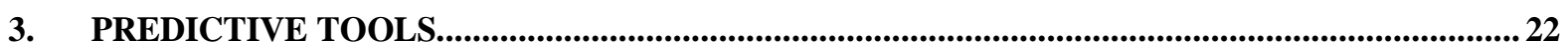

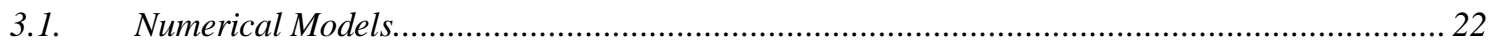

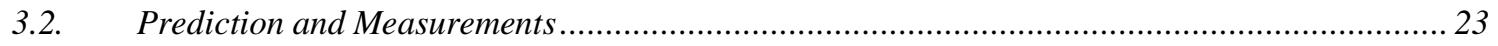

4. LOW TEMPERATURE COMBUSTION _......................................................................................29

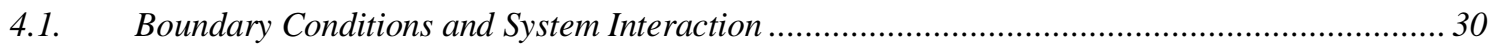

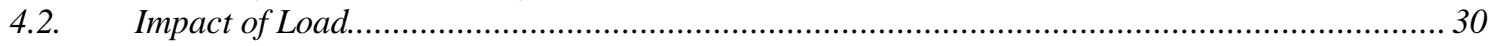

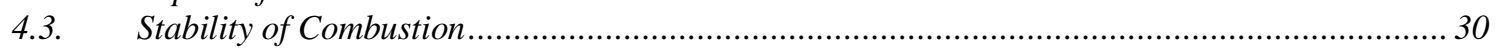

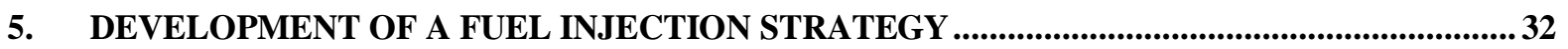

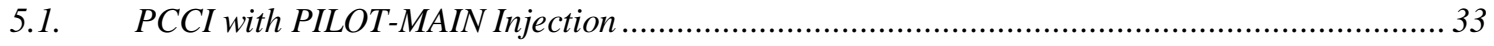

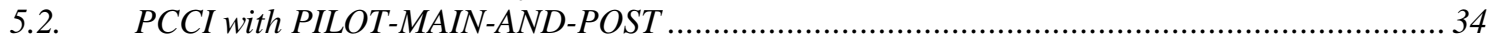

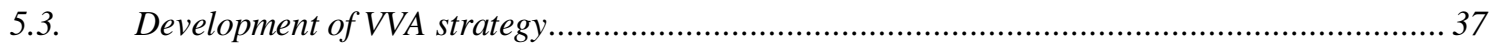

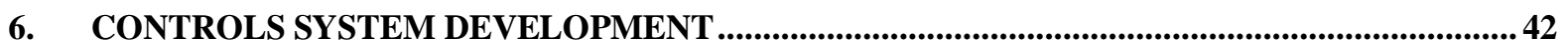

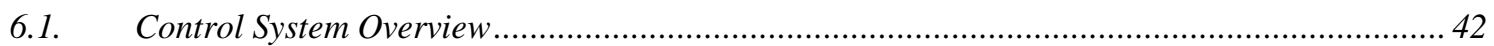

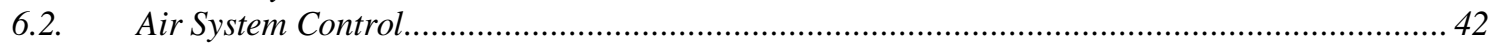

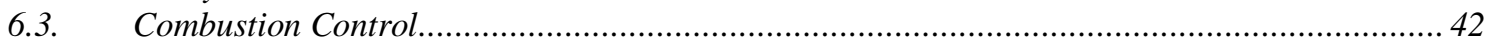

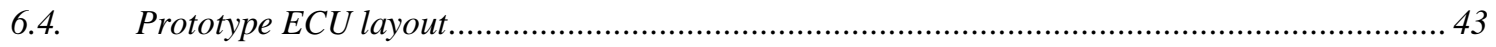

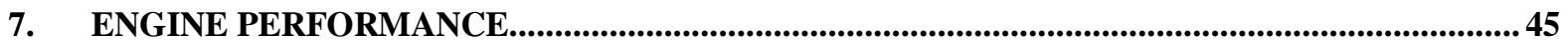

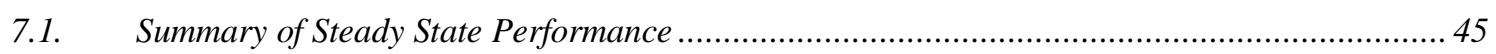

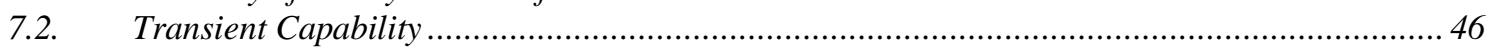

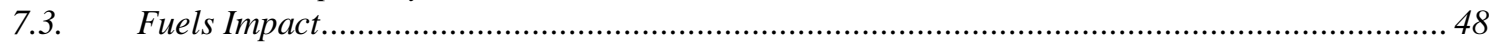

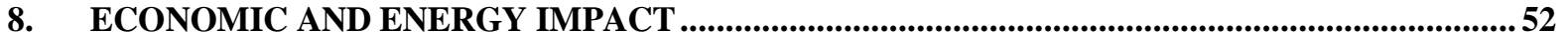

9. SUMMARY OF ACHIEVEMENTS.........................................................................................56

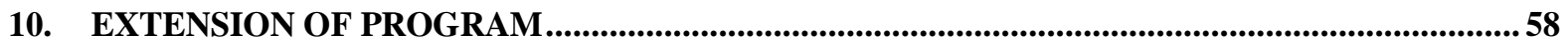

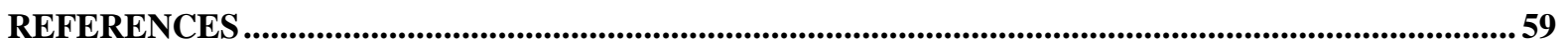




\section{Introduction}

Navistar has conducted research into future combustion technologies under the DOE project (DEFC26-05NT42413) entitled "Low Temperature Combustion Demonstrator for High Efficiency Clean Combustion"

The present project required the development and integration of several supporting technologies into a highly refined system to yield better performance and lower emissions than current Diesel combustion. Specifically, the goal was to achieve 2010 Federal emission requirements without the use of active NOx aftertreatment while demonstrating better fuel economy over the base engine.

A production version of the International 2007MY 6.4L V-8 engine was redesigned to support LTC conditions up to 16.5bar BMEP. These conditions yielded NOx levels below $0.2 \mathrm{~g} / \mathrm{bhp}$-hr with soot levels tolerable by present day DPF technology. The brake thermal efficiency was likewise improved over the base engine by over 5\% across the engine map, and over $10 \%$ in some operating conditions.

The main contributors to this work were:

- The air system design, consisted of a two stage turbo-compressor system matched to the operating conditions of the engine, specifically to the levels of EGR required in the program. The EGR system encompassed two parallel coolers with a separate cooling circuit, and regulating valves and sensors to accurately estimate the rates of flow.

- Injection system and strategy, which was optimized to prepare the in-cylinder fuel distribution as the load increased. Improved modeling capabilities, including 3-D CFD to capture the interaction between injection and chemistry of combustion provided valuable insight to optimize the injection strategies.

- A Variable Valve Timing Technology, providing the first successful demonstration of the application of VVA on a modern medium duty Diesel engine to successfully impact emissions and fuel economy. The system is simple and robust, providing fine intake valve closing resolution independently for each cylinder, and capable of cycle to cycle adjustments.

- Control system, designed to be capable of detecting in-cylinder combustion characteristics, including combustion phasing and torque. The system is capable to interact on a cycle base with the injection system (such as to maintain a target combustion phasing) and with the air-EGR systems to provide or ensure close uniformity across the cylinders. In effect, the system has the ability to provide tight control over fuel and air.

\subsection{Combustion Background}

The temporal and spatial generation of the emissions, particularly NOx and soot has been analyzed by laser-diagnostics, modeling and in-cylinder sampling studies. Based on these studies, the local incylinder temperature and local in-cylinder air-fuel ratio distribution are considered the primary factors effecting the in-cylinder NOx and soot formation. Researchers have tried to characterize the emission formation on the $\Phi-T$ space and identify the regions where simultaneous low-NOx and lowsoot combustion may be obtained. 
Figure 1 shows an illustrative $\Phi-T$ diagram with conventional combustion and two commonly used clean-combustion modes, homogenous charge compression ignition ( $\mathrm{HCCl}$ ) and low-temperature combustion (LTC).

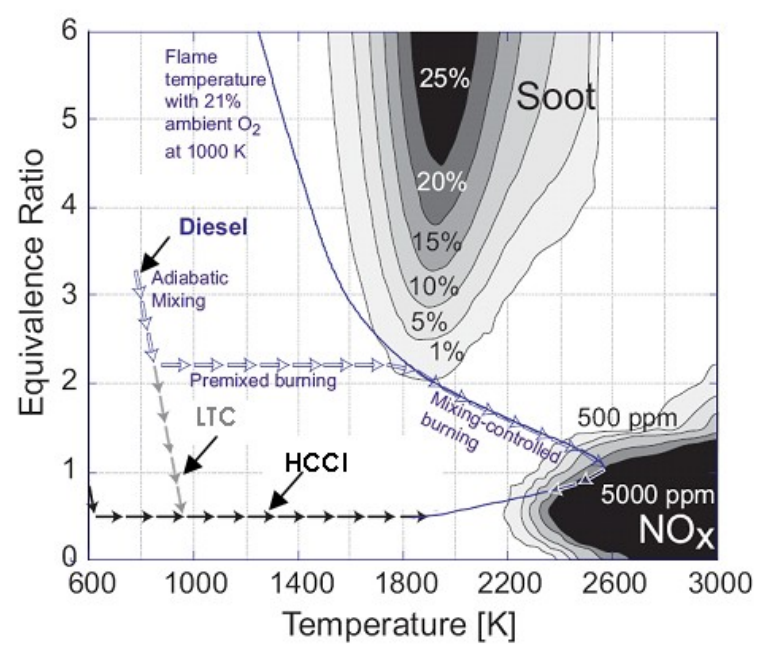

Figure 1 Illustration of conventional and variants of clean diesel combustion on $\Phi-T$ map [1]

Conceptually, for the conventional diesel combustion, the fuel-air charge undergoes rich combustion at the end of the adiabatic mixing process during the ignition delay period. This rich combustion may lead to soot-formation depending upon the sooting tendency of the fuel and the $\Phi-T$ distribution during the pre-mixed combustion phase. Once the fuel reaches the flammability limit it combusts, so the rate of combustion proceeds on a mixing-controlled basis. During the course of diesel combustion, the thermal NOx is generated at times when the local in-cylinder temperatures are in excess on 1800 2000K and there is sufficient oxygen availability. For the traditional diesel combustion, the local- $\Phi$ and the local-T stretch into NOx and the soot islands and as a consequence both engine-out NOx and soot are observed. The $\Phi-\mathrm{T}$ map has also been used to formulate pathways for simultaneous low-NOx and low-soot combustion and these have been called $\mathrm{HCCl}$ and LTC pathways as shown in Figure 1.

\section{$\underline{\mathrm{HCCl} \text { Combustion }}$}

The combustion of a lean or diluted, well-premixed cylinder charge has shown to yield simultaneous low-NOx and low-soot emissions and this type of combustion has come to be known as $\mathrm{HCCl}$ combustion. $\mathrm{HCCl}$ combustion does not rely on maintaining a flame front and is instead characterized by spontaneous auto-ignition of cylinder charge at multiple points and this allows for the combustion of very lean or the dilute mixture. The flame temperatures are significantly lower than the diesel combustion given the lean or diluted cylinder charge conditions and thereby result in low engine-out NOx. At the same time the well-premixed nature of the cylinder charge helps to lower the soot emissions as well. The pathway for $\mathrm{HCCl}$ has been shown by solid black arrows in Figure 1.

Challenges of $\mathrm{HCCl}$ Combustion. The traditional approach to prepare the lean-premixed mixture for conventional diesel fuel is by injecting all the fuel very early during the compression stroke in a single or series of injection events depending on the engine-speed and the load condition. The preparation of the lean-premixed mixture is considered challenging because of the low-volatility and the high cetane number for the conventional diesel fuel. The low-volatility of the diesel fuel necessitates that the in-cylinder injection strategies are initiated after $280 \sim 290^{\circ}$ which limits the time duration available for mixture preparation for a typical application. Note that these injection windows are dependent on compression-ratio, and intake-temperature. Similarly, the high cetane number of the conventional diesel fuel results in a strong propensity for the fuel to auto-ignite during the compression stroke, 
causing large rates of pressure rise and poor power output. Large amounts of cooled EGR, variablevalve timing (VVA) or variable-compression ratio (VCR) are some of the commonly used techniques for suppressing the auto-ignition of the fuel injected early during the compression and attain the appropriate combustion phasing. Tremendous progress has been made in understanding the $\mathrm{HCCl}$ combustion in the recent times, however, implementation of a robust combustion phasing control in a multi-cylinder engine with conventional diesel fuel in a production feasible way is still considered a major challenge.

\section{LTC Combustion}

Another alternative combustion mode being actively investigated for achieving clean-diesel combustion is LTC. In this combustion mode, the soot suppression is realized by lowering the combustion temperature below the threshold temperature for soot formation. At such low flametemperatures, the reactions forming soot particles from polycyclic aromatic hydrocarbons (PAH) are inhibited even at air-fuel ratios approaching near stoichiometric conditions.

Challenges of $L T C$. The low-temperature necessary for smokeless combustion has been traditionally obtained with the application of large amounts of cooled EGR. The high EGR rates necessary of this type of combustion also result in increasingly in-complete combustion as indicated by formation of large amounts of carbon-monoxide (CO) and un-burnt hydrocarbon (UHC), both of which result in a significant impediment to maintain the high fuel economy of the diesel engine cycle. Several LTC experiments, at moderate to high load with conventional diesel fuel have been reported on a single cylinder engine. The application of LTC in a single cylinder engine is facilitated by the decoupled behavior of the boost and the EGR system; however such an air-management is not possible with the turbocharger system commonly present in a production engine. For a production engine, the application of large EGR rates can incur a significant penalty on boost levels available and the soot may increase with EGR much more rapidly. In addition it may be noted that the single-cylinder LTC experiment results are usually reported for tests performed at constant fueling. This is in direct contrast to a production intent multi-cylinder experiment where the tests are performed on constant load, which necessitates that the fueling be constantly adjusted to maintain a constant load even in the regions where the LTC engine cycle efficiency begins to drop significantly in the presence of high $\mathrm{CO}$ and $\mathrm{HC}$.

\section{$\underline{\mathrm{PCCl} \text { as a middle path between conventional and clean-diesel combustion modes }}$}

A compromise to avoid the difficulties of $\mathrm{HCCl}$ or LTC combustion is the $\mathrm{PCCl}$ combustion. In the present work the authors have demonstrated that a NOx 0.2g/hp-hr and an after-treatment tolerant soot level may be obtained with PCCI combustion to a load 16bar BMEP (brake mean effective pressure). This concept borrows features from both $\mathrm{HCCl}$ and LTC combustion modes.

Table 1and Table 2 compare the characteristics of the PCCl combustion with the $\mathrm{HCCl}$ and LTC respectively.

\section{Comparison of $\mathrm{HCCl}$ and $\mathrm{PCCl}$ combustion}

$\mathrm{HCCl}$ combustion suffers from the challenge of combustion-phasing control, limited load range and homogenous mixture preparation for a multiple-cylinder engine. To overcome these challenges, in $\mathrm{PCCl}$ combustion, only a part of the fuel undergoes $\mathrm{HCCl}$ type of clean combustion, while the remainder of the fuel undergoes conventional combustion. Since the majority of the fuel is undergoing conventional combustion, the combustion-phasing control is still governed by the injection scheduling. Since, only a part of the fuel is used to prepare cylinder-charge of enhanced homogeneity, the mixture preparation for $\mathrm{PCCl}$ combustion is less challenging in comparison to $\mathrm{HCCl}$ combustion. For the PCCl combustion, the late-cycle "soot-oxidation" may be employed by post-injection to limit the engine-out soot, an aspect significantly different from the $\mathrm{HCCl}$ combustion that targets primarily the "soot-formation" process. In the current experiments with $\mathrm{PCCl}$ combustion, maximum soot level of 2FSN (Filter Smoke Number) is targeted, whereas the $\mathrm{HCCl}$ combustion targets a near zero soot 
level. The low-NOx emissions are obtained in $\mathrm{HCCl}$ combustion by either pre-mixing to very lean equivalence ratios or by diluting the cylinder charge with EGR. However, for the PCCI combustion, retarded combustion phasing and a moderate amount of EGR are the primary enablers for NOx reduction.

Table 1 Comparison of $\mathrm{HCCl}$ and $\mathrm{PCCl}$

\begin{tabular}{|c|r|r|}
\hline & Diesel HCCI & Diesel PCCI \\
\hline Injection strategy & $\begin{array}{r}\text { Lean homogenous mixture for } \\
\text { simultaneous NOx and soot reduction }\end{array}$ & $\begin{array}{c}\text { Lean homogenous mixture prepared by part of the fuel } \\
\text { Rest of fuel undergoes conventional combustion }\end{array}$ \\
\hline NOx & $\begin{array}{r}\text { NOx reduction due to lean } \\
\text { homogenous charge or EGR dilution }\end{array}$ & EGR for NOx reduction \\
\hline Soot & Homogenous mixture (near zero) & Engine-out target soot <2FSN \\
\hline
\end{tabular}

\section{Comparison of LTC and PCCl combustion}

From a mechanism point of view, the simultaneous low-NOx and low-soot combustion is realized during LTC by lowering the combustion temperature below the threshold for NOx and soot formation on the $\Phi-T$ map. The use of large amounts of cooled EGR along with lowered compression ratio is one of the principle strategies to limit the flame temperatures. The injection strategies for the LTC combustion primarily consist of a single injection close to the TDC. The lowered in-cylinder temperature and the use of large amounts of EGR help to prolong the ignition delay and thereby, enhance the homogeneity of the fuel-air mixture in comparison to the conventional diesel combustion and lower the in-cylinder soot formation. Note the short times between the fuel injection event and the start of combustion still preclude thorough pre-mixing during LTC.

For PCCl combustion, the use of EGR is limited to reduce the combustion flame temperature below the threshold limit for NOx alone and no attempt is made to approach the temperature threshold limit for soot formation. For the PCCI combustion, a retarded combustion-phasing (described by the crankangle of $50 \%$ mass fraction burnt, CA-50) and an appropriate level of EGR was applied to limit the NOx levels to less than $0.2 \mathrm{~g} / \mathrm{hp}$-hr. If the soot level was more than $2 \mathrm{FSN}$, then the appropriate $\mathrm{PCCl}$ injection strategy was applied to limit the engine-out soot. For soot reduction, two injection strategies were used; pilot-with-main (Pil-M), and pilot-with-main-and-post (PMP). In the Pil-M injection strategy, the pilot fuel was delivered very early during the compression stroke; while the main fuel was delivered at close to top-dead-center (TDC). The pilot fuel typically had an ignition delay of more than 2 milli-seconds (ms) which helped to enhance the homogeneity of the pilot fuel and air mixture before the combustion process. The enhanced homogeneity of the pilot fuel helped to reduce the soot-level by up to 1FSN depending on the quantity of fuel injected, as shown later in the experiments. On an energy basis, the pilot fuel was kept to less than $25 \%$ of the total energy. This injection strategy was valid up to a load of $\sim 10$ bar BMEP, while at higher loads the Pil-M injection strategy alone was insufficient for lowering the soot levels to less than 2FSN. Therefore, at higher loads late cycle soot oxidation was implemented using PMP injection strategy.

Table 2 Comparison between LTC and PCCI

\begin{tabular}{|c|c|c|}
\hline & Diesel LTC & Diesel PCCI \\
\hline Injection strategy & Primarily single-shot & Primarily multiple-shot \\
\hline NOx & EGR for NOx reduction. & EGR for NOx reduction. \\
\hline Soot & $\begin{array}{c}\text { Uses large amounts of EGR to } \\
\text { suppress soot formation. }\end{array}$ & Multiple injection to target soot $<2$ FSN \\
\hline
\end{tabular}




\subsection{Impact of Variable Valve Actuation}

The use of VVA has been pursued in recent years in research platforms across a wide range of engine displacements. No production Diesel engine has deployed this technology yet. The merits of VVA have nevertheless been made apparent in these research platforms, particularly in light of combustion strategies like LTC. It is likely that in time this technology will be incorporated into advanced Diesel powertrains. On the Light Duty side, the work of ref [2] performed in a SCTE (0.5L) showed the effects of Late Intake Valve Closing (LIVC) at $25 \%$ and $50 \%$ load. Results showed that VVA lowered the effective compression ratio, lowered in-cylinder temperatures, increased ignition delay (noted in Figure 2) and reduced smoke despite lower excess air ratios. The use of LIVC, EGR, supercharging and high-pressure fuel injection simultaneously reduced NOx and smoke. The authors noted that high $\mathrm{CO}$ and THC competed with fuel economy.

On the Heavy Duty, the work of ref [3], performed in a SCTE (2.4L displacement), demonstrated that LIVC at $50 \%$ load was capable to reduce NOx to below the EPA 2010 limit. The authors further showed the boost compensation required to keep soot at $\sim 0.01 \mathrm{~g} / \mathrm{kW}$-hr, noted in the Figure 2 below.
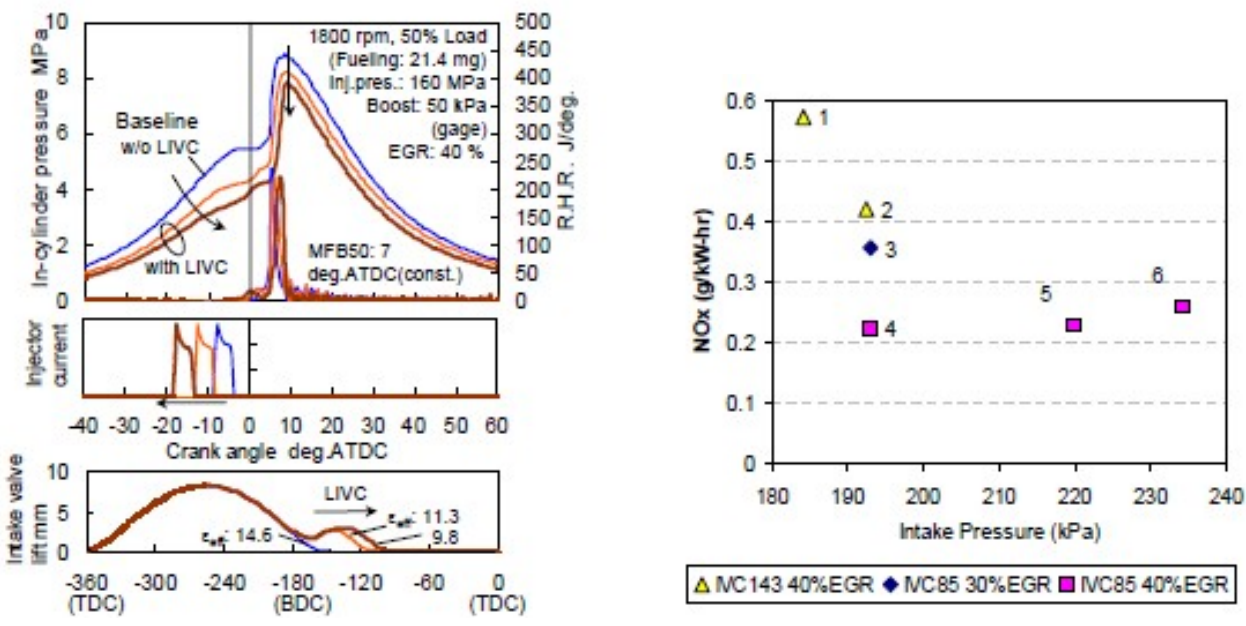

Figure 2 Application of VVA to LD [ ] and HD [ ] Diesel engines

\subsection{Review of Project Goals}

The project consisted in attaining low engine NOx and high efficiency through a four phase program as outlined in the figure below. The initial target load of 12bar BMEP was met by April of 2008, and further work showed the system capable of running LTC at above 16bar BMEP. Updates of the ongoing research have been made available through the Diesel Engine-Efficiency and Emissions Research (DEER) conferences.

Five specific goals were outlined from the onset of the program.

Goal 1: US10 Emissions. LTC has shown its feasibility in achieving compliance with heavy-duty US10 emission standards [4]. Due to its low temperature operation LTC would be used to lower NOx emissions levels. An oxidation catalyst would be used to mitigate the inherent high $\mathrm{HC}$ emissions and keep the total PM level in line with target emissions.

Goal 2: Ten Percent Efficiency Improvement. The program sought to provide a target improvement of $10 \%$ higher efficiency compared to the base engine. 


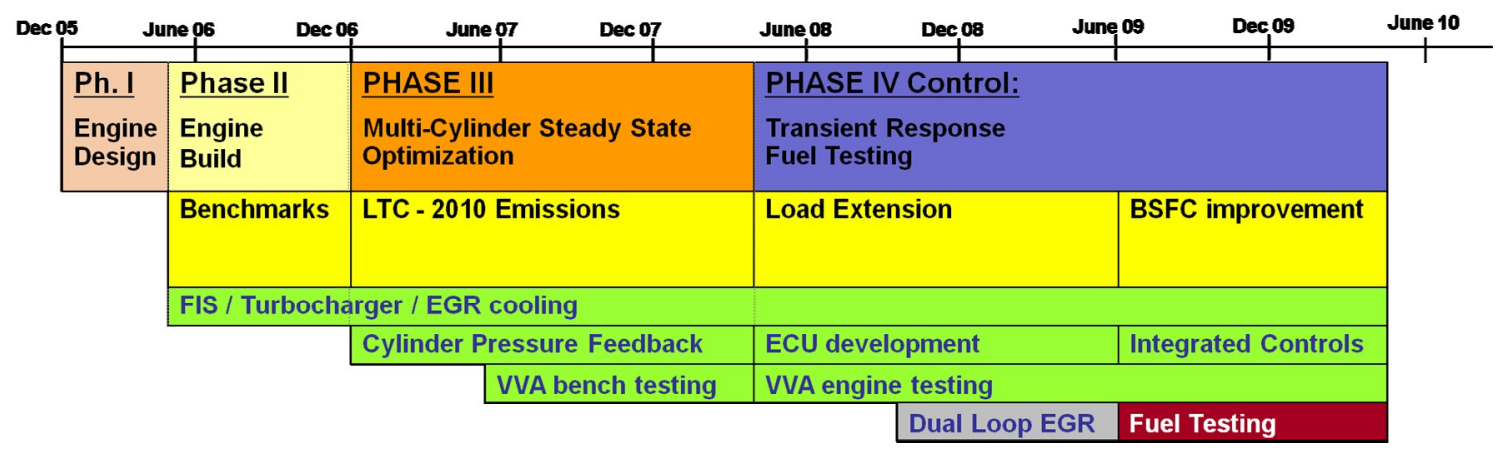

Figure 3 DOE LTC program demonstrator timeline

Goal 3: Conventional Power Density. The project was to address the LTC challenges with light load misfire and high load early ignition by enabling advanced technologies.

For light load, a combination of EGR and early injection (single or multiple) was expected to provide locally lean mixtures. Although not truly homogeneous, the system would provide low NOx and soot.

For high load, pilot with main injection, EGR, and higher boost pressure would enable LTC conditions. Further capability would be provided by the use of intake valve closing (IVC) control to lower effective compression ratio. Decreased in-cylinder pressures and temperatures would limit heat release rates, and enable better control over NOx and soot emissions. Testing would show that the injection strategy would play a critical role in managing the soot emissions during low NOx combustion, including the application of post injection.

Goal 4: Ability to Operate over Transient Conditions. LTC combustion is sensitive to in-cylinder and intake manifold conditions. Any mismatch can lead to either misfire or very rapid heat release rates. The project would utilize a cylinder pressure based system to monitor the in-cylinder conditions on a cycle-to-cycle basis. Efficient execution would be needed to run the high speed algorithms necessary to control the fuel injection equipment (FIE) and the Variable Valve Actuation (VVA) devices.

The control system based on cylinder pressure feedback would enable a well-controlled start of ignition without misfire throughout the testing.

Goal 5: Compatible with Exhaust Aftertreatment Devices. LTC combustion results in low exhaust gas temperatures. The low temperatures will make it difficult to achieve catalyst light-off and hence lower catalyst conversion and decreasing efficiency at lighter loads. The project would attempt to utilize conventional Diesel operation at light load, VVA, or post-injection to increase exhaust temperatures for catalyst light-off.

\subsection{Phase I Milestones Summary}

The engine design was accomplished by the procedure illustrated in Figure 4 encompassing (1) defining the engine torque curve, (2) defining the boundary conditions to sustain $\mathrm{PCCl}$ combustion, (3) selection of engine hardware, (4) optimized fuel injection equipment, and (5) set up of control supervisor. The modified air management system consisted of a dual-stage turbocharger with a bypass system. It allowed implementation of boundary conditions that target equivalence ratios $(\Phi)$ between 0.6 to 0.9 and EGR levels of $40 \%$ to $50 \%$. A combination of modified EGR-coolers and the intake charger cooler let engine operation at lower intake manifold temperatures compared to the baseline engine. 
Simulation work formed the basis for the hardware specification and subsequent hardware design and procurement. The target compression ratio range was defined between 14 and 16 . During Phase III of the project various compression ratios ranging from 12 to 17 were experimentally examined. The impact of variable intake valve closing (IVC) times was determined and its impact assessed on the air handling equipment. Fuel spray modeling was completed, and fuel injection hardware and strategies were identified that facilitated no or very limited cylinder wall wetting. Engine simulation studies were completed. Utilizing existing test data from the baseline engine, a prediction was made of the FTP cycle fuel consumption. The target engine efficiency was a $5-15 \%$ fuel consumption improvement compared to the LNT/DPF equipped US10 baseline. Finally, an initial economic feasibility study was conducted.

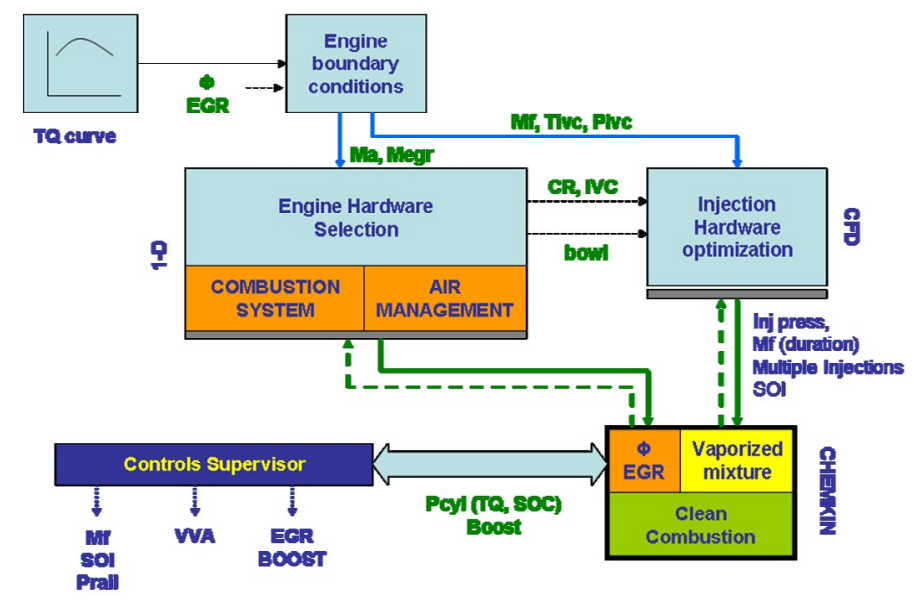

Figure 4 Engine design optimization procedure

\subsection{Phase II Exploratory Development}

The exploratory development of the advanced combustion and controls system consisted of procurement and demonstration of functionality of individual components from the engine designed in Phase I. These components were categorized as engine build components and control system hardware and software. The engine, based on the ITEC 6.4L V8 platform was redesigned to support a low temperature combustion mode for high efficiency and low emissions targeting 2010 federal standards using standard Diesel fuel. The engine was designed to operate in LTC mode to 12.6bar BMEP with room for further expansion.

The key technologies implemented and function tested in Phase II included:

\section{Engine Build Items}

- A custom Charge Air Cooler (CAC).

- Intake Heater Bypass system.

- Multiple sets of new injector nozzles to provide better atomization and mixture.

- Multiple piston bowl configurations including reduced compression ratios.

- An injector bench test unit and calibration procedure used to validate new injector drivers and map injector characteristics prior to engine installation.

- A two-stage BorgWarner turbocharger system.

- Two parallel EGR coolers with a custom two-EGR valve mixer.

- An improved flow cylinder head with flush-mounted pressure transducers. 


\section{Control System Development}

- Stand alone processor, with crank angle based data acquisition with flexible control over custom injector drivers.

- Software to provide combustion diagnostics based on cylinder pressure feedback control, allowing for control over start of combustion and torque.

- Air System control over EGR, VNT and CAC/Bypass.

Production Path for Control System

The above control system was developed based on a Rapid Prototype System hardware, with a Real Time processor speed of $800 \mathrm{Mz}$, flexible in regards to multiple analog and digital I/O. The highly capable system provided a useful proof-of-concept platform. It sought to illustrate the impact of a close loop combustion feedback system on the optimization of the low NOx proposed solution. The following Phase III and IV would be designated to translate this work into a production intent platform.

\subsection{Phase III Advanced Development}

The Phase III or Advanced Development Phase was primarily concerned in demonstrating steady state US10 emission targets. The demonstration took place in a dynamometer lab. The demonstration was successful, as the testing extended the operation of LTC from the target 12.6 bar to 16.5 bar.

In addition, Phase III achieved two major significant milestones:

- The completion of a Variable Valve Actuation (VVA) system. The system was designed as part of this project (a patent application was filed) and was fabricated. The system underwent extensive bench testing, accumulating over 300 hours of operation. It was installed on the engine and tested. The expectations were that this system would have a positive impact on fuel efficiency on part load operation and further improve the emission results.

- $\quad$ Commissioned a control system on engine. An automotive grade Engine Control Unit (ECU) was designed (based on the MPC5554 module) to incorporate cylinder pressure data acquisition channels and combustion feedback software. The strategies developed in the earlier Phase II were transferred to this ECU. The production like ECU was implemented in the engine test cell and demonstrated the ability to control engine under steady state and transient conditions.

In this Phase too, a Variable Compression Ratio (VCR) concept was proposed following a detailed feasibility study. The VCR unit was put on hold however, partly due to time and funding limitations.

\subsection{Phase IV Transient Demonstration}

Phase IV studied the full impact of VVA on the engine performance, specifically on the impact that the valve timing had to reduced the effective compression ratio and its effects in reducing cylinder temperatures. The impact of a dual loop EGR was examined briefly, specifically in the effects of further enabling the air system.

Phase IV of the project continued by demonstrating the transfer of the steady state results to a federal transient cycle. The control system and transient strategies developed to date in Phase III proved successful in coordinating the fuel and air systems when undergoing rapid accelerations. High dilution rates, such as the ones under high rates of EGR, are the primary tool for NOx control. Under high EGR rates however the combustion system is prone to large swings in combustion phasing. These 
conditions can lead to poor combustion efficiency and even to misfire if not properly managed. The present control supervisor was considered a key enabler to maintain combustion stability.

Finally, the program concluded with the evaluation of LTC under a variety of fuels. The fuels examined were the FACE (Fuels for Advanced Combustion Engines) fuels, which are a result from DOE project reviewers to have a consistent set of fuels that could be used in various advanced combustion ( $\mathrm{HCCl}, \mathrm{PCCl}, \mathrm{LTC}$, etc.) engines examining fuel effects. A consistent fuel set would allow comparison of the different engine and control scheme designs. The FACE working group was set up at CRC (the Coordinating Research Council) with the support and participation of oil, auto, government and other interested participants to design a matrix of gasoline and a matrix of diesel fuels.

\subsection{Contributing Partners}

The table below summarizes the team assembled to conduct the research and development work.

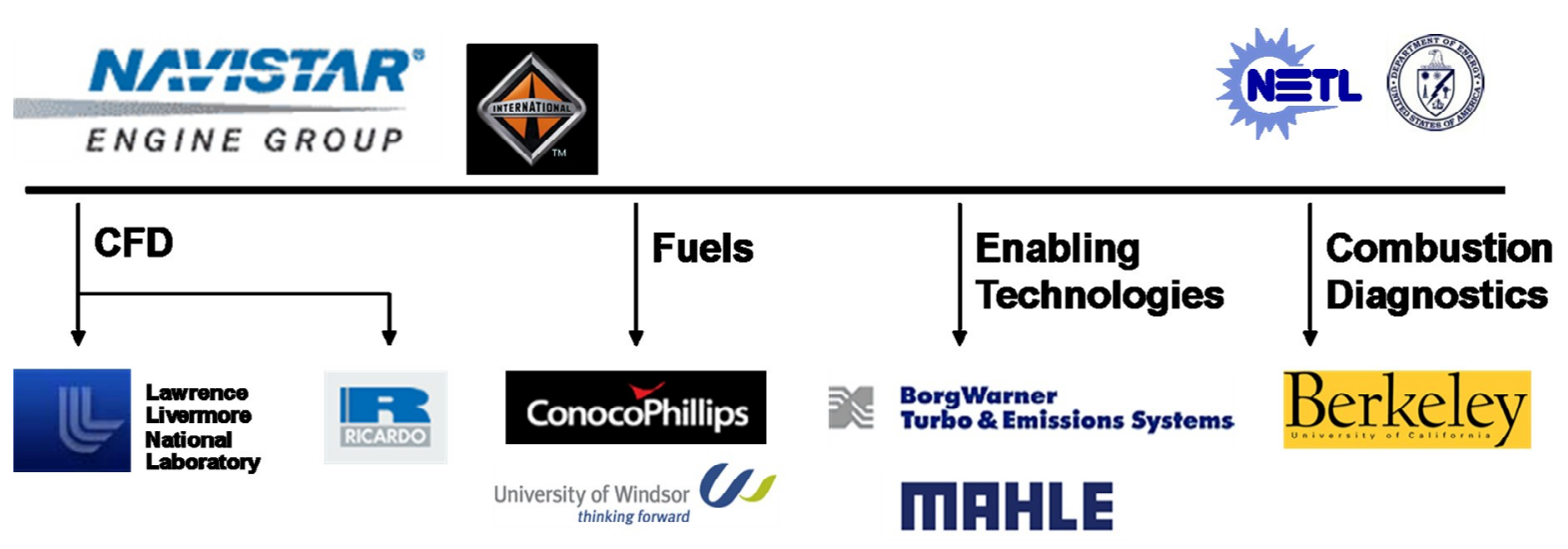

\section{Continental 3}

\section{Thomas}




\section{Engine Build}

\subsection{Engine Design}

The engine used in the present study, beginning in late 2005, was the International's 6.4L V8. The engine was introduced into production in 2007. The engine rating was $220 \mathrm{~kW}$ (300 hp) with peak torque $870 \mathrm{Nm}(650 \mathrm{ft}-\mathrm{lb})$. The engine featured a common rail fuel injection system, a single stageturbocharger, and a high-pressure EGR loop (cooled with engine coolant). Comparison of the base engine data with the present build is presented in Table 3 . The engine was upgraded to a two stage turbocharger, dual parallel coolers and with a variable valve actuation device. Modifications are descried later in this section.

Table 3 Test Engine Specification

\begin{tabular}{|c|c|c|}
\hline & Base Engine & Test Engine \\
\hline $\begin{array}{c}\text { Displacement } \\
\text { Bore } \\
\text { Stroke }\end{array}$ & $\begin{array}{c}6.4 \mathrm{~L} \\
98.5 \mathrm{~mm}\end{array}$ & $\begin{array}{c}6.4 \mathrm{~L} \\
98.5 \mathrm{~mm} \\
105 \mathrm{~mm}\end{array}$ \\
\hline FIE & DI Common Rail & DI Common Rail \\
\hline CR & 16.5 & $12,14.3,16.2^{*}$ \\
\hline Turbo Charger & Single Stage VNT & Dual Stage VNT with by-pass \\
\hline EGR system & HP Loop Single Cooler & HP Loop Dual Cooler \\
\hline IVC & -133 BTDC & -133 BTDC / Variable \\
EVO & 132 ATDC & Wide (non re-entrant) \\
\hline Bowl Geometry & Re-entrant & WTDC \\
\hline
\end{tabular}

${ }^{*}$ Final compression ratio. Other compression ratios tested shown.

\subsection{Experimental Layout}

The engine system schematic for the lab setup is illustrated below in Figure 5. The engine air system incorporated a heater system in parallel to the charge air cooler and the two circuits together allowed intake manifold temperature regulation by using a set of two bypass valves. The heater system was used for the low compression ratio configuration only.

The total hydrocarbons were measured via a heated flame ionized detector, $\mathrm{CO}$ and $\mathrm{CO}_{2}$ via a nondispersive infrared analyzer, and oxides of nitrogen with a heated chemiluminescense detector. The smoke was measured by means of a classical filter paper method with resolution of 0.01FSN or soot concentrations of $0.1 \mathrm{mg} / \mathrm{m}^{3}$. The cylinder pressure was measured with a piezo type transducer and was used to calculate cycle indicated torque and the heat release trace. The EGR ratio was expressed as the ratio of the intake to the exhaust $\mathrm{CO}_{2}$ concentration.

The coolant temperature has a significant effect on the fuel efficiency and the emissions and therefore was tightly controlled during the experiments by a heat-exchanger system. For instance, during the high-load experiments at 16bar BMEP the coolant temperature was maintained within a window of $100 \sim 103^{\circ} \mathrm{C}$. 


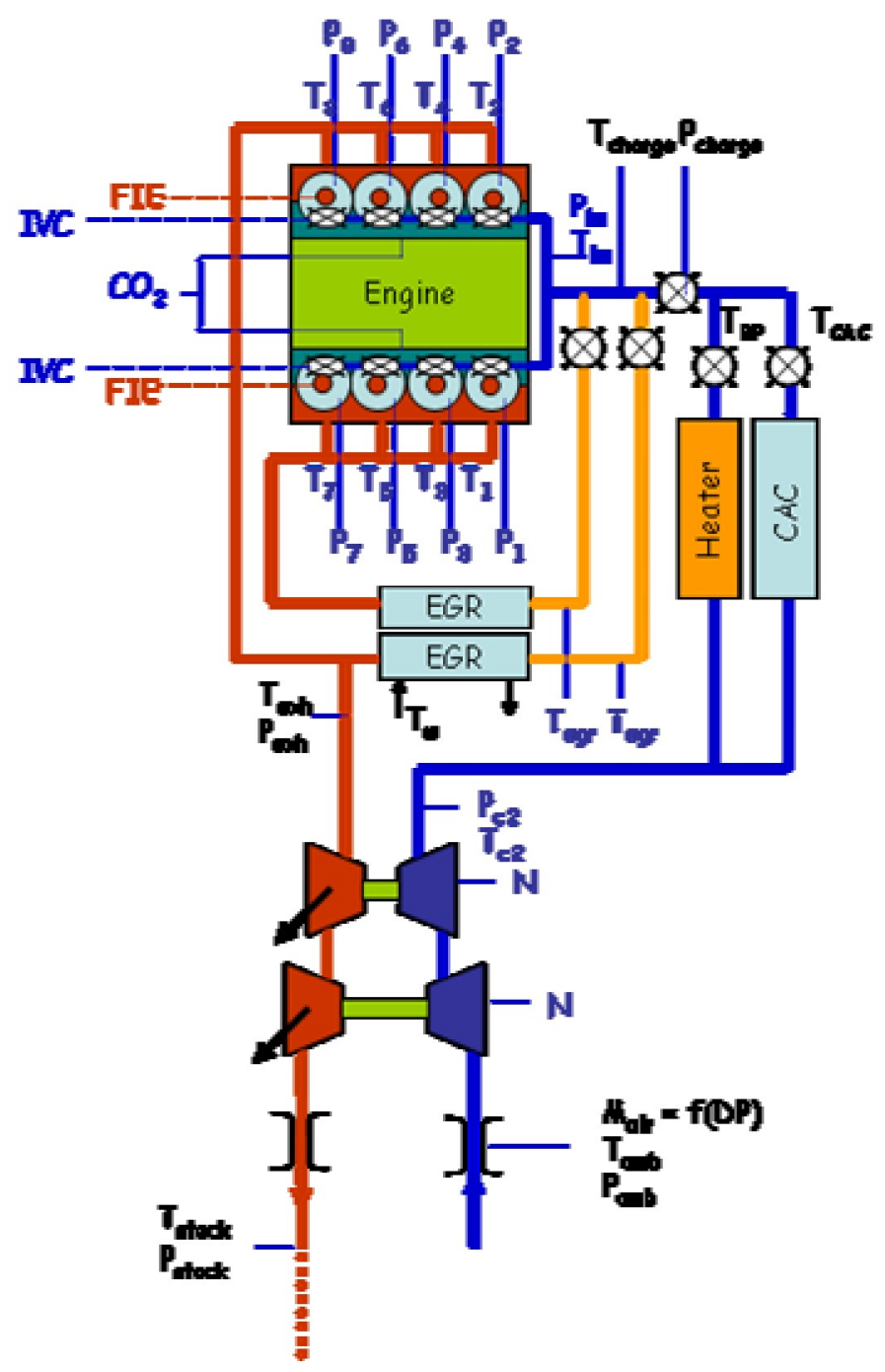

Figure 5 Experimental Layout

The following sections summarize the systems introduced throughout the course of the program, including the injector testing and validation, turbocharger specification, EGR system layout, cylinder head modifications, and CAC. An overview of the VVA and VCR devices are also included.

\subsection{Fuel Injector Bench Testing}

Injector characteristics and validation of the new injector drivers were performed. New drivers were necessary as the engine controller was phased out to allow for full flexibility from the Rapid Prototype System and future production-intent controller.

Fuel Bench setup: As shown below on Figure 6, the set up was instrumented to yield pressure in the fuel rail and in the feed tube from the rail to the injector. All testing was done with one injector alone. Not shown is the Rate of Injection (ROI) measuring device below the injector. All three transducers are keys to properly characterize the injector. 
Figure 7 shows a typical injector behavior under multiple shots. The start of injection delay (ti) has a little dependency on number of events, but it is dependent on rail pressure. The mean nozzle sac pressure had a strong relation to the mean pipe pressure at injection duration. Ratio between mean sac pressure and mean pipe pressure could vary from $35 \%$ to $75 \%$ and depended on the injection duration. For the case of multiple injections, the mean sac pressure decreased for successive injection events. For short dwell the drop in rail pressure was larger then for a long dwell and. For low rail pressure the drop is even greater. The biggest range of rail pressure drop is from $2.6 \%$ to $8 \%$.

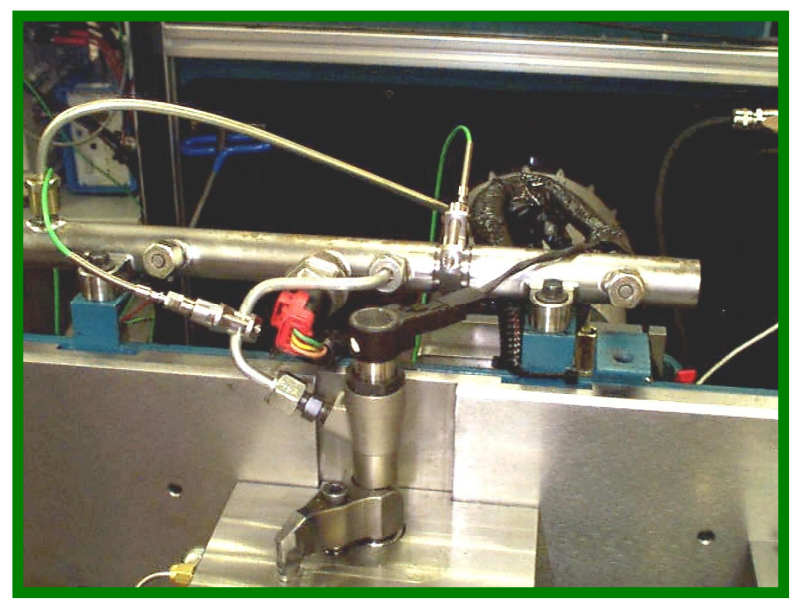

Figure 6 Fuel injector test rig

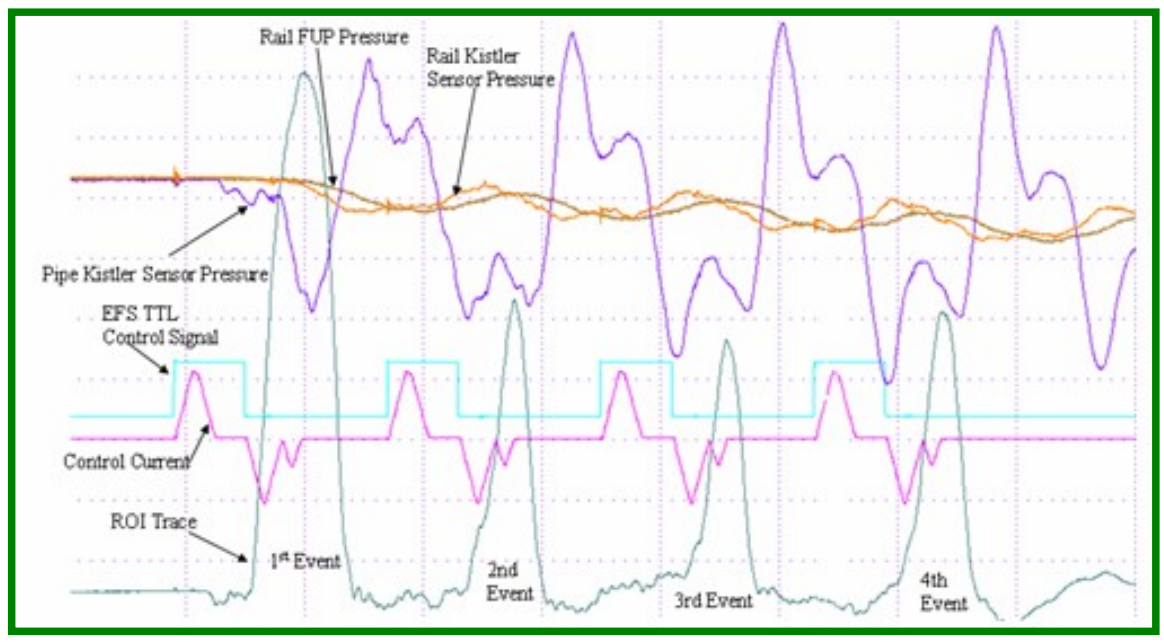

Figure 716 hole injector nozzle performance (FUP 160MPa, ti=0.3ms, dwell=0.6ms)

Results: Fuel Injector bench testing was performed on a baseline injector and injectors spanning 7 to 20 holes, with holes as small as $0.100 \mathrm{~mm}$. Testing showed that the increased number of holes had limited improvement over the base injector and most of the tests on engine were performed with 6 to 8 hole nozzles, with flows relatively close to the base injector.

The EFS made injector driver that substituted the PCM drivers allowed for flexibility in voltage and charge energy to the piezo stack. The current levels were tailored to approximate the base driver as shown in Figure 8. 


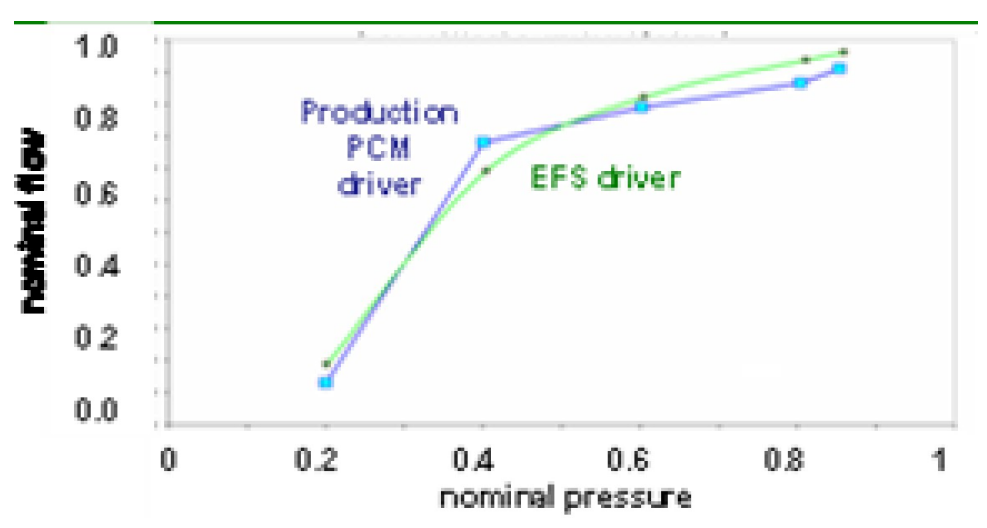

Figure 8 Effect of driver on injector characteristics

\subsection{Turbocharger}

Two configurations were available, a non inter-stage cooled, and an inter-stage cooled unit. The latter combination gave improved turbine performance, the high-pressure unit operating at higher efficiency. The intake manifold temperatures however were nearly identical owing to the performance of the charge air cooler and its capability to bring down the post compressor temperatures. The noncooled unit was chosen for the application. In a latter embodiment, as tests were conducted beyond the original 12.5bar BMEP levels; a HP turbo and compressor bypasses were installed. Full load (corresponding to the 12.5 bar lug curve and not the 16.5 bar line) and half load points are plotted in the turbocharger maps in Figure 9.
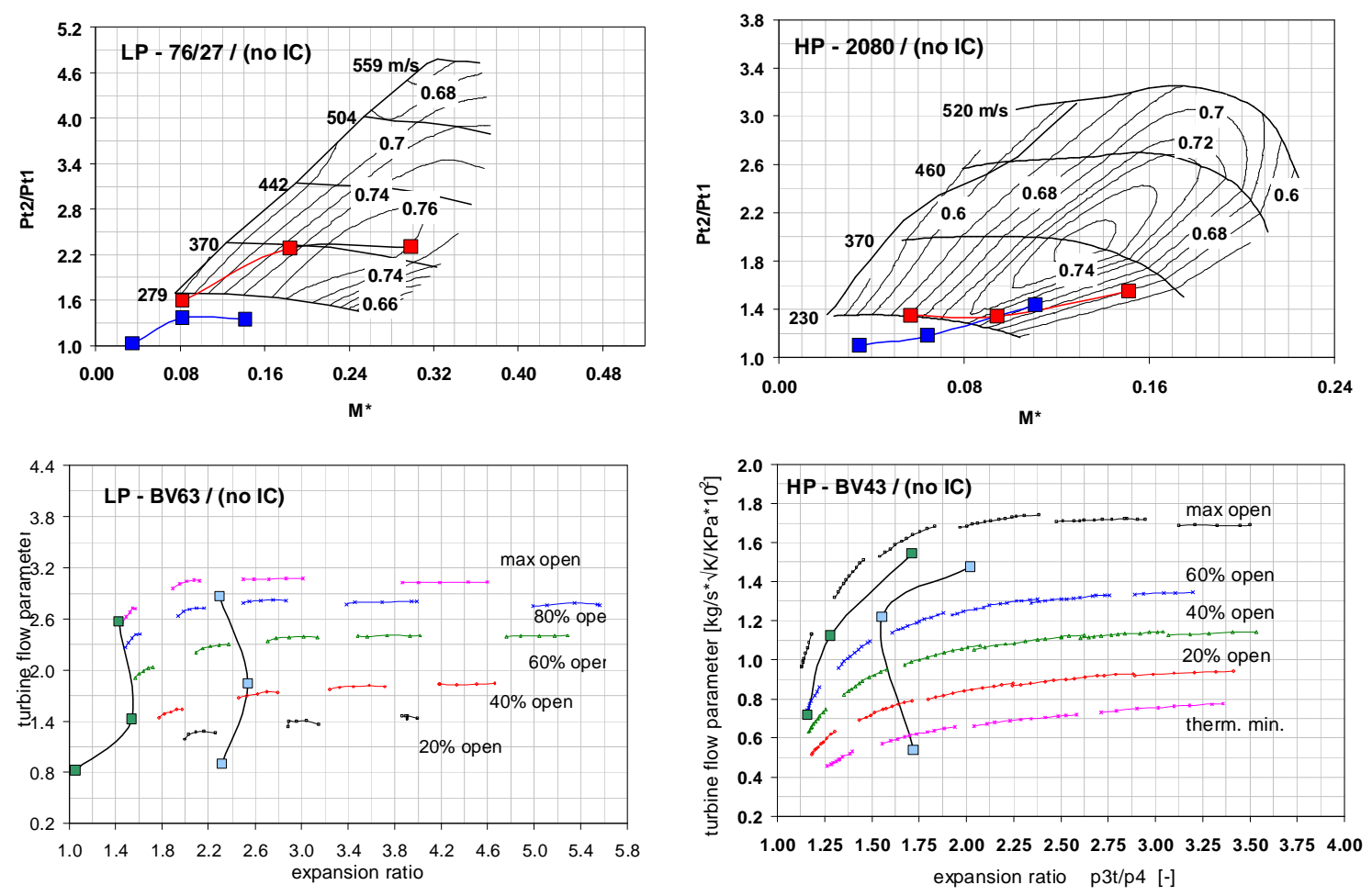

Figure 9 Turbocharger mapping without intercooler (12.6bar BMEP at lug line) 
The High Pressure (HP) and Low Pressure (LP) turbines have $43 \mathrm{~mm}$ and $63 \mathrm{~mm}$ turbine wheel diameters respectively. Both stages have variable vanes and are adjusted pneumatically and electronically respectively.

\section{Turbocharger Designation}

Turbine Compressor

$\begin{array}{lll}\text { LP stage } & 63 Y A-16 & 76 / 27 C K-A K M \\ \text { HP stage } & \text { BV43 } & 2080 \text { DCB/BV63 }\end{array}$

\subsection{EGR System}

An EGR system based on 2010 engine emission levels technology was selected. This system was designed to handle $26 \mathrm{lbm}$ EGR mass flow while keeping cooling effectiveness above $82 \%$. The system consists of two Modine finned tube type EGR coolers $(430 \mathrm{~mm} \times 100 \mathrm{~mm} \times 90 \mathrm{~mm})$ in parallel, one cooler per cylinder bank. The EGR coolers are comprised of two cooling circuits; the engine coolant loop $\left(95-100^{\circ} \mathrm{C}\right)$, and an auxiliary cooling circuit $\left(40^{\circ} \mathrm{C}\right)$. The dual circuit setup allows flexibility and sufficient range in gas out temperature.

Two Pierburg EGR valves meter the flow of EGR gas into an EGR mixer which features a long mixing chamber to facilitate thorough mixing and promote even distribution of EGR gas to each of the cylinder banks. The intake manifold design, with a balancing tube at the end, promotes better mixing and uniformity of air and EGR to each of the cylinders.

Figure 10 shows the relocation of EGR coolers (1) and the position of the two-stage turbocharger (2) on engine. Also shown are the new valve covers (3), resized to accommodate the variable valve train system, and EGR-fresh air mixture manifold (4).
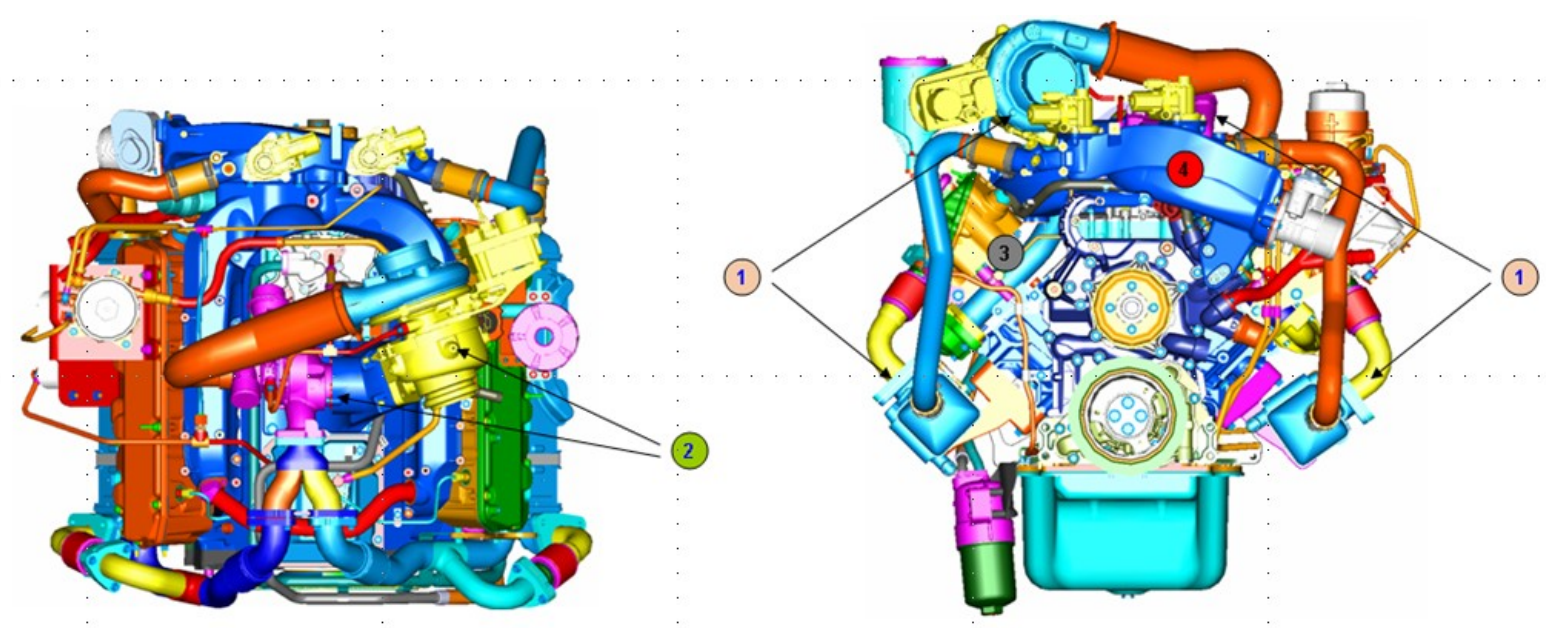

Figure 10 Relocation of turbocharger and EGR coolers

\subsection{Dual Loop EGR System}

A low pressure loop system was installed on the engine to further explore the efficiency of the turbocharger system with the VVA hardware. A production 2007MY DOC (3) and DPF (2) were added to clean the exhaust flow before it flows through the coolers (1). Valves $(4,5)$ were added to the system to be able to direct flow through either the after-treatment system or out the exhaust stack as desired. The set up is shown in Figure 11. 


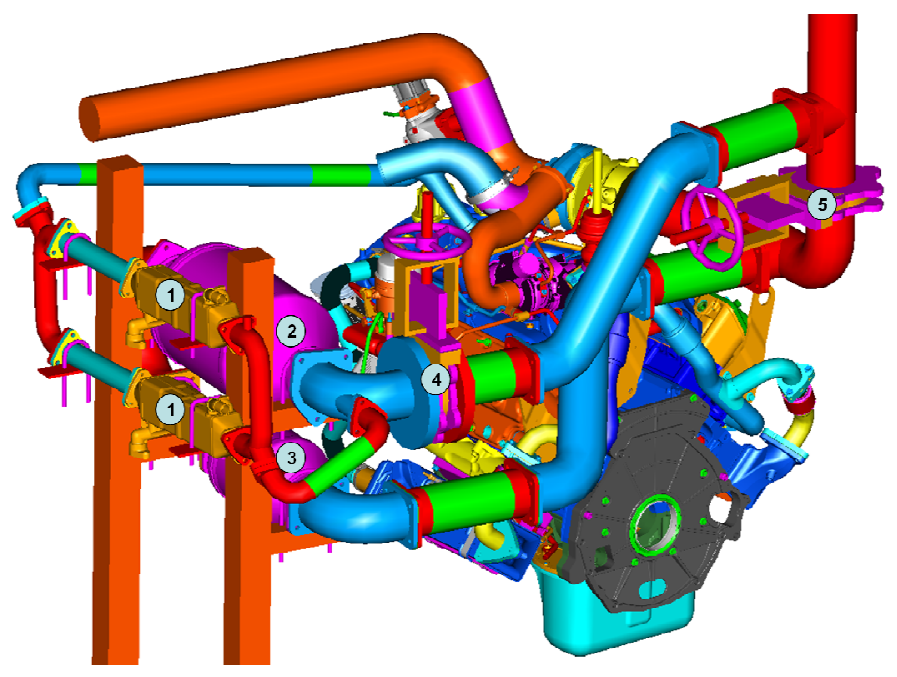

Figure 11 Dual loop EGR system

\subsection{Cylinder Head Modifications}

The base engine was designed using inlet ports with relatively high swirl. The opportunity to improve the flow capacity of the ports was identified. The port configuration before and after the changes is shown in Figure 12. The solid geometries represent the initial and the mesh represents the modified configuration. The helical feature was minimized and the ports were overall straightened and widened. The figure also shows the shows a cutaway of the pressure transducer installation.

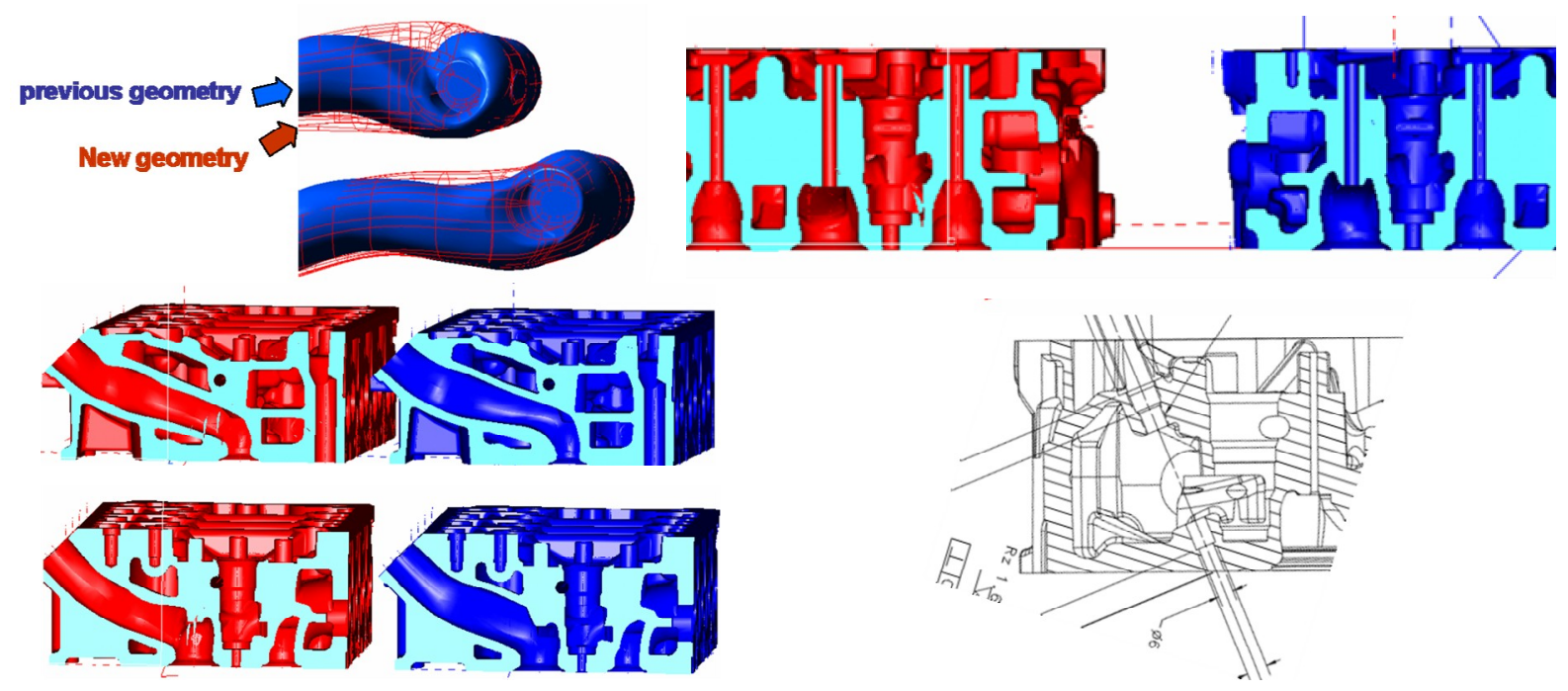

Figure 12 Original (solid) and modified ports (mesh)

\subsection{CAC Bypass and Heater System}

The lean conditions at which the engine operates yielded intake manifold temperatures too low to sustain stable combustion at low loads at the lower compression ratios studied. A by-pass system with a heater system was designed to provide better stability at the low loads. A preliminary estimate 
showed that an $8 \mathrm{~kW}$ heater unit would be sufficient to raise temperatures at part load to approximately $410 \mathrm{~K}$ (see Figure 13).
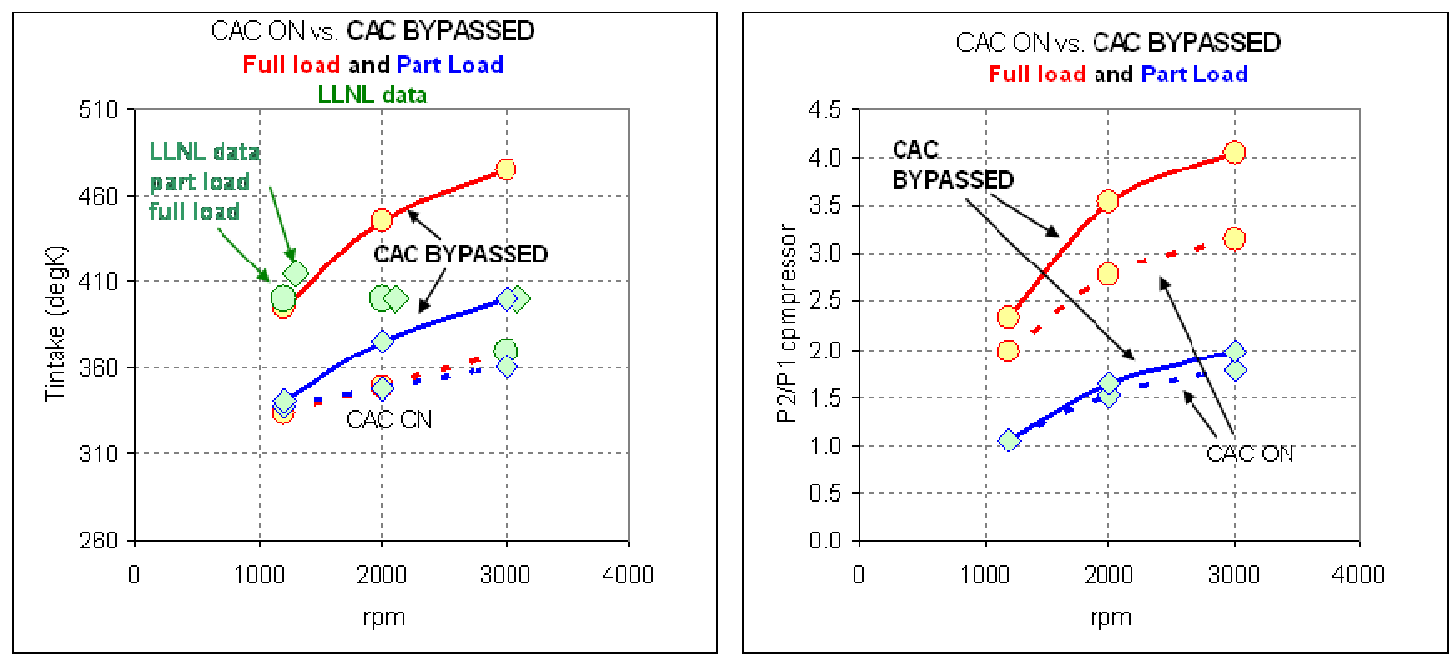

Figure 13 CAC bypass and heater requirements

\subsection{Variable Valve Actuation (VVA)}

The development engine was a $6.4 \mathrm{~L}$ V8, 4 valves per cylinder, push-rod configuration. The two intake and exhaust valves are each adjusted by a valve bridge. The valve functionality required from the VVA system required the intake valve closing (IVC) to be adjustable while retaining the opening timing. The valves were manipulated at the valve bridge, so both intake valves are adjusted alike. No manipulation was required of the exhaust valve. The system was to accommodate a maximum engine speed of $3600 \mathrm{rpm}$ and a maximum engine torque of $870 \mathrm{Nm}$ (650 ft-lb) at $2000 \mathrm{rpm}$.

Figure 14 illustrates the design of the VVA system. Noticeable details included the fuel rail position, shifted to accommodate the VVA intake valve solenoids, yet preserving feed tube lengths comparable to the original engine. The features on the high pressure line into the fuel rail were maintained despite the relocation of the rail. Injectors were rotated, and a special feature incorporated to allow its clamping to the cylinder head. A new valve spacer and cover were adopted to accommodate the increase height (on the order of $50 \mathrm{~mm}$ ) and allow easy access, including access to pressure transducers. Overall the design was an effective use of space and had minimum impact on the injection system. The same figure includes a picture of the system assembled on the engine prior to installation in the test cell.

The system underwent extensive bench testing, accumulating over 300 hours. Examination of parts showed no unusual wear. Measurements of valve motion were made with a magnetic pick up. One example of valve motion at various commanded valve closing commands is shown on Figure 14. Overlaid on the figure are 16 valves, two intake valves over the 8 cylinders. The motion profiles include occasional noise detected by the magnetic pickups onto a measuring cup during bench testing. 

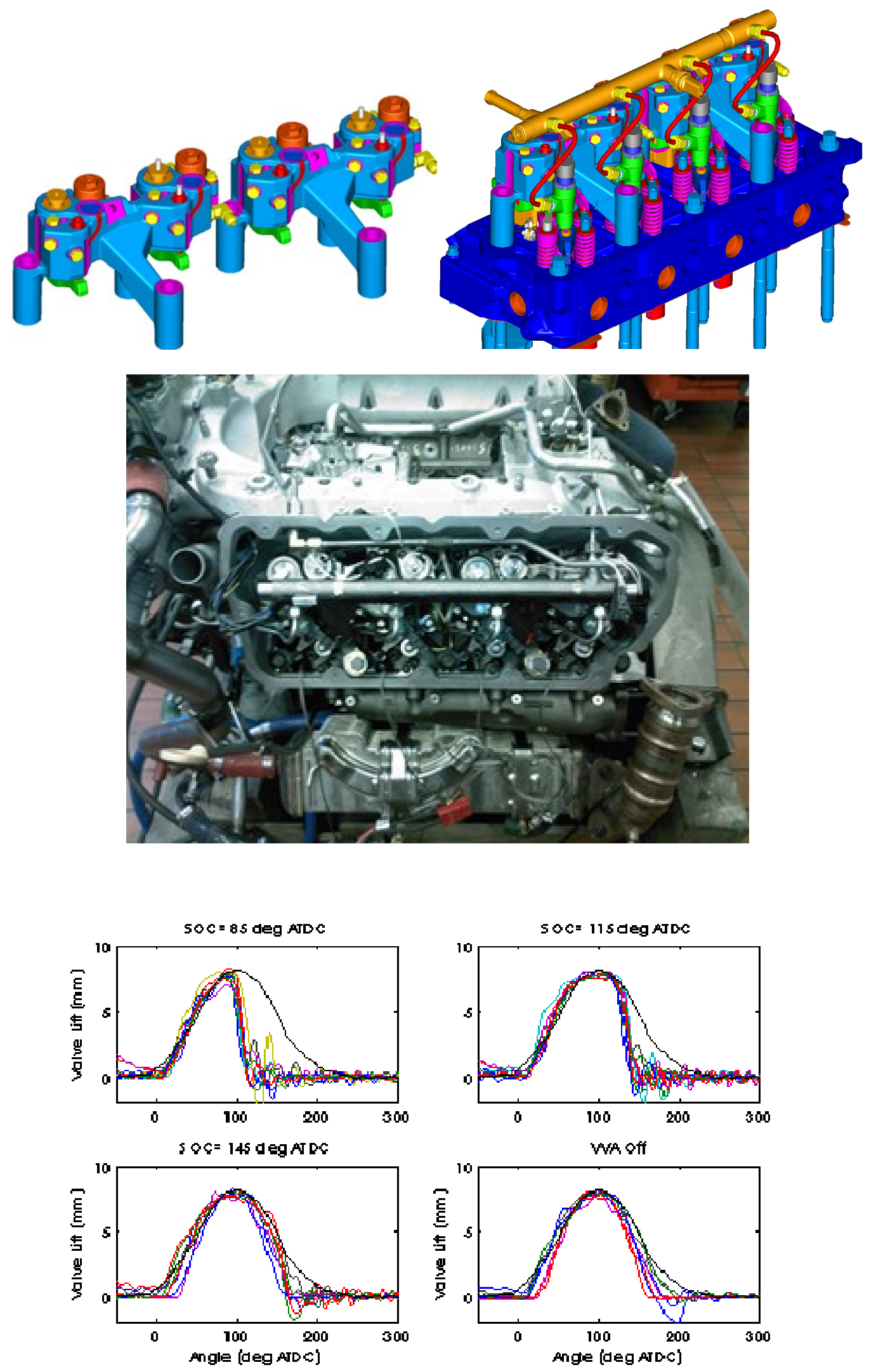

Figure 14 Valve Actuation packaged on a 6.4L V8 cylinder head. 
Program DE-FC26-05NT42413

\section{Predictive Tools}

Predictive tools become a necessary element in the development process. This was especially true under the present project goals to reduce engine out emissions to US10 levels. The task required thorough understanding of the fuel spray dynamics, its interaction with the surrounding air, and the chemical paths that lead to NOx and soot. The efficiency of combustion was likewise a high priority, and special care was necessary to limit the production of $\mathrm{CO}$ and $\mathrm{HC}$.

The scope of work was unique, and to a certain extent groundbreaking, as the simulations included PCCI like conditions attained with single and multiple shot injections. Simulations were performed with post injections but they are not mature enough for presentation at this time. The numerical models are based on KIVA [5]. A brief description of the major sub-models and particular adaptations to the present work are described below.

\subsection{Numerical Models}

\section{Spray model (Liquid Break-up)}

The break-up of the liquid parcel and the subsequent droplet was based on the Kelvin HelmholtzRayleigh Taylor (KH-RT) model. The KH-RT model recognizes two different types of liquid breakups. The first breakup occurring at or in the vicinity of the injection nozzle-orifice and is referred to as the primary breakup. During the primary breakup the liquid core disintegrates into parcels and large droplets. The relatively large initial droplets are further distorted and subsequently broken up into smaller secondary droplets and this phenomenon is referred to as secondary breakup. The breakup modes are characterized mainly by the breakup lengths and the size of the resulting droplets. The detailed equations used in the model are discussed in $[6,7]$. In addition to the breakup model, the spray model included other sub-models such as drop-turbulent dispersion model that are same as in standard KIVA-3V and are described in the above references. The physical property of the fuel modeled is based on tetradecane. The spray models were tested and verified with spray visualization experiments in a constant volume chamber.

\section{Fuel-oxidation chemistry}

A parallel detailed chemistry solver was used for ignition and combustion modeling in the present study. The chemistry solver was implemented into KIVA-3V code using the Message-Passing Interface (MPI). The MPI allows for the chemistry to be solved in parallel on multiple CPUs while the fluid dynamics was solved on a single processor. This was accomplished at each computational timestep by determining the subset of KIVA's cells that meet the temperature cutoff criterion for detailed chemistry calculation. A reduced chemical mechanism for $n$-heptane $\left(\mathrm{C}_{7} \mathrm{H}_{16}\right)$ was used to model Diesel fuel. $\mathrm{N}$-heptane is commonly used as surrogate for the diesel fuel due to the similarity in cetane numbers and two-stage ignition phenomenon. This reduced mechanism consisted of 34 species and 74 reactions. Similar reduced mechanism has been successfully used by Patel et. al for $\mathrm{HCCl}$ engine simulations [8].

\section{Emission Model}

The $\mathrm{NO} / \mathrm{NO}_{2}$ reactions reduced from the GRIv3 mechanism were used $[9,10]$. The resulting mechanism consisted of 10 species and 9 reactions. No modifications were made to the rate constants of the original GRI mechanism. As discussed in these references no significant changes in NOx emission estimation are expected as a result of the simplified mechanism, since the thermal NO, $\mathrm{N}_{2} \mathrm{O}$ pathway and $\mathrm{NO}_{2}$ formation are still adequately accounted. The mechanism simplification 
ignores the "prompt-NO" contribution which is considered to be formed in small amounts during the diffusion portion of the diesel combustion process.

The soot model was a two-step phenomenological model based on the Hiroyasu and NSC model with $\mathrm{C}_{2} \mathrm{H}_{2}$ as soot precursor. The rate of change of soot-mass within a computational cell is evaluated as the difference between the soot formation rate and the soot oxidation rate. The soot-formation rate was given by an Arrhenius type of expression, while the soot oxidation rate was adopted from the Nagle and Strickland-Constable oxidation model [11,12].

KIVA's native grid generator package K3Prep was used for grid generation. The grid consisted of 3 blocks and a total of 49924 cells. Since, a 7-hole injector was used for the study; a sector mesh of 51.42 degrees was used for computational efficiency. The details of bowl grid are shown in Figure 15.

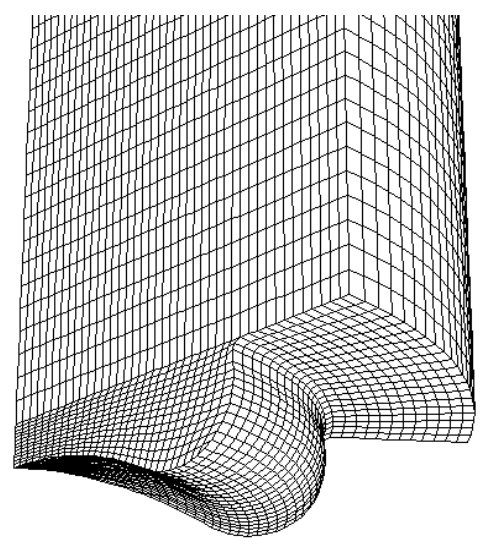

Figure 15 Bowl grid detail of CR14.3:1

\section{Navistar-ROI Model}

The rate of injection profiles (ROI) for both single shot and multiple-shot cases were estimated using an AMESIM model. The AMESIM model of the piezo-electric Common Rail injection system correlated well with $\mathrm{ROI}$ data from experiments. The $\mathrm{ROI}$ model has the ability to generate accurate $\mathrm{ROI}$ profiles for any fuel pressure and pulse width, with a rapid turn around rate. The quick turnaround-time for custom ROI profiles greatly enhanced the efficiency for using the KIVA code. The $\mathrm{ROI}$ model included pressure wave corrections.

\subsection{Prediction and Measurements}

The in-house KIVA code was calibrated first for single shot cases. This was a necessary process to verify the accuracy of the model predictions. The parameters modified during the KIVA process are listed Table 4 and Table 5 below.

Table 4 Parameters modified during KIVA calibration for heat-release rate correction

\begin{tabular}{|l|l|}
\hline Characteristic & Chemical reaction \\
\hline Heat-released during first (cool flame) stage of ignition & $\mathrm{C}_{7} \mathrm{H}_{15} \mathrm{O}_{2}=\mathrm{C}_{7}$ ket $_{12}+\mathrm{OH}$ \\
\hline Heat-released during main stage & $\mathrm{CO}+\mathrm{OH}=\mathrm{CO}_{2}+\mathrm{H}$ \\
\hline
\end{tabular}

The modifications were limited to the "A" pre-exponential or the frequency factor in the Arrehenuis 
form of equation $k(T)=A T^{b} \exp \left(-E_{a} / R_{u} T\right)$ for the reaction rate coefficient below. No modifications were made to constants "b" and " $E_{a}$ ".

Table 5 Parameters modified during KIVA calibration for emission predictions

\begin{tabular}{|l|l|l|}
\hline Emission & KIVA Parameter & Calibration \\
\hline NOx & Reciprocal of Schmidt number (rsc) & 1.4 \\
\hline Soot & Pre-exponential soot formation factor (Asf) & 200 \\
\hline
\end{tabular}

Table 6 shows a single-shot test condition used for verification. The model successfully captured the start of combustion characteristics of the experiment. The modeled heat-release rate showed a higher premix combustion peak in comparison to the experimental heat-release rate (Figure 16). This is likely to arise from the mismatch of properties between the simulated fuel and the actual Diesel fuel used (which has a lower CN).

Table 6 Test-conditions for baseline KIVA simulation

\begin{tabular}{|l|l|}
\hline Engine Speed (RPM) & 1750 \\
\hline BMEP (bar) & 10.8 \\
\hline Equivalence Ratio & 0.7 \\
\hline EGR Ratio & 47 \\
\hline Intake Temperature $\left({ }^{\circ} \mathrm{C}\right)$ & 42 \\
\hline Intake Pressure (kPa, abs) & 230.3 \\
\hline Commanded Rail Pressure (MPa) & 144 \\
\hline $\begin{array}{l}\text { Main Injection fueling } \\
\text { Commanded Start of Injection }\end{array}$ & $51 \mathrm{mg} / \mathrm{stk}$ \\
\hline
\end{tabular}

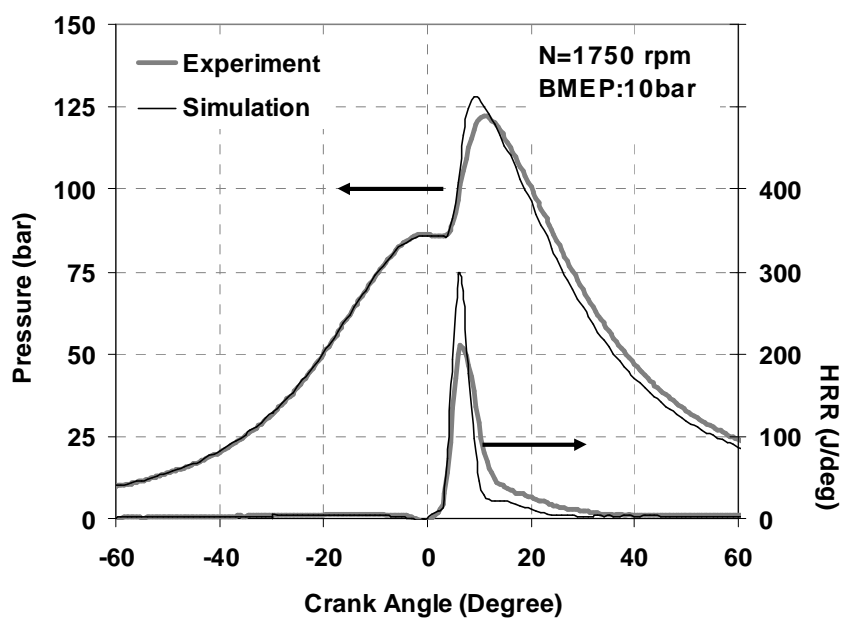

Figure 16 Comparison for baseline KIVA simulations

Table 7 shows the conditions tested for the PCCl combustion and results are shown on Figure 17. For $\mathrm{PCCl}$, the simulation prediction for the start of combustion timing was in agreement with experiments. The amounts of predicted heat-release during the various stages of combustion were slightly different than those measured. More work is in progress to develop improved reaction 
mechanisms to better represent conventional diesel. This effort will help minimize the discrepancy between the experimental and modeled heat-release rates.

An examination of the experimental heat-release rate and $\mathrm{ROI}$ profiles suggested that $\mathrm{PCCl}$ combustion can be divided into distinct stages: a pilot ignition delay and pilot combustion, followed by main ignition delay and main combustion (Figure 18). A discussion of these stages of combustion based on experimental and modeling results has been provided below.

Table 7 Test Conditions for PCCI KIVA simulations

\begin{tabular}{|l|l|}
\hline Engine Speed (RPM) & 1750 \\
\hline BMEP (bar) & 10.8 \\
\hline Equivalence Ratio & 0.7 \\
\hline EGR Ratio & $44.4 \%$ \\
\hline Intake Temperature $\left({ }^{\circ} \mathrm{C}\right)$ & 43 \\
\hline Intake Pressure (kPa, abs) & 230 \\
\hline Commanded Rail Pressure (MPa) & 144 \\
\hline Pilot Injection & $14 \mathrm{mg} / \mathrm{stk}$ \\
Commanded Start of Main Injection & $50^{\circ} \mathrm{BTDC}$ \\
\hline Main Injection fueling & $35.7 \mathrm{mg} / \mathrm{stk}$ \\
Commanded Start of Main Injection & $7.7^{\circ} \mathrm{BTDC}$ \\
\hline
\end{tabular}

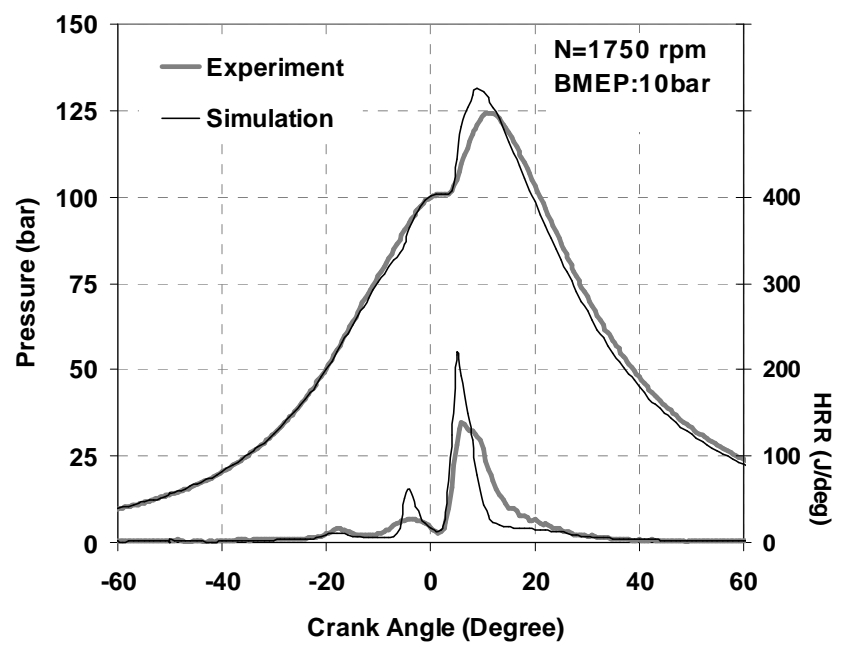

Figure 17 Comparison actual for $\mathrm{PCCl}$ with pilot injection

\section{Pilot Ignition Delay}

A pilot injection of $14 \mathrm{mg} / \mathrm{stk}$ was commanded at $50^{\circ}$ BTDC. KIVA simulations showed the pilot fuel vaporized before the main injection (Figure 19). The experimental and the simulation heat-release rates showed the pilot combustion process initiating at $25^{\circ} \mathrm{BTDC}$, which provided an ignition-delay of approximately $20^{\circ}$ or $2 \mathrm{~ms}$ of mixture-preparation time for the pilot-injection. The equivalence-ratio distribution in this period showed that the pilot fuel had prepared a lean fuel-air mixture before the combustion. 


\section{Pilot Combustion}

The pilot combustion was characterized by two distinct stages. The first one, called Pilot-LTR or pilot low-temperature reaction was initiated at approximately $25^{\circ} \mathrm{BTDC}$. The second, called Pilot-HTR or pilot high-temperature-reaction was initiated at approximately $6^{\circ} \mathrm{BTDC}$.

The Pilot-LTR was less sensitive to pilot-injection timing or quantity. This suggested that the Pilot-LTR combustion was determined by the chemical-kinetics process, a feature which is closely shared by $\mathrm{HCCl}$. The long ignition delay, chemical kinetics controlled combustion and an "apparent" cool-flame reaction suggested that the pilot injection was able to achieve a significant homogenization before the combustion was initiated. Figure 19 temperatures are below $800 \mathrm{~K}$ and the contours of equivalence ratio show a very homogenous mixture at $35^{\circ} \mathrm{BTDC}$.

The temperature distributions during -20 to $2^{\circ} \mathrm{BTDC}$ indicated that the in-cylinder temperatures during the Pilot-LTR were representative of cool-flame reactions. Figure 19 shows temperatures reaching $1100-1200 \mathrm{~K}$ near the cylinder wall, corresponding to a slightly richer mixture zone (point A).

During the pilot high-temperature reaction the remainder of the pilot fuel experienced a rapid combustion lasting only a few crank-angle degrees similar to $\mathrm{HCCl}$ high-temperature reaction. Analysis of the heat release trace, shows, on an energy basis, more than $70 \%$ of thermal energy of pilot fuel liberated by the end of the high-temperature heat release.

\section{Main injection}

The main injection commenced at approximately at $3^{\circ} \mathrm{BTDC}$ (corresponding to $7^{\circ} \mathrm{BTDC}$ start of command) and continued up to $6^{\circ}$ ATDC. The cylinder charge temperature was high due to pilot combustion. Location $B$ in Figure 20 indicates an active combustion region as the main injection is introduced. The heat release drops, arising from the heat of vaporization. The main ignition delay is short, $2^{\circ}$.
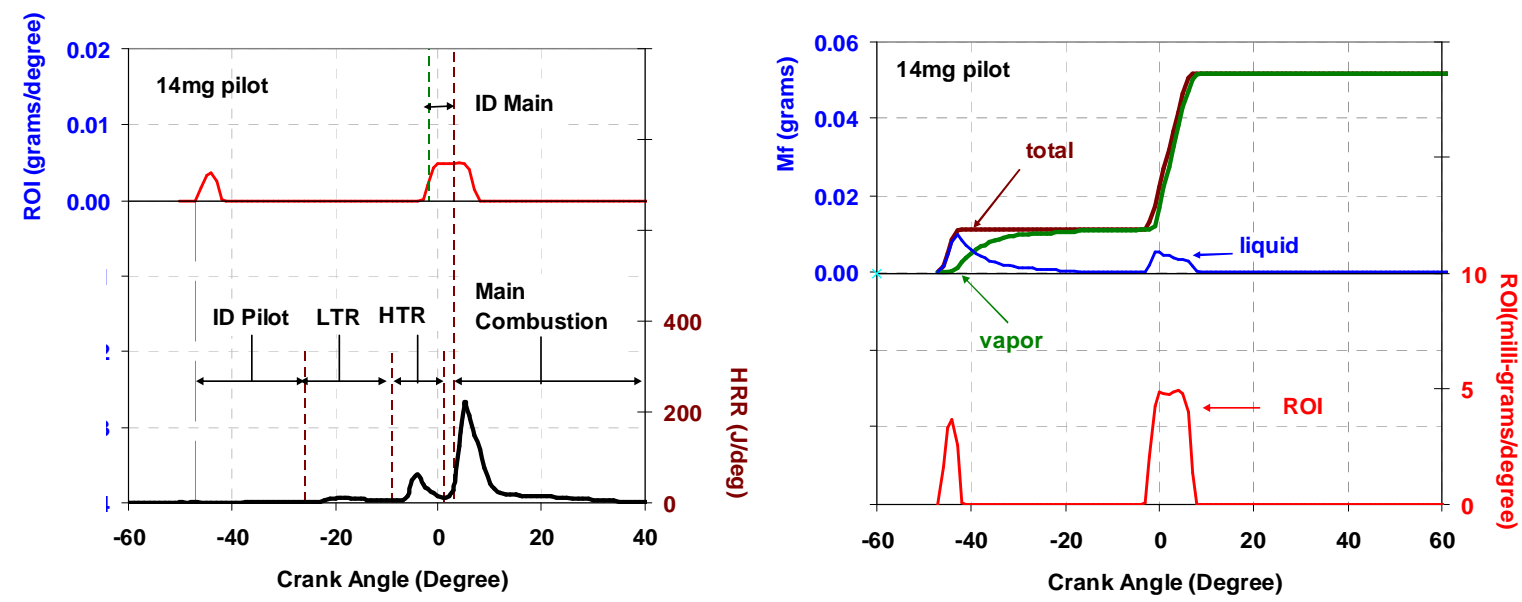

Figure $18 \mathrm{PCCl}$ combustion with pilot-main injection, $\mathrm{N}=1750 \mathrm{rpm}, \mathrm{BMEP}=10 \mathrm{bar}$

\section{Main combustion}

The combustion for the main injection was initiated after a very short ignition-delay. At the end of the ignition delay, the fuel proceeded on conventional combustion with distinct premixed and diffusion combustion phases.

Locations C-D-E of Figure 20 shows the rapid propagation of the flame front from the Pilot-HTR region to the main spray. The modeling results capture the trends of NOx and soot emissions. 
Figure 21 shows the NOx predictions are accurate for pilot ranging from 2 to $14 \mathrm{mg}$. The trend of decrease in soot with increasing pilot quantity was captured in simulations as well, though it is under predicted at low pilot quantities.

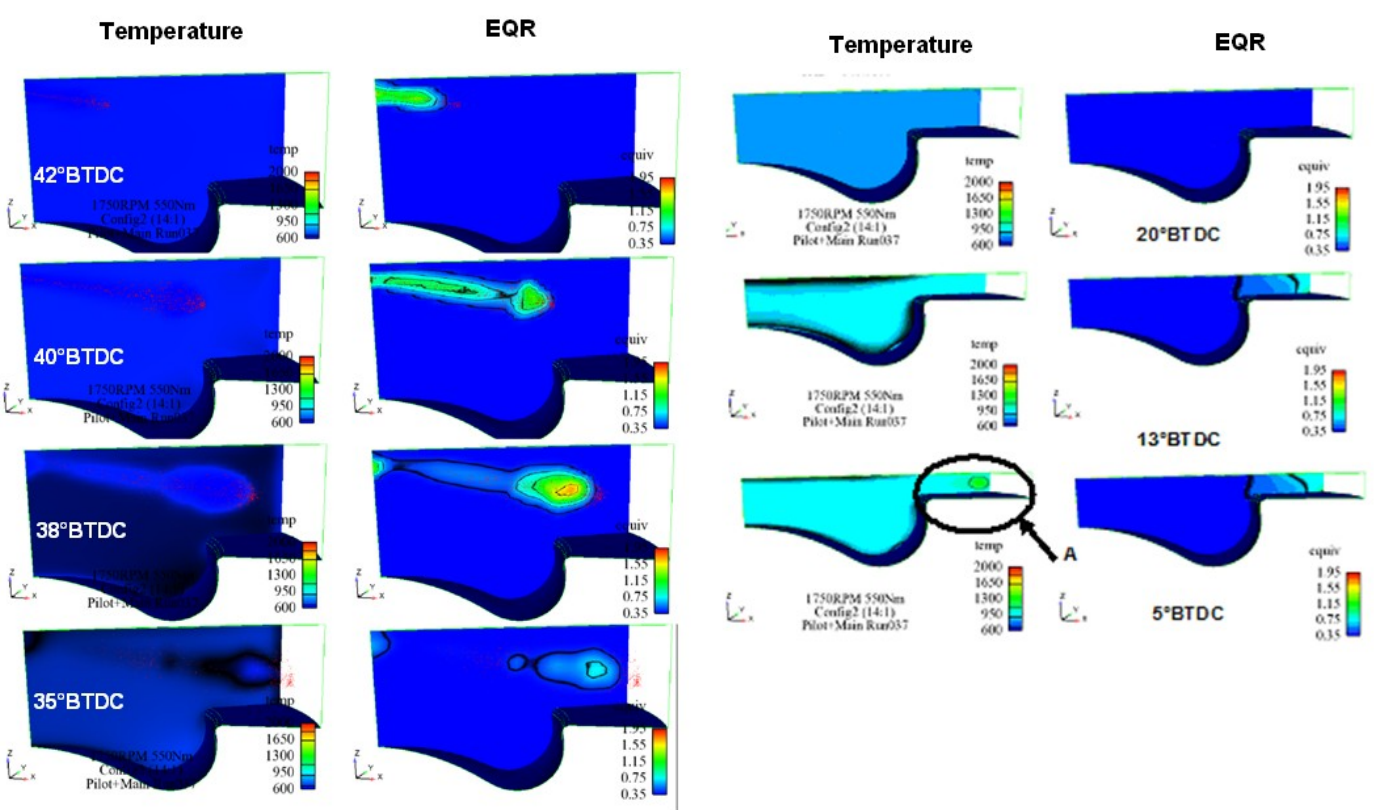

Figure 19 Vaporization-mixture preparation of pilot fuel followed by low temperature combustion

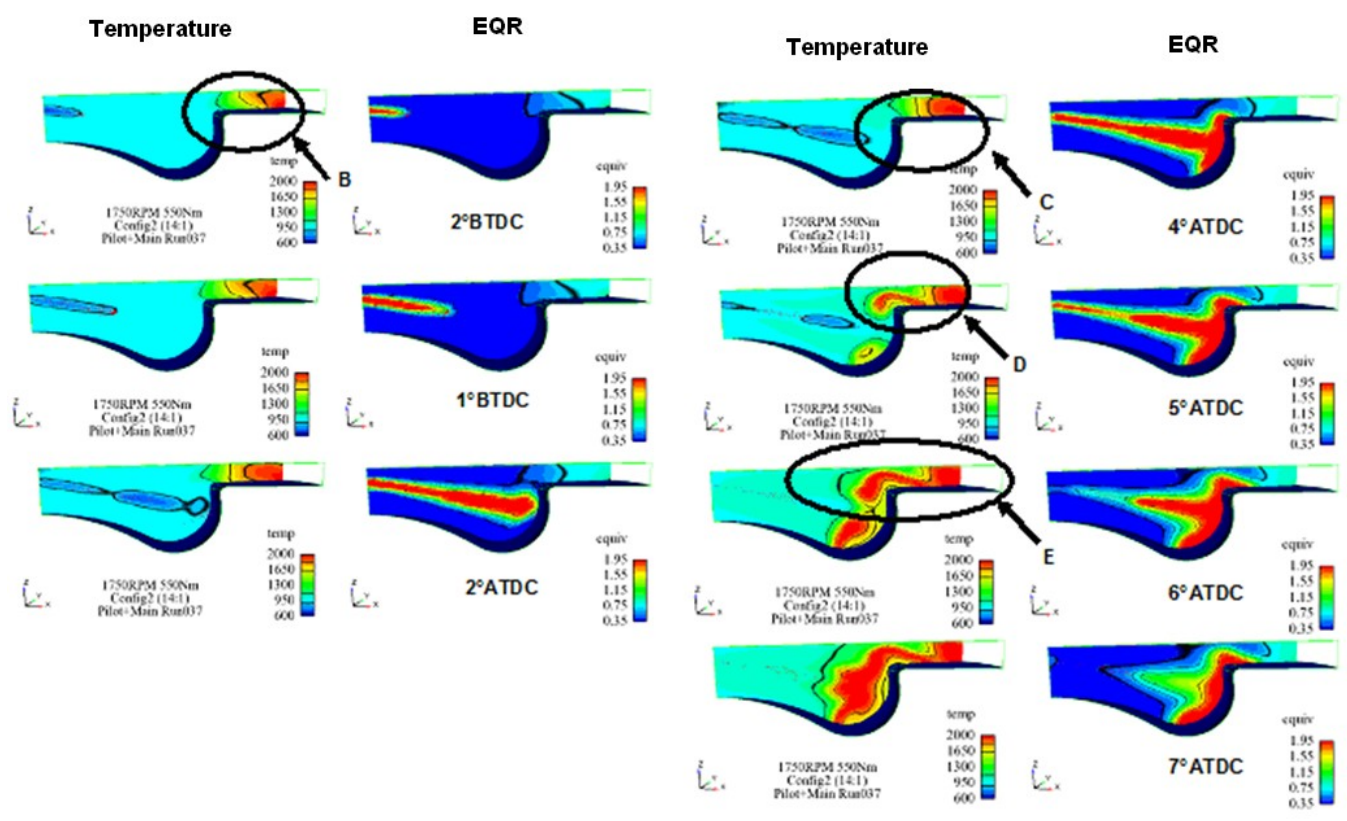

Figure 20 Main injection with Pilot fuel triggering main combustion 
Program DE-FC26-05NT42413

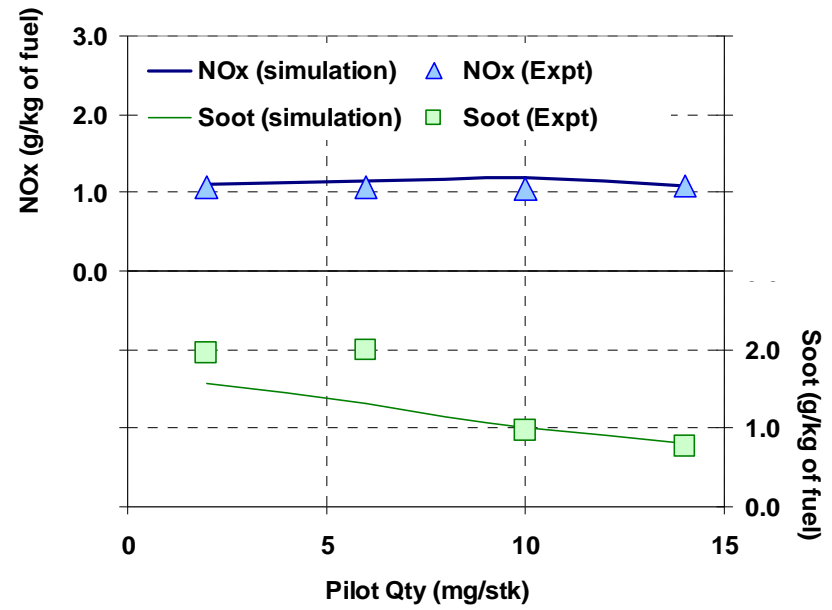

Figure 21 Comparison of emission results 


\section{Low Temperature Combustion}

LTC relies on cooled EGR to limit in cylinder temperatures and prolong ignition delay. The dilution effect of the EGR is responsible for limiting flame temperatures and NOx formation. Lower in cylinder temperatures restrict soot formation. The soot suppression is further enhanced by the increased ignition delay which promotes fuel and air homogeneity. The following sections highlight the challenges incurred in LTC. These consist in maintaining the boundary conditions necessary to suppress NOx and soot, the impact of increased load, and the challenge of combustion stability. Its description is the followed by the PCCl strategy, where EGR is still employed for NOx suppression but no attempt is made to attain the temperature limit of soot formation.
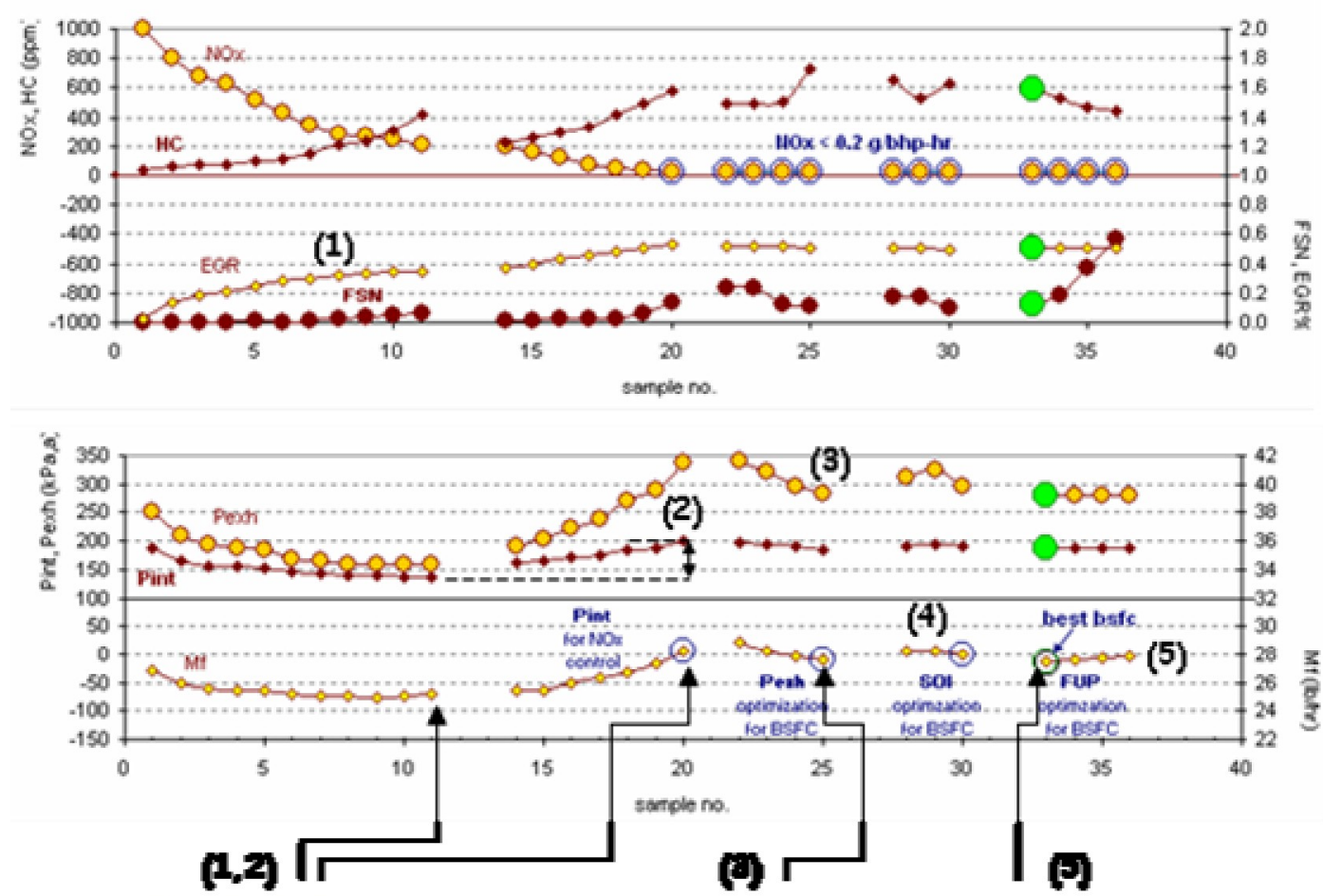

1500 ipm, 6 ba BMEP
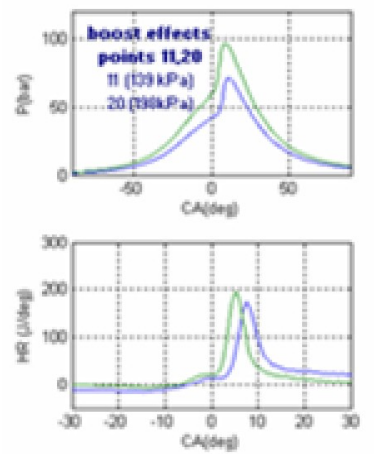
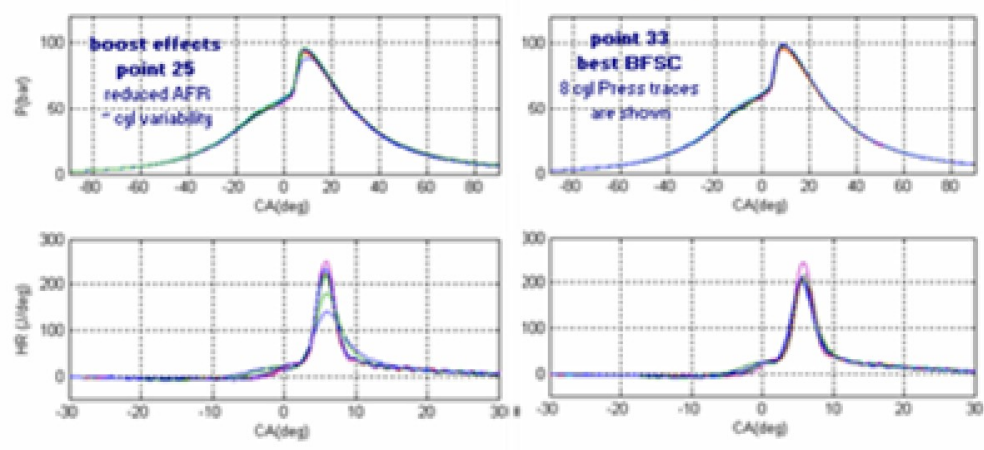

Figure 22 Sample EGR and AFR control for LTC 


\subsection{Boundary Conditions and System Interaction}

The conditions to attain LTC outlined earlier may appear simple, but are complicated by the various systems required to yield these conditions. The effort becomes increasingly difficult as the engine load and speed increase, and each respective system is pushed to its full capability. This coordination of subsystems is illustrated in Figure 22.

The engine speed and load are $1500 \mathrm{rpm}$ and 6bar BMEP respectively. The optimization process begins by (1) introducing EGR to reduce NOx. During the process HC increases, partly due to poor combustion efficiency. Boost is increased (2) to reduced $\mathrm{HC}$ by half and improves the combustion stability. At the end of this sweep NOx is negligible, and so is soot. At this point, sweep (3) adjusts the back pressure to lower the pumping losses and improve overall thermal efficiency. Further sweeps of (4) start of injection (SOI) timing and (5) fuel pressure (FUP) are performed to improve the tradeoff between soot-HC-efficiency.

\subsection{Impact of Load}

A further illustration of LTC and the increasing difficulty to achieve the necessary conditions is illustrated in the Figure 23 below. Results were obtained in a SCTE version of the production engine with compression ratio of 16.5 .

a. The top left figure illustrates LTC attained at 6bar iMEP using a single injection strategy. At a high EGR percent $(57 \%)$, LTC can be attained with a relative wide range of boost pressures $(1.13-1.50$ bar, abs) as shown on the red points. For a fixed boost (1.13 bar, abs) a sweep of EGR shows that only higher levels of EGR yield LTC like conditions, as illustrated on the blue/yellow points. The main conclusion is that a minimum EGR level is required to attain low NOx. Secondly, a minimum boost is required to have low soot.

b. The lower left figure illustrates a similar case study at 8bar iMEP, but either case is not capable to reduce soot as EGR increases from $42 \%$ to 50\% (O2 exhaust concentration ranging from $8 \%$ to $5 \%$ respectively). The high levels of soot are indicative that LTC is not attained.

C. The right hand figure shows the same data as (b) with an additional point with a larger amount of EGR (62\%) coupled with multi-injections. Five to seven injection events in the cycle are necessary to reach the LTC conditions. The multiple injections however lowered combustion efficiency as noted by a rapid increase in $\mathrm{CO}$ and $\mathrm{HC}$, amounting to approximately to a $10 \%$ fuel penalty. This penalty would highly question the validity of the approach.

\subsection{Stability of Combustion}

High levels of EGR, early injection timings coupled with necessary variations in flow patterns, cooling across the cylinder head, will yield conditions sufficiently different to affect combustion phasing, combustion efficiency. In the extreme case, sufficient variability could lead to misfire. The following Figure 24 illustrates the advantages of Low Temperature Combustion.

The LTC injection strategy is applied to a low speed and load condition, $1000 \mathrm{rpm}$ and 3.3bar iMEP. The EGR is approximately $20 \%$. LTC is attained by early fuel injection timing. The nearly homogeneous conditions, characteristic of $\mathrm{HCCl}$, are responsible for the $95 \% \mathrm{NOx}$ reduction. Under these early injection timings, the cylinder to cylinder combustion phasing variability is pronounced and was responsible for the increased soot. The application of combustion feedback, by which injection timing is varied to target same combustion phasing, is successful to bring in the cylinders to operate uniformity. The result was a dramatic decrease of the soot. 

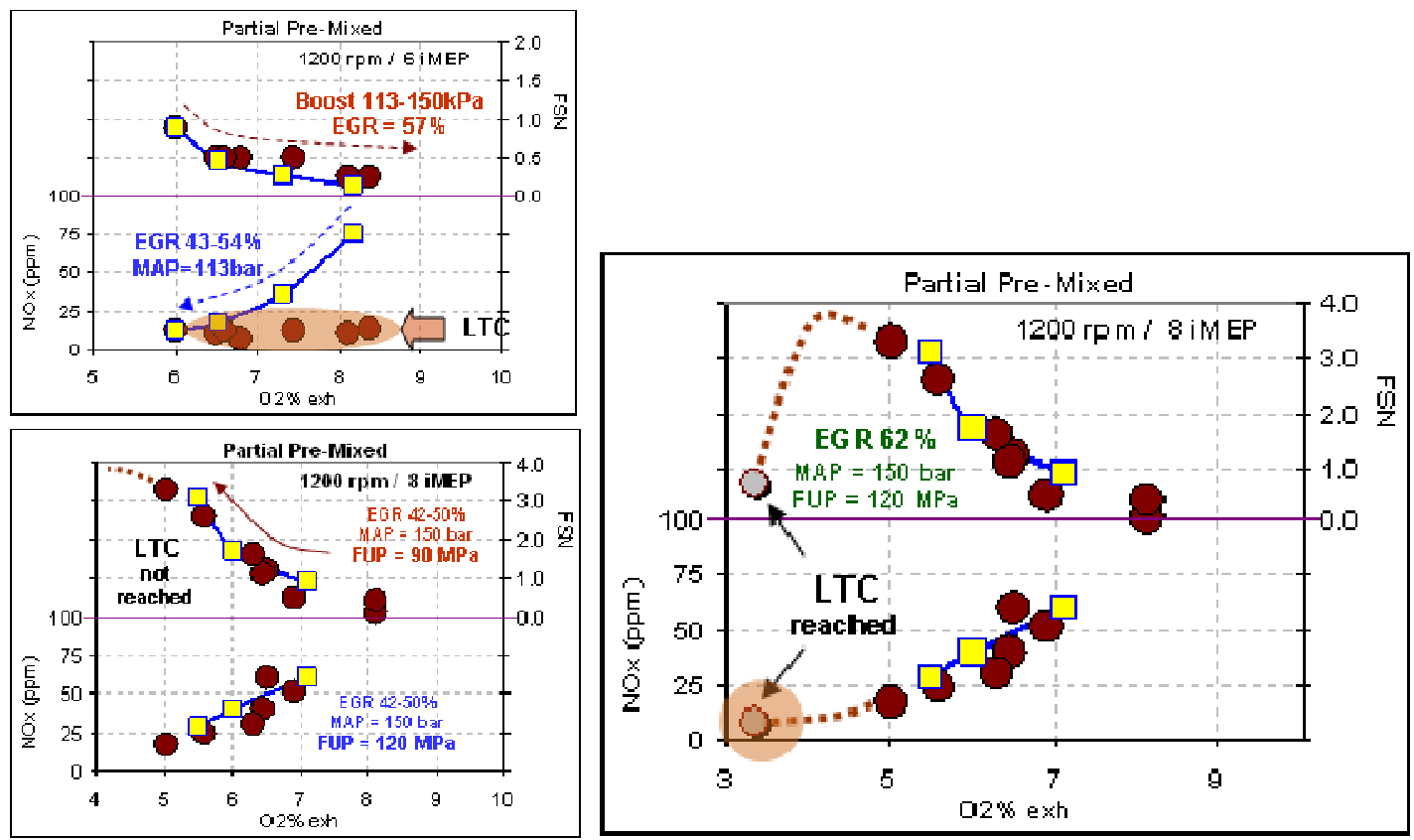

Figure 23 LTC as load increases
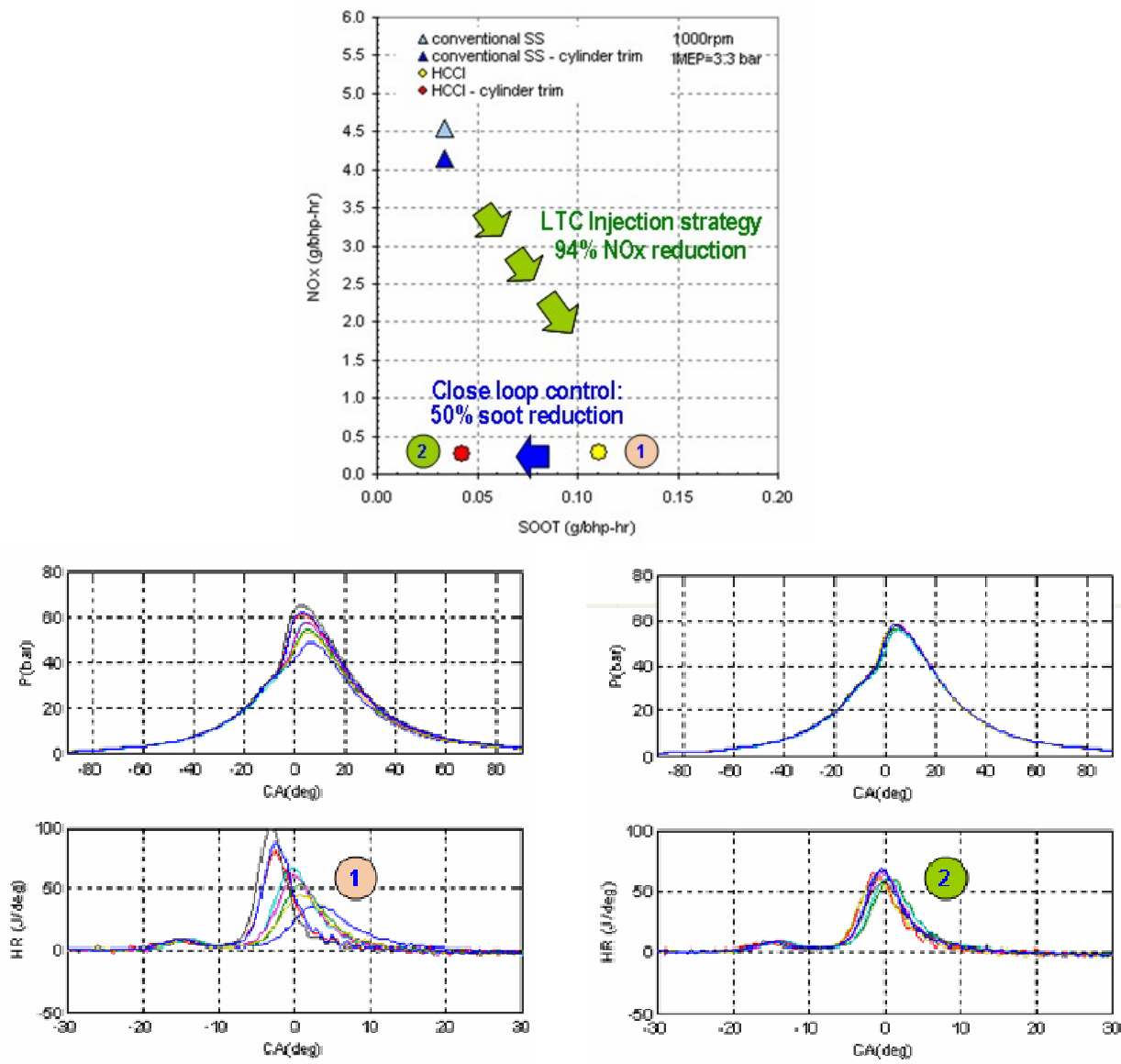

Figure 24 Impact of Cylinder Pressure Feedback on Combustion Stability 


\section{Development of a Fuel Injection Strategy}

A production version of a $\mathrm{V}-8$ engine was redesigned to run on partially premixed charge compression ignition $(\mathrm{PCCl})$ combustion mode with conventional diesel fuel. The objective of the $\mathrm{PCCl}$ combustion experiments was to obtain low engine-out nitrogen oxide (NOx) and after-treatment tolerant soot emission level. Two fuel injection strategies were used during the $\mathrm{PCCl}$ combustion experiments: a) pilot-with-main injection strategy (Pil-M), b) pilot-with-main-and-post (PMP) injection strategy.

In the Pil-M injection strategy, a significant fraction of the fuel was delivered early during the compression stroke. The early pilot helped to prepare a lean-mixture of enhanced homogeneity before the combustion was initiated. The combustion of this pilot injection followed by the main combustion helped to reduce soot for a constant NOx value. The pilot-injection timing and quantity had to be selected appropriately to retain the fuel-efficiency. Such an injection strategy was successful up to an engine load-level of 10bar BMEP. At higher load levels, it was found that the Pil$\mathrm{M}$ injection strategy was insufficient for a soot reduction. Therefore, the soot reduction was enhanced by using a small quantity of post injection to promote the late-cycle oxidation of soot. The PMP injection strategy helped to expand the load-limits of clean combustion to a load of 16.5bar BMEP; however this injection strategy had a higher fuel-efficiency penalty as compared to the Pil-M injection strategy.

The injection strategy approach on the engine operating map is illustrated in the Figure 25 below.

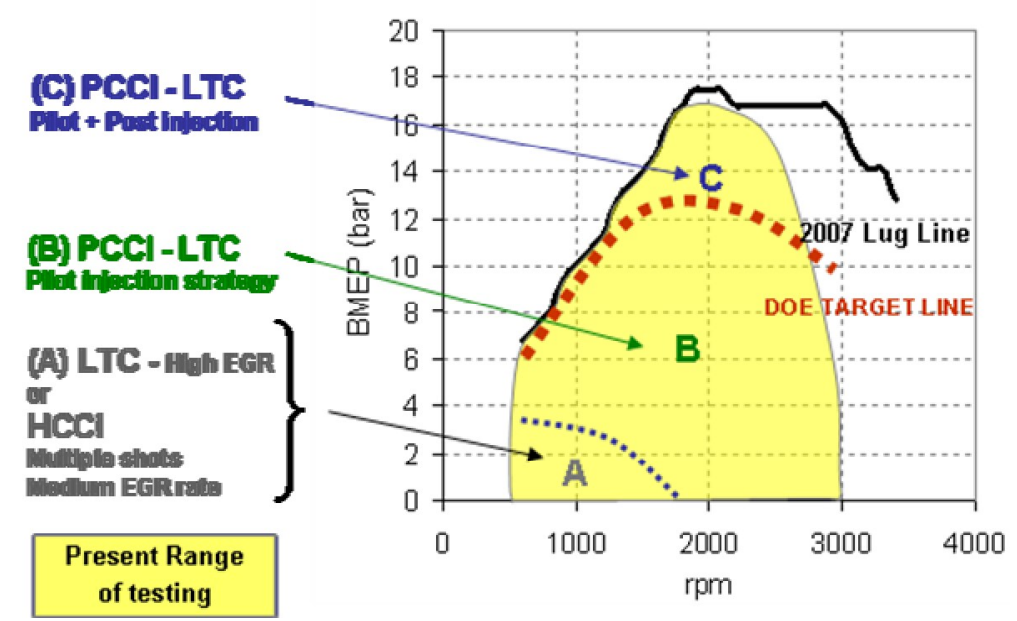

Figure 25 LTC Operation Range and Injection Strategy

This paper reports results from a 7-hole injector-nozzle with an included spray-angle of $158^{\circ}$. The fuel tested had a cetane index (ASTM D4737) of 43.1. 


\subsection{PCCI with PILOT-MAIN Injection}

The effectiveness of the Pil-M injection strategy to achieve the $0.2 \mathrm{gNOx} / \mathrm{bhp}$-hr target was valid up to $12 \mathrm{bar}$ BMEP. The PCCl combustion with the Pil-M injection strategy was implemented to enhance the homogeneity of the pilot fuel and thereby reduce the engine-out soot. A part of the fuel was delivered early during the compression stroke at appropriate injection timing, so that this fuel had a chance to vaporize and form a lean homogenous mixture before the initiation of the combustion process. This increased homogeneity was expected to assist in the soot reduction. The first step was to identifying the crank-angle and the quantity of fuel that may be implemented as the pilot injection.

The following tests performed at 1750rpm and 10bar BMEP illustrate the impact of pilot for soot reduction. The baseline experiment with no pilot was performed with a single injection strategy configured to provide a CA-50 timing of $7.5^{\circ}$ after-top-dead-center (ATDC). The EGR rate was selected so that a NOx emission of $0.18 \mathrm{~g} / \mathrm{hp}$-hr was obtained. At this baseline operating condition, the soot was observed to be 3.3FSN.

Effect of pilot timing. A sweep of the pilot injection timing showed no soot improvements for close to TDC injection timings. However as the pilot injection timings were advanced soot decrease was more apparent. If the pilot timing was advanced ahead of $50^{\circ} \mathrm{BTDC}$, the $\mathrm{HC}$ emissions began to increase slowly, while there was no significant advantage for soot emissions (Figure 26). The CO also increased from 15.5 to $22 \mathrm{~g} / \mathrm{hp}$-hr as the pilot injection timing was advanced to $70^{\circ} \mathrm{BTDC}$ from $50^{\circ} \mathrm{BTDC}$. Based on emission considerations a pilot timing of $50 \sim 60^{\circ} \mathrm{BTDC}$ was used for the tests.

Effect of pilot quantity. An increase in the pilot injection quantity at $50^{\circ} \mathrm{BTDC}$ was associated with a gradual decrease in the soot emission as shown in Figure 27. The rapid prototyping system (RPS) continuously adjusted quantity and the timing of the main injection so that the individual cylinder torque and the overall CA-50 was kept constant during the pilot quantity sweep. Note that at the baseline condition of no pilot-injection, an EGR of $45 \%$ was implemented. However for the case with a pilot of $10 \mathrm{mg} / \mathrm{stk}$ the EGR was reduced to $44 \%$ to maintain a constant NOx level at $\sim 0.2 \mathrm{~g} / \mathrm{hp}$-hr. The same figure shows that the pilot injection quantity of $10 \mathrm{mg} / \mathrm{stk}$ was sufficient to reduce soot emissions to the desired level of $2 \mathrm{FSN}$. At this operating condition a pilot quantity of $10 \mathrm{mg} / \mathrm{stk}$ represented $20 \%$ of the total fuel. With the implementation of a small pilot quantity, it was possible to avoid wall-impingement of fuel associated with early injection. There was a slight increase in the hydrocarbon emission $(\mathrm{HC})$ emissions but it was possible to retain the fuel-efficiency close to the baseline case.

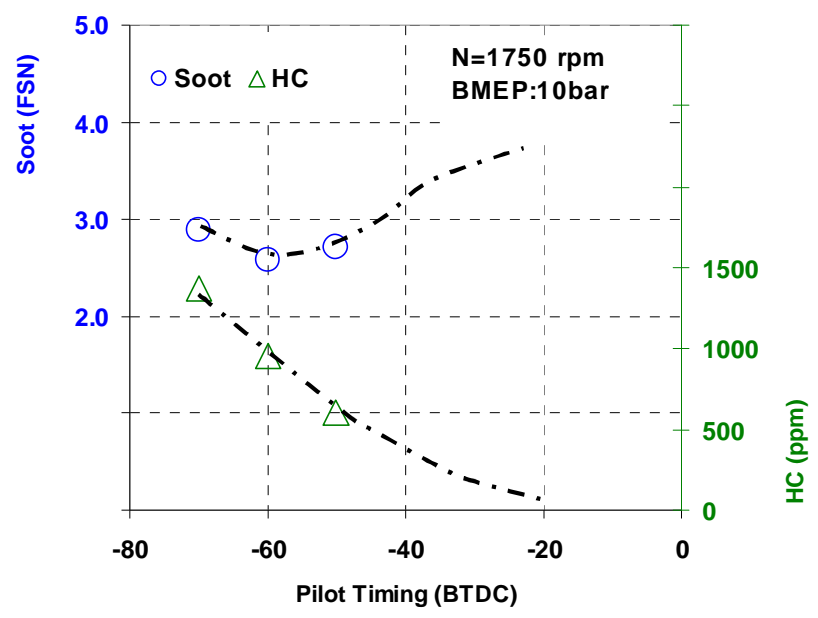

Figure 26 Effect of pilot injection timing on soot and $\mathrm{HC}$ emissions 

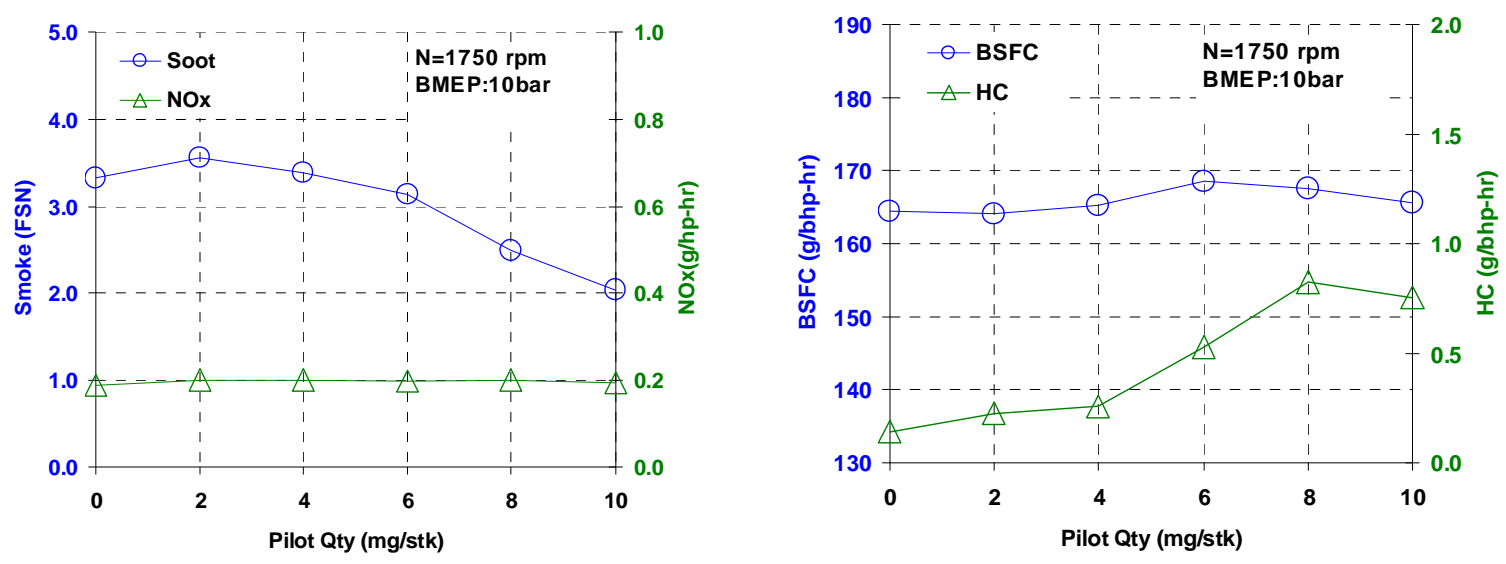

Figure 27 Effect of pilot quantity on soot, BSFC and HC

Figure 28 shows the effect of $\mathrm{PCCl}$ at $2400 \mathrm{rpm}$ and $75 \%$ load (C75). In this case the pressure curves that illustrate the gain of efficiency are illustrated in group A. Further use of pilot quantity however reverses the efficiency trend though the soot is further decreased as illustrated in grouping $B$.

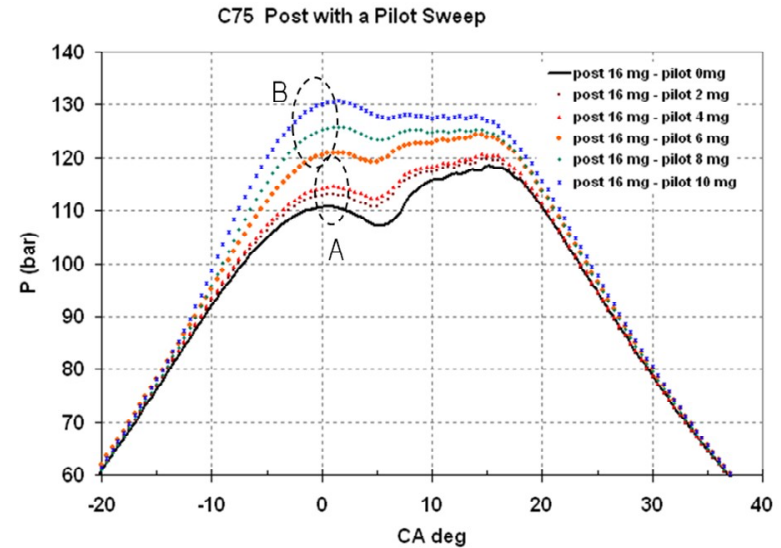

BSFC improvement of $1-2 \%$ can be

A identified by PCCl or fuel pilot and harvested with accurate cylinder pressure control.

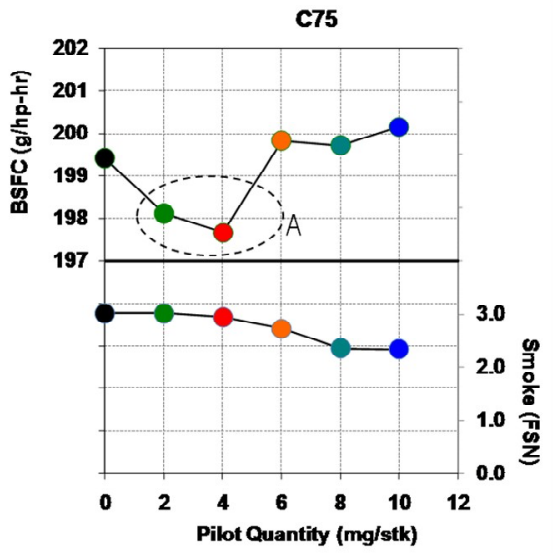

B Excess pilot deteriorates performance due to premature combustion.

Figure 28 Effect of pilot quantity on soot and BSFC at $75 \%$ load

\section{2. $\mathrm{PCCl}$ with PILOT-MAIN-AND-POST}

It has been well documented, that a small amount of post injection can help in the post oxidation of soot. The impact is very dependent on timing. It is important to identify the crank-angle window for best soot oxidation by studying the impact post-injection timing and quantities.

Post Injection. The post-injection timing and quantity optimization are illustrated at $1750 \mathrm{rpm}$ and $8 \mathrm{bar}$ BMEP. The baseline case with no-post injection had soot close to $2 \mathrm{FSN}$. The single injection timing was implemented at $6^{\circ}$ BTDC to achieve a CA-50 of $12^{\circ}$ ATDC. 
A post-injection timing sweep was performed at two fixed post-injection quantities (Figure 29). The post injection implemented in the crank angle window of $10 \sim 20^{\circ} \mathrm{ATDC}$ had either no soot advantage or higher soot as compared to the baseline soot values. For the timing window between $20 \sim 30^{\circ}$ ATDC there was a gradual decrease in the soot values as the post-injection timing was gradually retarded. As the injection timing was retarded more than $30^{\circ}$ ATDC there was little or no impact on the soot emissions. The post-injection approach to reduce soot needs to be exercised with caution as this approach leads to a significant fuel penalty (Figure 29). This was primarily due to the fact that the heat-released so late during the engine-cycle process contributed very little to power production. Based on the present discussion an effort was made to use the smallest quantity of post-injection at a timing of $30^{\circ}$ ATDC for tests at higher loads.

\section{$\underline{\text { Pil-M vs. PMP injection }}$}

Emission and efficiency characteristics of Pil-M vs. PMP have been compared at 10bar BMEP. The base condition was a single injection implemented to give a CA-50 of $7.5^{\circ} \mathrm{ATDC}$. The CA-50 of $7.5^{\circ} \mathrm{ATDC}$ was maintained constant in the following discussion. The reference single shot injection, point 1, had an EGR of $44 \%$. The soot was measured at $2 \mathrm{FSN}$ and NOx at $0.26 \mathrm{~g} / \mathrm{hp}$-hr. The EGR was increased to $46 \%$, point 2, to reach the desired NOx<0.2 g/hp-hr. Soot increased to $3.5 \mathrm{FSN}$. Both Pil-M (point 3) and PMP (point 4) were then applied to limit the soot to less than 2FSN at constant NOx, but the PMP injection strategy had a higher fuel-efficiency penalty (Figure 30). A $\mathrm{NOx} \sim 0.2 \mathrm{~g} / \mathrm{hp}$-hr and soot of $2 \mathrm{FSN}$ were attained with single-injection strategy as well (points 5). The injection pressure needed increase from $142 \mathrm{MPa}$ to $165 \mathrm{MPa}$, and combustion phasing needed to be retarded to $15^{\circ} \mathrm{ATDC}$ to meet simultaneously NOx and soot requirements. The late CA-50 of $15^{\circ} \mathrm{ATDC}$ resulted in a significantly higher BSFC penalty.
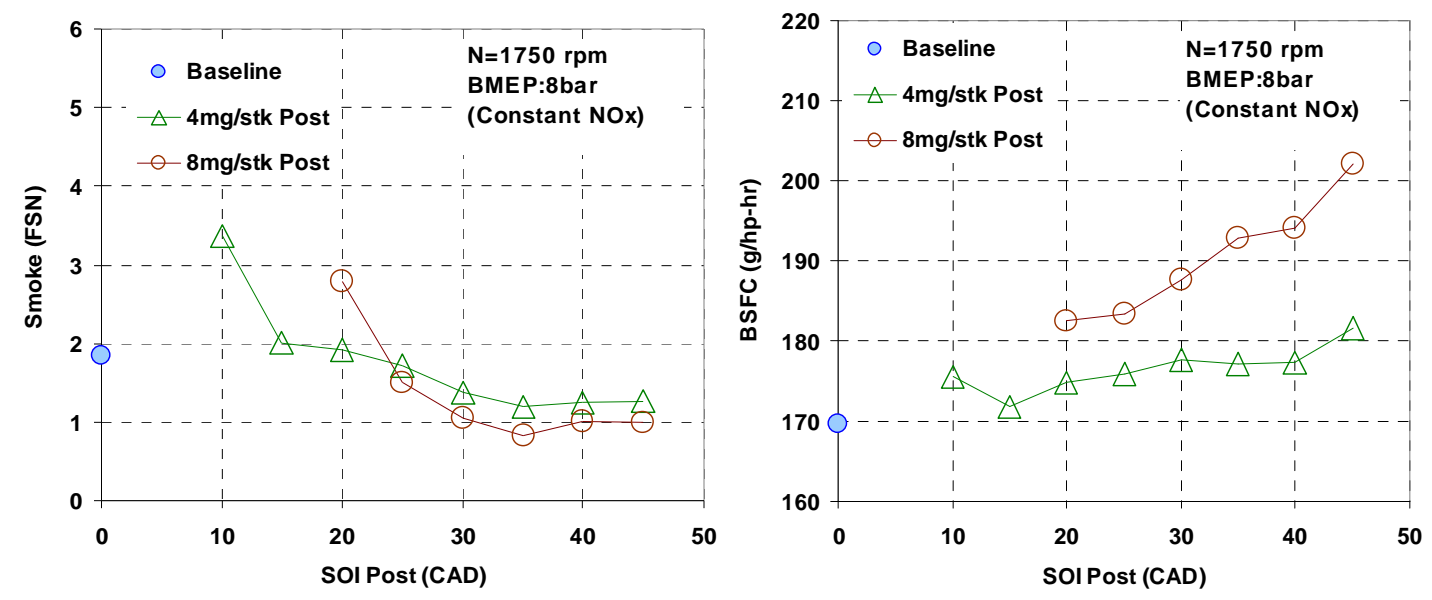

Figure 29 Effect of post-injection timing on soot and BSFC

In summary, it was possible to meet simultaneous low-NOx and low-soot requirements with a multitude of ways, but the PMP and single-injection with a very late CA-50 had the highest fuelpenalty when compared with Pil-M alone in this load range. This trend however does not hold at higher loads as illustrated next.

PMP injection at high-loads:

Figure 31 summarizes the procedure that was followed for soot-reduction at high-loads with a PCCI strategy. The procedure consisted of soot reduction by: 

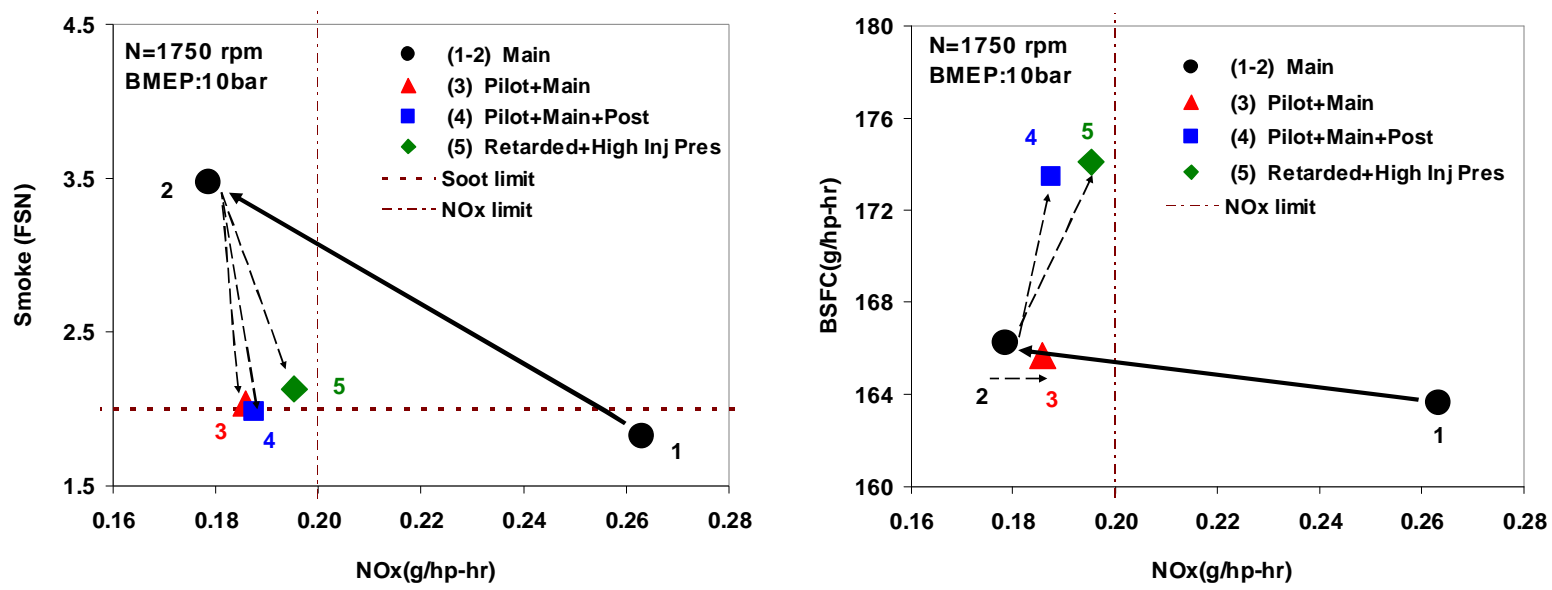

Figure 30 Effect of injection strategy on NOx-soot and NOx-BSFC trade-off

1) Air-system management with single injection

2) Soot reduction by implementation of pilot injection

3) Soot reduction by implementation of post injection

The case considered is a load of $16.5 \mathrm{bar}$ BMEP at $1671 \mathrm{rpm}$. At the baseline condition a combination of EGR and a single-injection strategy with CA-50 of $12.5^{\circ}$ ATDC achieved a NOx $\leq 0.2 \mathrm{~g} / \mathrm{hp}$-hr. A CA50 of $12.5^{\circ}$ ATDC was selected as a compromise between the BSFC and emission considerations. At the baseline condition indicated as point 1 on Figure 31, a soot level of 5FSN was observed. From here, the boost was gradually increased by closing the vanes of the turbocharger (points 1 through 2). This vane sweep was implemented at constant NOx, which required EGR to be adjusted. This step reduced the soot as the oxygen availability increased. The engine back-pressure and the overall airsystem design limited the range of VNT settings. The increased boost reduced soot from 5.1 to 4FSN. Next the Pil-M injection strategy was implemented. The pilot quantity was gradually increased up to $20 \mathrm{mg} / \mathrm{stk}$ (points 3 through 4 ). Soot was reduced further to $3.2 \mathrm{FSN}$. Pilot quantities were limited to avoid premature autoignition. A pilot quantity of $20 \mathrm{mg} / \mathrm{stk}$ represented approximately $22 \%$ of the total fuel injected per cycle.

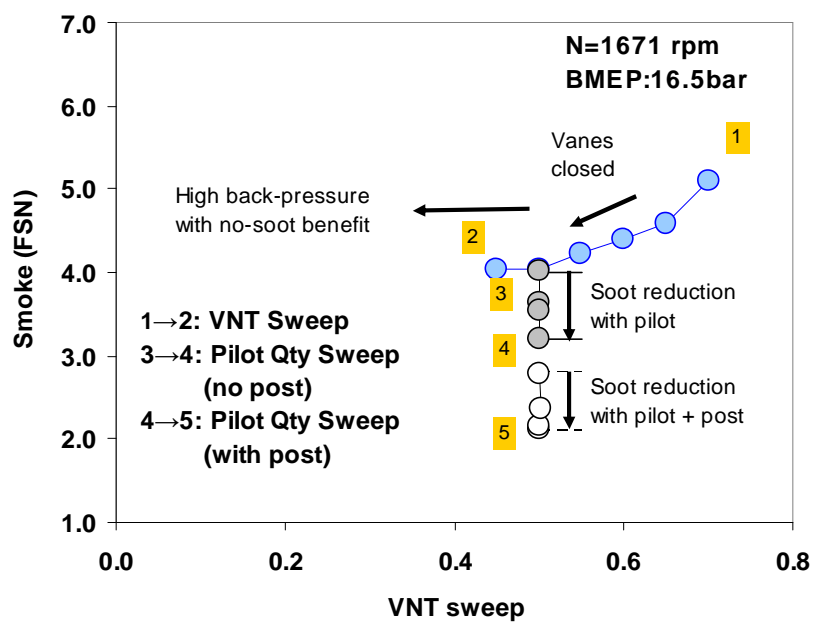

Figure 31 Effect of injection strategy on NOx-soot

The PMP injection strategy was implemented to further reduce soot (point 5). With a small postinjection of $6 \mathrm{mg} / \mathrm{stk}$ it was possible to meet the desired soot target of $2 \mathrm{FSN}$. The post-injection 
quantity of $6 \mathrm{mg} / \mathrm{stk}$ represents approximately $7 \%$ of the total fuel injected per cycle. The implementation of the PMP injection penalty incurred little fuel-penalty as shown in Figure 32. The CO and $\mathrm{HC}$ emissions during the injection strategy investigation are shown in same figure.
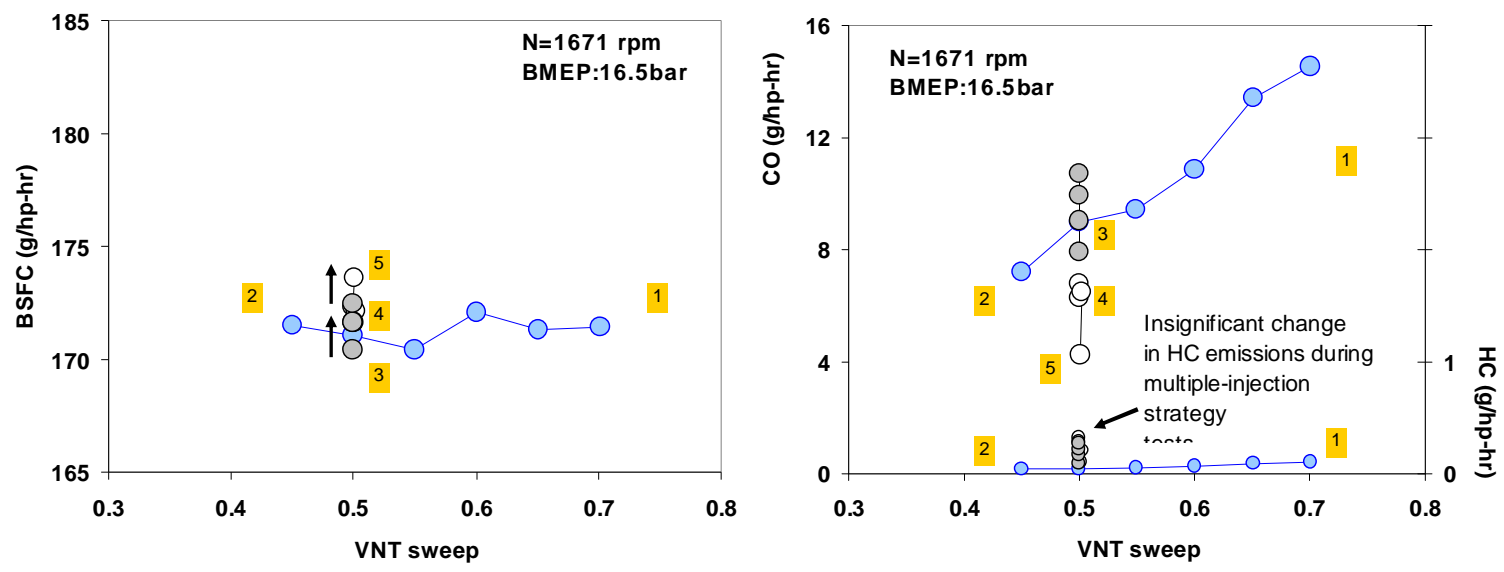

Figure 32 Effect of injection strategy on bsfc, $\mathrm{CO}$ and $\mathrm{HC}$

For reducing the NOx at high-loads the authors had an option of increasing the EGR or retarding the combustion phasing. At the 16.5bar BMEP condition the soot penalty due to increasing EGR was more than the soot penalty due to retarding the combustion phasing. Therefore for the high-load case the retarding the combustion phasing was aggressively used to reduce NOx.

\subsection{Development of VVA strategy}

The program investigated the effects of variable valve actuation on the earlier LTC combustion work. Early inlet valve closing (EIVC) lowered the pressure and temperature during the compression stroke, resulting in a longer ignition delay as the fuel mixed more homogenously with the charge air ahead of combustion. Combustion was characterized by prominent cool flame chemistry and a faster, more energetic, premixed combustion. The use of EIVC showed significant reductions of soot (above $90 \%$ ) and fuel efficiency improvements (of $5 \%$ ) while maintaining NOx levels below $0.2 \mathrm{~g} / \mathrm{bhp}-\mathrm{hr}$. The improvements in emissions and fuel economy came from controlling in-cylinder temperatures and optimizing combustion phasing. For a constant engine-out NOx emission, EIVC improved fuel economy as the amount of EGR and the engine back pressure requirement were reduced.

\section{Thermodynamic Effects of EIVC}

The largest effect of EIVC upon in-cylinder conditions was the reduction in charge mass from the throttling of flow through the intake valves. EIVC reduced the effective compression stroke and compression pressure. The impact of EIVC is illustrated in Figure 33. For a constant brake power, advancing IVC by 90 degrees reduced compression pressures by $40 \%$ at TDC. Max combustion pressures were reduced by less, $20 \%$, due to the more rapid combustion achieved by EIVC. EIVC had a cooling effect upon the charge mass, reducing the temperatures at TDC by 100K. The same fuel energy applied to a reduced charge mass inducted into the cylinder when EIVC is applied caused the peak bulk combustion temperatures to climb 200-300 K higher than the baseline condition. Decreasing the pressure and temperature at the start of combustion promoted the low temperature reaction (LTR) of Diesel fuel. Longer ignition delays (through the use of EIVC) increased the amount of fuel burning in the premixed burn. The heat released during the premixed burn had a shorter duration and a higher peak value, indicative of faster and more efficient combustion. The diffusion flame portion of combustion after the premixed burn was reduced in magnitude and duration. 


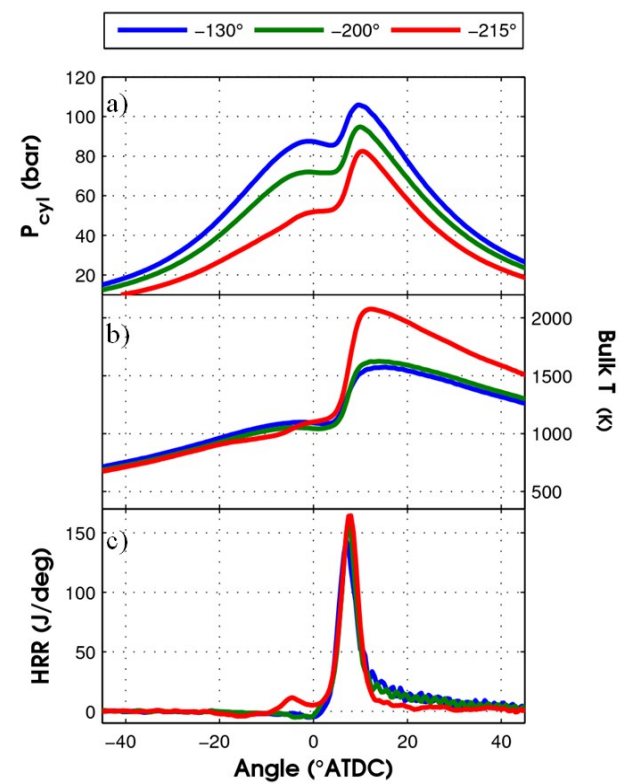

Figure 33 (a) Pressure, (b) Temperature, and (c) HRR

EIVC caused the charge in cylinder to undergo expansion after IVC. The expansion effect near bottom dead center for the earlier figure is detailed in the pressure traces of Figure 34. The same data is re-represented in accompanying the P-V diagram. The latter figure was particularly insightful as it demonstrated the expansion process produced by this lost motion VVA device to be nearly isentropic as seen by the near collapse of the pressure curves after IVC. The area trapped between the curves is almost negligible. The EIVC process, even in its very advanced timings, therefore did not contribute to pumping losses.

The advantages of IVC over inlet throttle are well understood and established in the industry. The inlet throttle yields significant pumping losses in the induction stroke whereas they were negligible with EIVC. Both early and late IVC have similar effects over the effective compression ratio. On a closer look, however, it will be noted that a late IVC device requires work to induct air, and after BDC, a negative pressure differential is created (higher $\mathrm{P}$ in cylinder) in order to drive out cylinder charge. This is work required from the cylinder piston, which could result in an increase in brake specific work vs. EIVC.
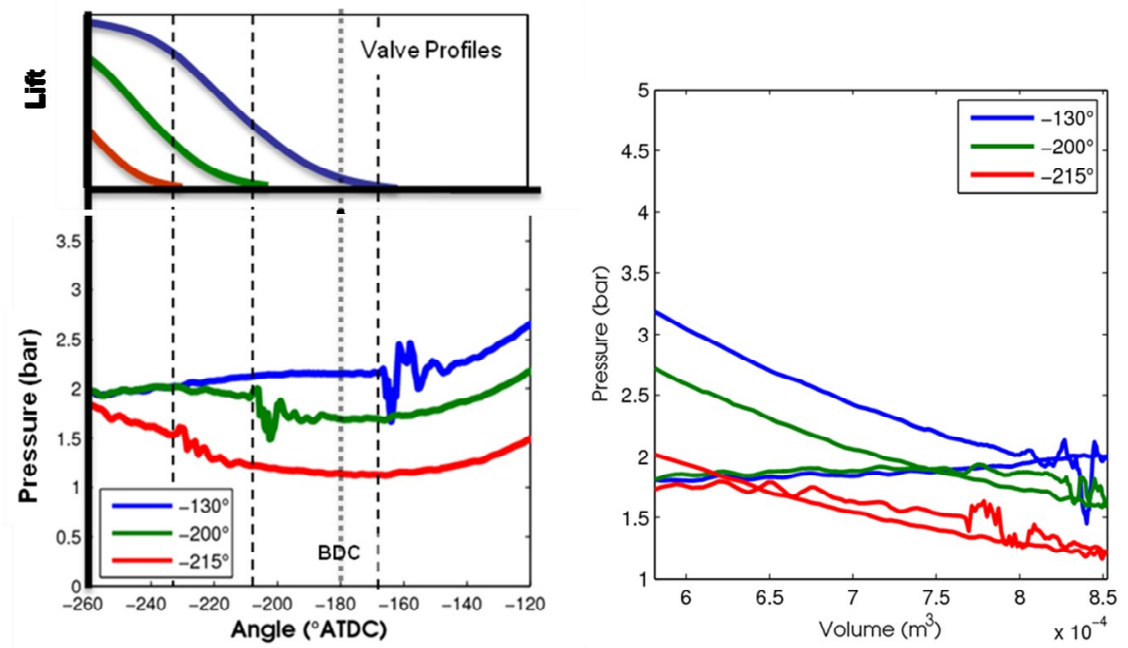

Figure 34 Detail of pressure traces near EIVC 


\section{Effects of EIVC on performance and emissions}

The impacts of EIVC on engine performance and emissions are presented here for constant combustion phasing of $\mathrm{CA} 50=7.5 \mathrm{deg}$ ATDC. To keep phasing constant, SOI was altered to accommodate changes in ignition delay. The baseline SOI was -6.7 deg ATDC. Figure 35 shows the changes in BSFC, emissions, and engine operating conditions with respect to IVC. The timing was advanced until the limit of stability was attained as determined by combustion variability not exceeding a COV of 5 degrees in SOI among all cylinders.

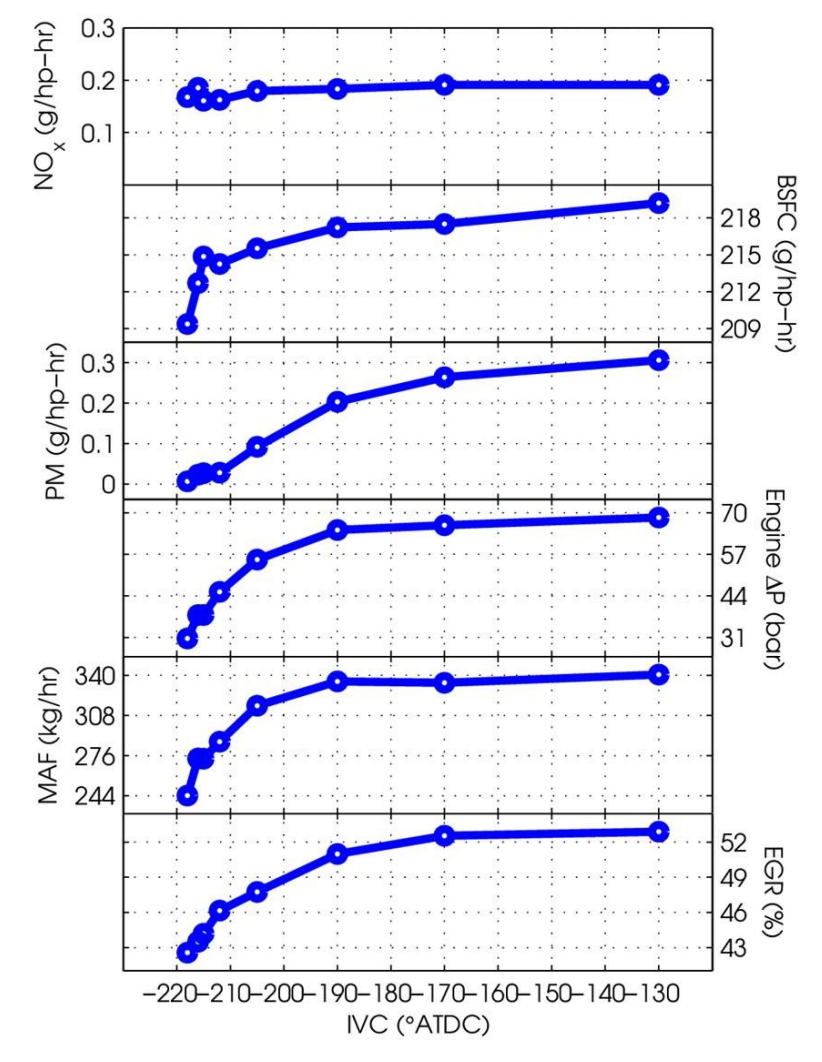

Figure 35 Engine Performance as a function of IVC

\section{Emissions}

EIVC demonstrated a drastic reduction of soot at constant NOx while reducing fuel consumption. Smoke decreased sharply as IVC was advanced. Longer ignition delay due to reductions in pressure and temperature increased mixing of the fuel with the charge air. Reductions in soot reached as high as $95 \%$. BSFC reductions of $4 \%$ were attained. The mass air flow into the engine declined with EIVC due to the reduction of the intake valve duration, but did not cause any detrimental effects on the soot formation.

The amount of EGR required to hold 0.2 gNOx/hp-hr decreased by $12 \%$. The O2\% in the intake remained nearly constant, between $14.2 \%$ and $14.5 \%$. O2\% remains a strong control variable for NOx. The increased $\mathrm{CO} 2$ concentration in the exhaust (due to the reduction of other components from MAF reduction) reduced the amount of EGR required to dilute the intake to the proper oxygen concentration. For fixed combustion phasing, the start of injection advanced as IVC advanced.

CO emissions increased as IVC was advanced, but started to decrease at very early IVC timings. HC emissions increased monotonically with early IVC. The drop in CO is particularly interesting as it 
corresponds with a rapid improvement in BSFC. The phenomena should be studied further in collaboration with chemical kinetic specialists.

Fresh mass into the engine (MAF) was reduced by as much as $25 \%$ from the standard IVC. The global equivalence ratio, $\Phi$, increased from 0.6 to 0.8 . Typically, the increased $\Phi$ would increase soot emissions as the engine approaches stoichiometric conditions. However, in this case, the longer ignition delays reduced local $\Phi$ to the point that much lower soot levels were reached.

\section{Performance}

Boost was maintained relatively constant by adjusting the turbocharger settings. Very advanced IVC, however, reduced the boost in the intake manifold. A reduction in pressure differential across the engine, the difference between exhaust and intake pressures, was observed. The pressure reduction improved the engine efficiency. The increased $\mathrm{CO}$ and $\mathrm{HC}$ during early IVC partially offset this improvement and remain a challenge to fully capitalize in the overall engine efficiency.

Temperatures in the exhaust manifold were raised by over $100 \mathrm{C}$ with early IVC. The ability to reach higher exhaust temperatures in the exhaust at part load conditions contribute to better management of Diesel Particulate Filters (DPF), which require high temperatures to operate effectively. EIVC provides the opportunity to regulate temperatures upstream of the aftertreatment more effectively than other commonly used strategies such as an in-cylinder late post injection to produce excess $\mathrm{HC}$ for the pre-DPF Diesel Oxidation Catalyst or a separate HC doser. EIVC can thus play a significant role to avoid the deterioration of fuel economy from the present DPF thermal management strategies.

\section{Effect of Ignition Parameters}

The earlier section showed the impact of EIVC on physical boundary conditions such as pressure, temperature and mass flow. EIVC changed conditions which drive the chemical processes of the combustion. Figure 36 shows the effect of the VVA system on the ignition pressures and temperatures for the three different CA50 values (captured by the symbol shape). For the same IVC, the ignition temperatures were higher at more advanced CA50. The earlier CA50 ignited at an angle close to TDC, raising the temperature at the same pressure due to boost effects.
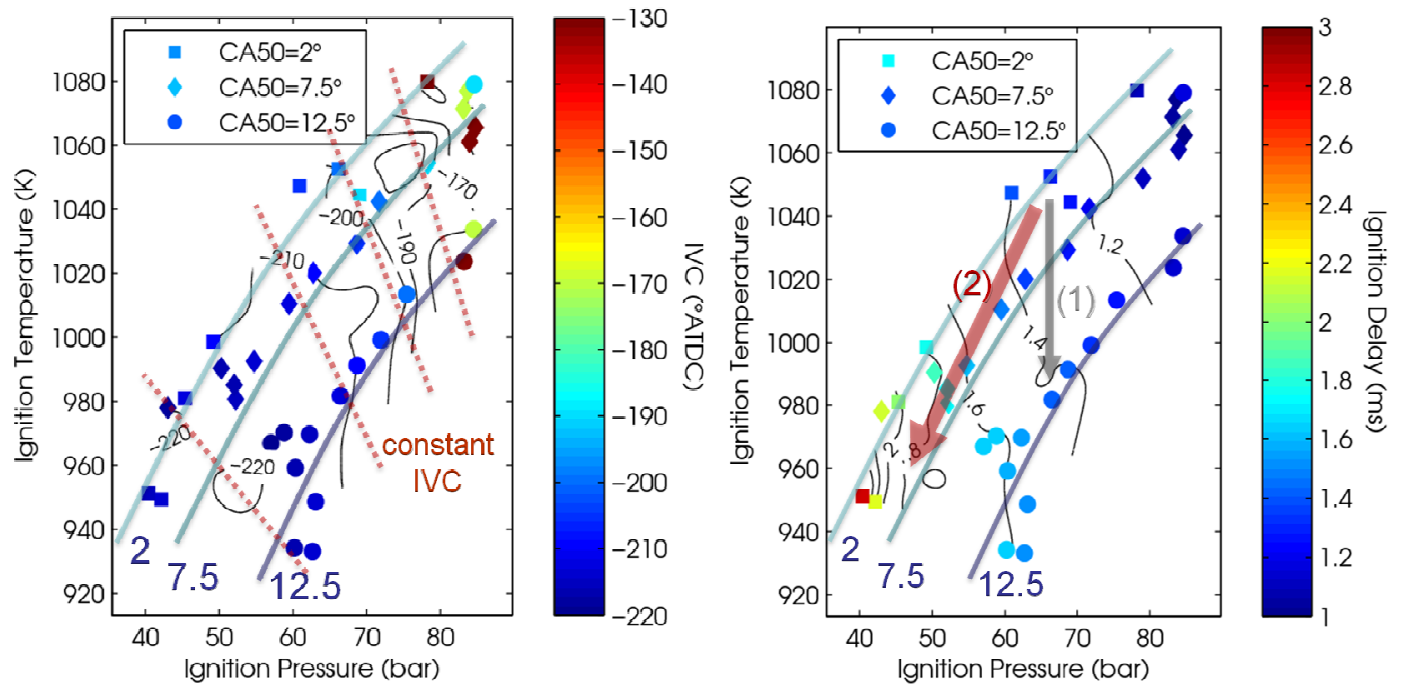

Figure 36 Ignition $(\mathrm{P}, \mathrm{T})$ and ignition delay according to IVC and CA50 
The pressures and temperatures at time of ignition from Figure 36 produced by IVC had a strong correlation with ignition delay. The figure shows the ignition delay increased as IVC was advanced and combustion phase was retarded. The effect of IVC was much more dominant than the combustion phasing. For a given ignition pressure, the ignition delay was higher when the combustion temperature was lowered as accomplished by late combustion. Line (1) showed a representative $0.1 \mathrm{~ms}$ increase in ignition delay. The effect of early IVC is captured in line (2). A 20 deg shift in IVC, at a constant combustion phasing, yielded $0.3 \mathrm{~ms}$ increase in ignition delay. Further shift in IVC of 10 deg as indicated in line (3) increased the ignition delay by $1 \mathrm{~ms}$.

The effect of increased ignition delay in the soot emissions is shown in Figure 37. Long ignition delays increased the amount of fuel in the premixed burn (refer to earlier discussion of the heat release traces). The premixed burn did not have the tendency to soot heavily and the soot emissions decreased with the amount of fuel in the premixed burn. The use of IVC yielded engine out soot and NOx below the US 2010 emission standards (0.01 g/hp-hr and $0.2 \mathrm{~g} / \mathrm{hp}-\mathrm{hr}$ ).

The soot reduction with use of early IVC was attained with improvements in BSFC making this an attractive emission and fuel economy technology. Figure 37 shows the effect of pressure and temperature at the time of ignition on BSFC. Whereas soot and ignition delay were very dependent upon IVC, the data represented indicated BSFC was more dependent upon the combustion phasing. The reduction in BSFC due to the reduction in pressure and temperature due to early IVC was overshadowed by ignition timing. Results clearly indicated that the lowest BSFC was achieved at the earliest ignition timing, when combustion took place closer to TDC.
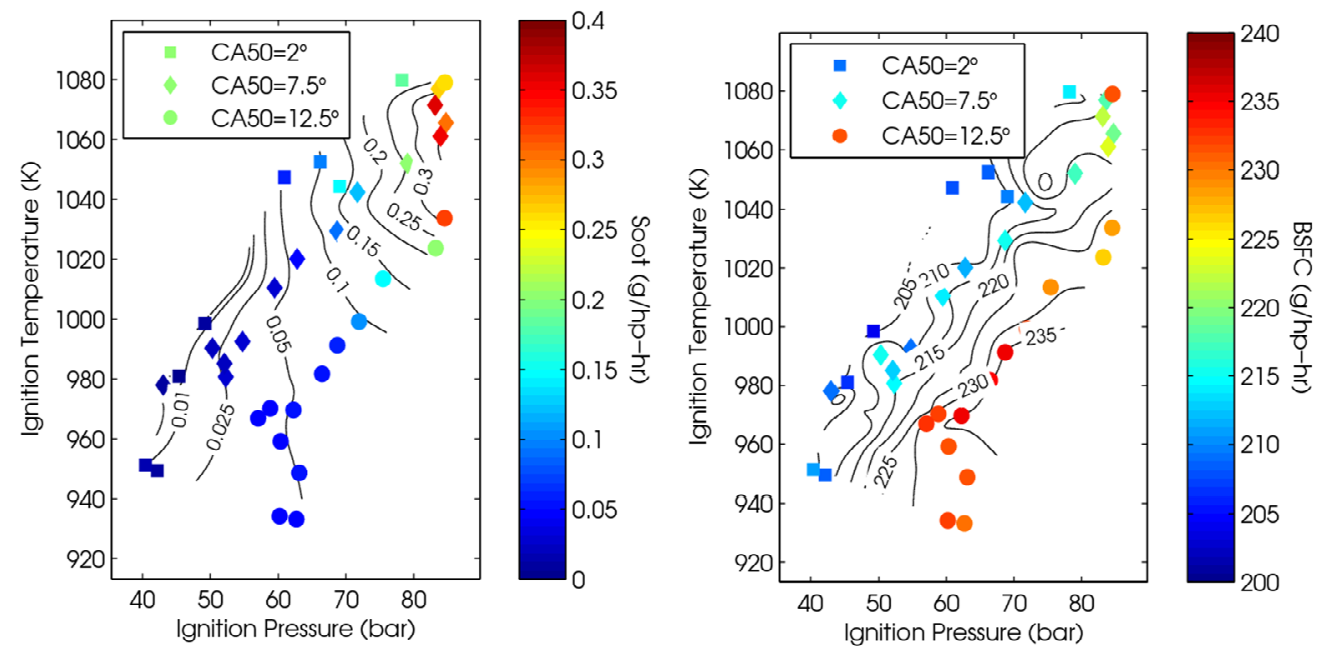

Figure 37 Soot and bsfc according to IVC and CA50 


\section{Controls System Development}

\subsection{Control System Overview}

The early controls work was performed on a Rapid Prototype System (RPS), operating at a clock frequency of $800 \mathrm{MHz}$, with little limitation towards the basic engine functions and the in-cylinder pressure feedback. The in-cylinder pressure feedback system was first demonstrated with the RPS. The results were very favorable and proved to be a key enabling feature to support the low-NOx engine technology. Thereafter, the in-cylinder pressure feedback system was migrated into the production controller.

\subsection{Air System Control}

The air handling system provided conditions to support low temperature combustion consisting of,

1. Two stage turbocharger with independent control over vanes at each turbine, coordinated to provide target boost levels;

2. A by-pass on the high-pressure turbo and compressor stages activated at approximately $80 \%$ and above load levels;

3. EGR throttling valves to yield precise target re-circulated mass;

4. CAC cooling by-pass and heater unit, used occasionally at the low load conditions.

All the above controls have an inherent time constant scalable with the flow paths, typically on the $100 \mathrm{msec}$ range. No special requirements from the ECU are necessary to handle this function.

\subsection{Combustion Control}

Control of combustion consisted in adjusting injector timing and width of pulse to adjust fueling to target combustion phasing and torque output. Figure 38 shows cycle-to-cycle variation as a target SOC is zeroed in from an arbitrary initial condition.

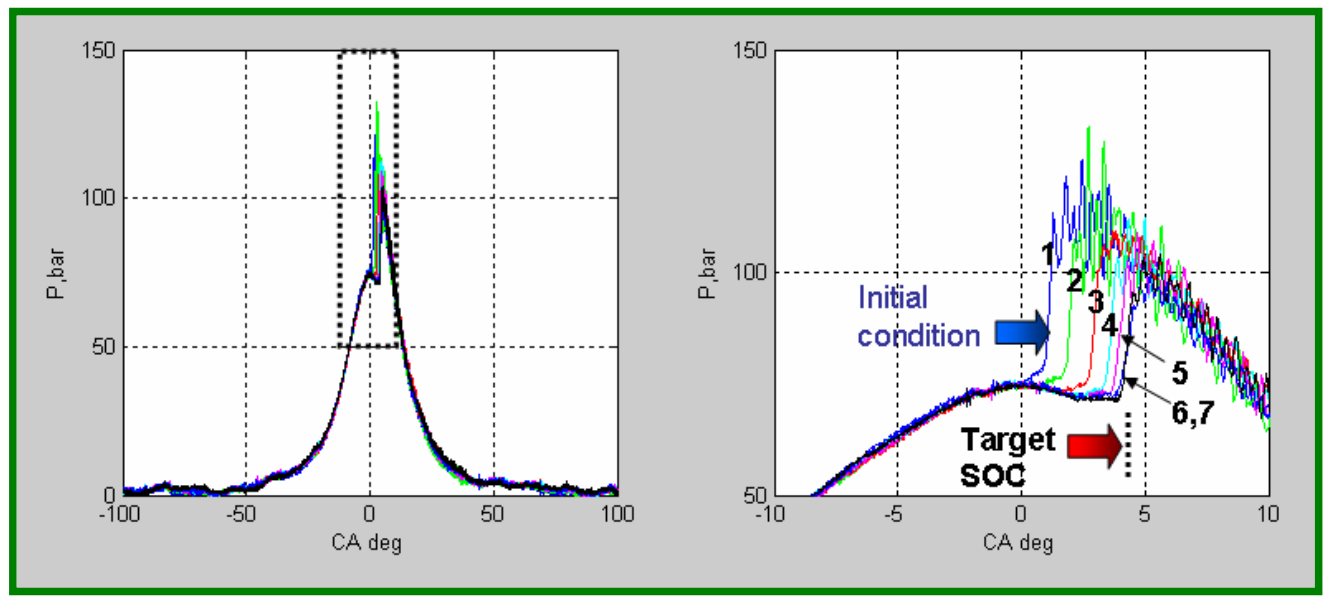

Figure 38 Control over Start of Combustion 


\subsection{Prototype ECU layout}

A prototype ECU was developed to handle the special combustion control features investigated with the RPS. Figure 39 provides a summary of the features between the selected platform (MPC 5554) for demonstration and the current ECU. No special features are brought to play by the MPC controller except the capability to access its operating system to handle the acquisition of pressure signals. Minimum adjustment on the hardware was made to accommodate the higher rates of acquisition required.

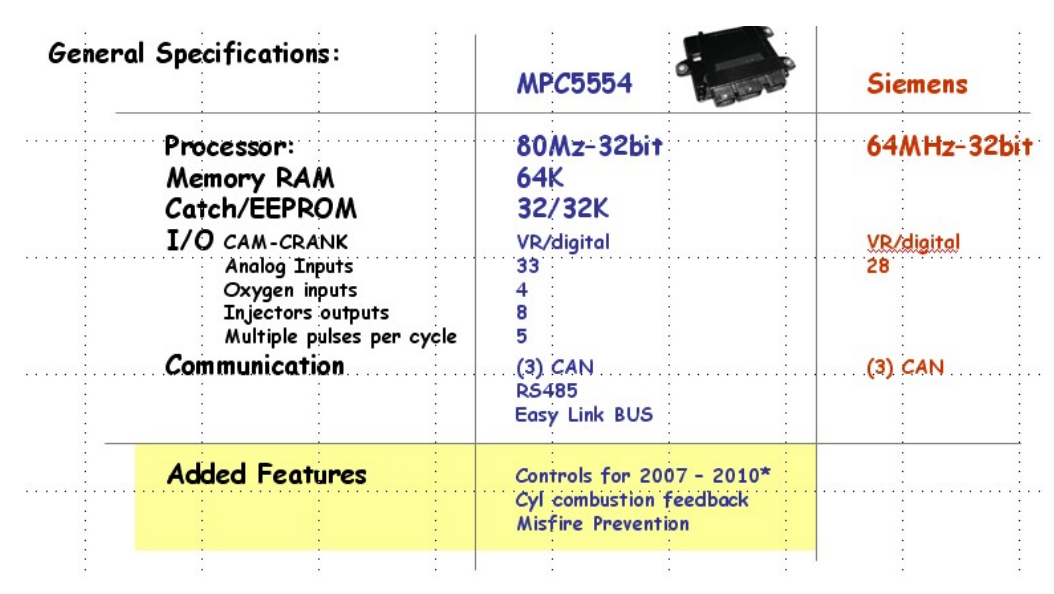

Figure 39 Prototype (MPC5554) and Current ECU

Navistar's upgrade to MPC5554 includes modification to several subsystems. An Analog to Digital Conversion (ADC) Triggering Subsystem was implemented to generate a 0.5 deg trigger for acquisition. Discrete ADC channels were upgraded to accommodate higher cylinder pressure time constants. An ADC Command Queue and a Receipt Subsystem was established to store pressure vector data for each cylinder. Finally an output Vector Generation Subsystem was implemented to make the pressure data available to the main processor.

The above functions are hardware intensive and rely and dedicated eTPUs which do not task the main processor. The pressure diagnostic routines on the other hand reside in the main processor and need to be efficient to meet the criteria of cycle-to-cycle feedback correction. At $3500 \mathrm{rpm}$, the processor needs to estimate from the pressure vector combustion phasing and torque within a window of $4.8 \mathrm{~ms}$. Figure 40 shows various stages of execution times during the optimization effort. To date, the processor was timed at $0.55 \mathrm{~ms}$, significantly below the $4.8 \mathrm{~ms}$ requirement.

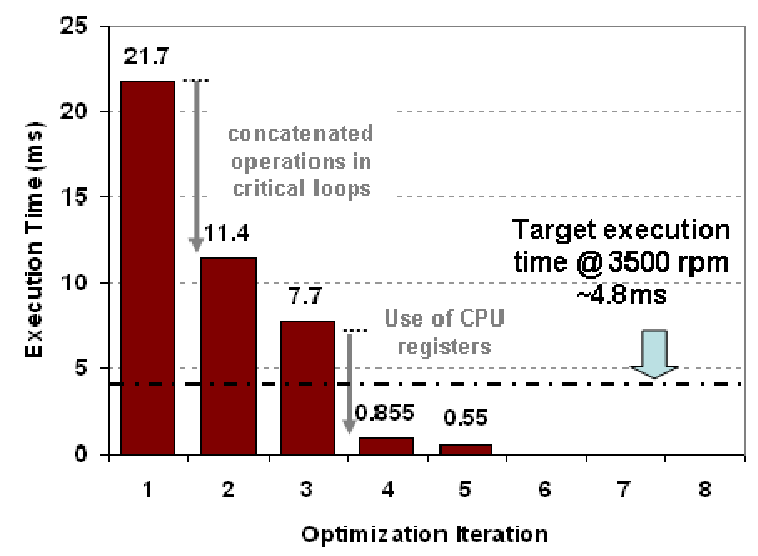

Figure 40 Optimization of pressure diagnostic routines 
Figure 41 shows the prototype ECU processing the multiple cylinder pressure data at $3500 \mathrm{rpm}$ well within the accuracy of 0.5 degrees.
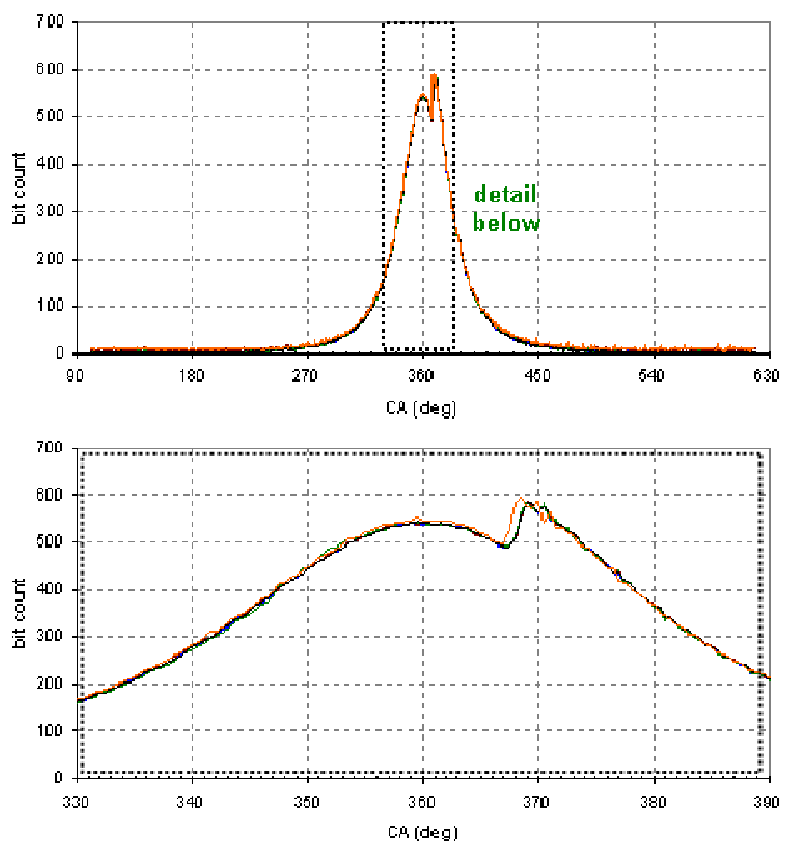

Figure 41 Pressure acquisition demonstrated at 3500rpm

\section{Pressure measurements:}

The Kistler $6052 \mathrm{C}$ pressure transducer was chosen for the present application, with a resolution of $20 \mathrm{pC} / \mathrm{bar}$ and a frequency response of $160 \mathrm{kHz}$. The pressure and temperature ranges are 0 to 250 bar and $-50^{\circ} \mathrm{C}$ to $350^{\circ} \mathrm{C}$ respectively. The sensitivity shift is \pm 0.5 to $\pm 2 \%$ according to temperature. The cylinder heads may also accommodate the Kistler 6043, water cooled unit with improved sensitivity shift of $0.5 \%$. The latter unit has same resolution and temperature and pressure ranges though has lower frequency response $(70 \mathrm{kHz})$.

In the latter part of the program Piezo resistive transducers, intent for production, were obtained but data are not available from these transducers at the moment. The reader may contact the $\mathrm{PI}$ of this publication for more up to date information on these transducers. 


\section{Engine Performance}

\subsection{Summary of Steady State Performance}

The impact of Low Temperature Combustion on the engine performance is favorable at high load and on the overall engine operating map. LTC and its variant of partial Premix-Charge Compression Ignition are employed foremost to reduce NOx to the $0.2 \mathrm{~g} / \mathrm{bhp}-\mathrm{hr}$ level. Soot is held to a DPF tolerable level of approximately 0.1 to $0.15 \mathrm{~g} / \mathrm{bhp}$-hr. Figure 42 shows a load sweep under LTC with respect to three different Diesel like production calibration settings. The data corresponds to B-speed, approximately $2000 \mathrm{rpm}$. The family of production calibrations spans the range of 0.5 to $1.2 \mathrm{gNOx}$. As the NOx is further reduced by LTC, the fuel savings are demonstrated across the load range, in some cases spanning $10 \%$ better fuel economy than the high-NOx product.

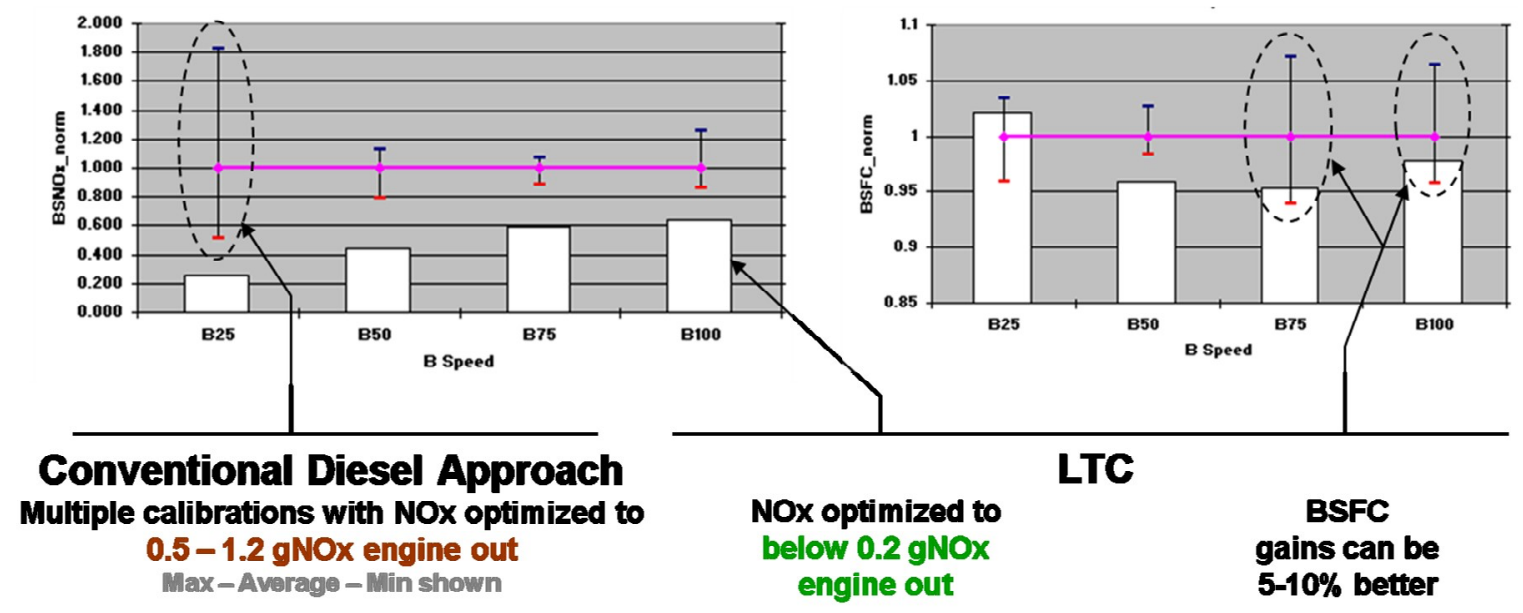

Figure 42 Comparison of three product calibrations with LTC at B-speed

Data above was normalized was normalized around the average of baseline product. The comparison with respect to multiple production calibrations provided a statistical analysis of multiple calibrations and demonstrated that LTC can maintain favorable tradeoff between emissions and fuel economy.

Figure 43 shows the combined 13 mode test results. The figure illustrates the overall technology roadmap towards reducing emissions and at the same time increasing the engine's break thermal efficiency.

Fuel improvements were approximating $2.5 \%$ over the cycle with the optimized EGR and boost technologies. Introduction of $\mathrm{PCCl}$ further increased the efficiency to $4 \%$ over the baseline at $0.19 \mathrm{gNOx} / \mathrm{bhp}$-hr. The introduction of VVA brought the efficiency improvement to over $5 \%$ and took the NOx to $0.15 \mathrm{gNOx}$. The application of cylinder pressure feedback provided further gains due added robustness. The application of cylinder pressure feedback was not insignificant, as it provided a strong knob to adjust both fuel and air in cylinders to balance the engine. 
Fuel Consumption improvement (\%)

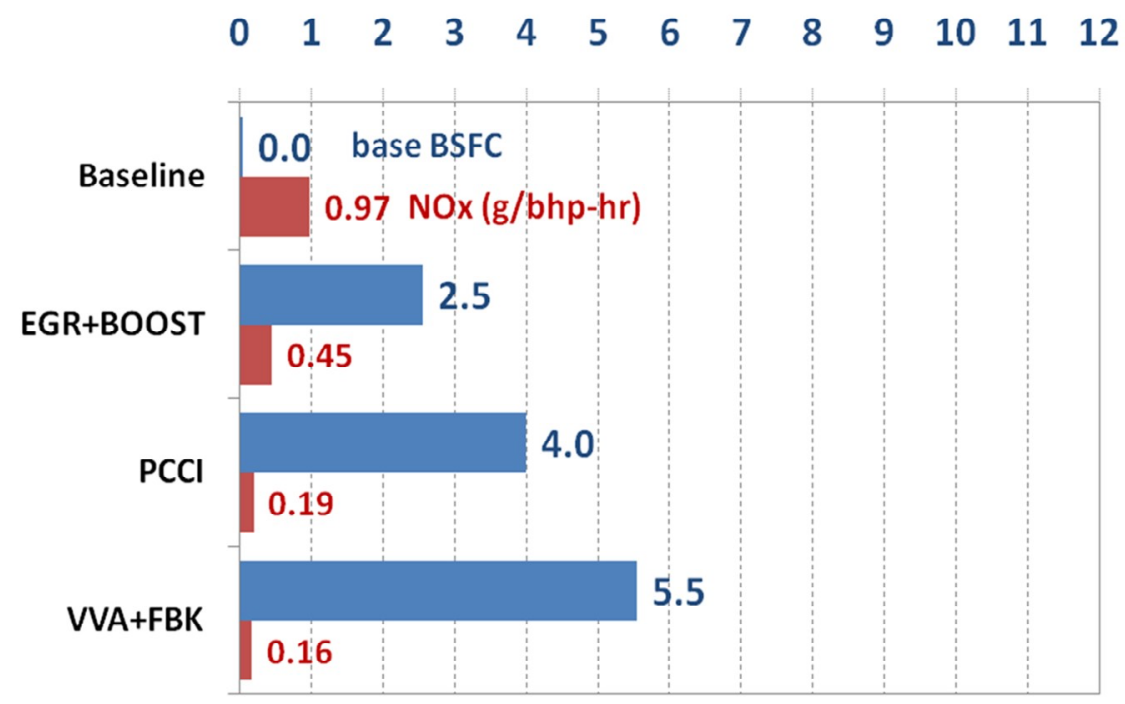

Figure 4313 Mode Composite Comparison

\subsection{Transient Capability}

The current engine is well positioned to transfer the steady state combustion strategy to the transient environment. Any combustion system for that matter, but more so in the high EGR strategy that leads to LTC, requires accurate injection timing. Precise injection timing holds combustion phasing to limit emissions and preserve good combustion efficiency.

Figure 44 shows a section of the heavy duty FTP cycle. Data is also shown as function of combustion cycle numbers for cylinder 1 . This is done to illustrate the cycle-to-cycle feedback capability of the controller.

The top-left plot illustrates the engine speed and torque along 1000 consecutive cycles. The top-right figure highlights a section of the earlier plot, indicating the engine speed and torque, and the total engine mass flow $M_{\text {tot }}$ (composed of the fresh air MAF and EGR flow $M_{\text {egr }}$ ). The colored points indicate specific cycles reproduced on the bottom-left plot as cylinder pressure traces. The pressure traces correspond to cylinder 1 in the engine. The pressure at TDC on these pressure curves correlate very well with $\mathrm{M}_{\text {tot }}$. The bottom-right plot illustrates the active control over start of injection (SOI). SOI is corrected to retain the combustion phasing. The combustion phasing is represented here as the 50 percent of the fuel mass burnt or CA50. Also shown is the indicated torque for the cylinder.

Overall, the control system is very effective in holding the combustion phasing under strong transients. It also provides exceeding useful information that with time will serve to improve the control and optimization of combustion.

The impact of better control over the combustion timing is illustrated in the following Figure 45. The sequence shown here corresponds to the 1000 cycles shown on the earlier Figure 44. 


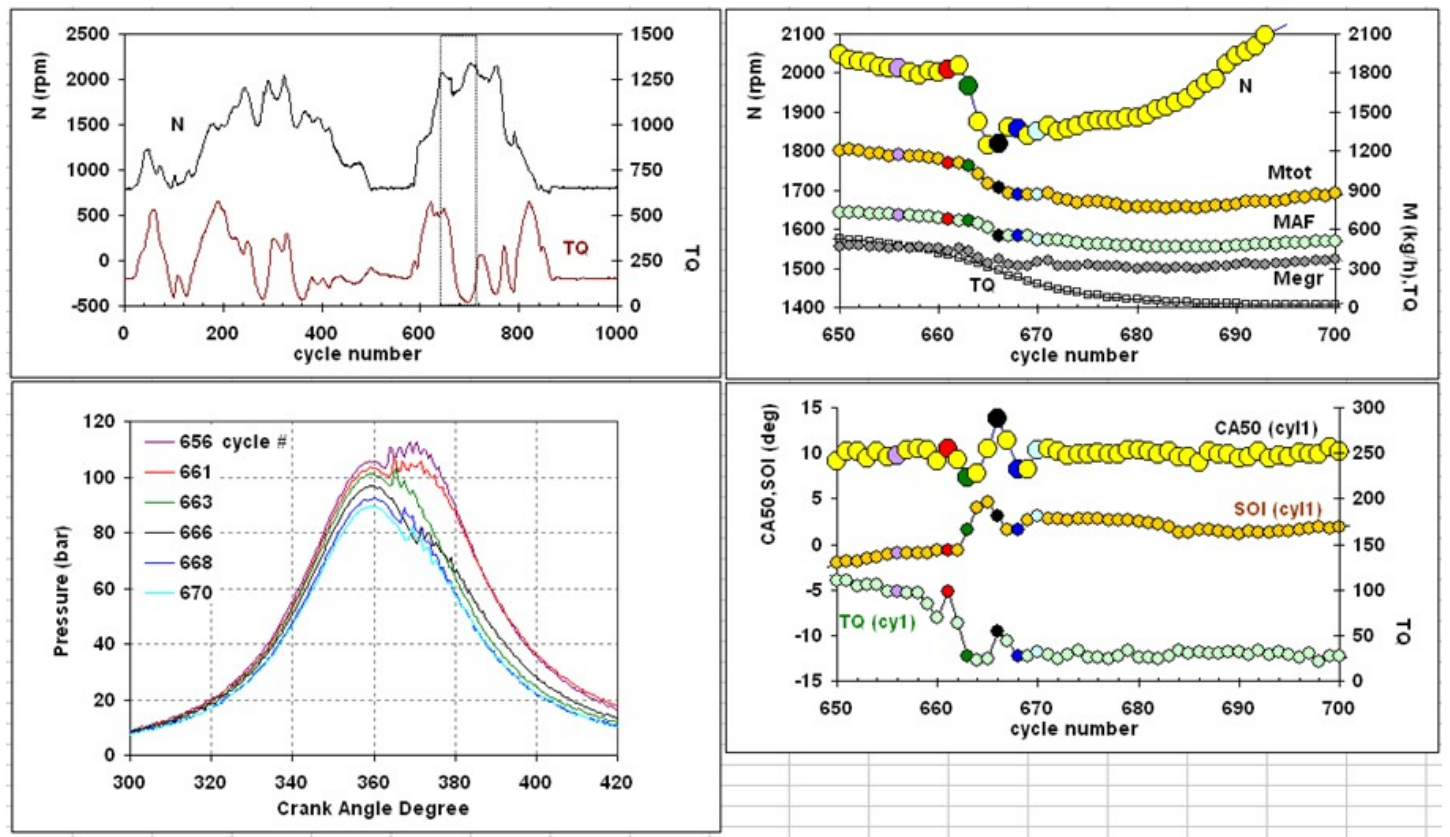

Figure 44 Transient schedule with detail

The average combustion phasing, corresponding to the cycle average across all engine cylinders, is plotted with the control system on and off. With no feedback, the combustion phasing can swing up to 5 degrees off the steady state value, set here at 10 degrees ATDC. Acceleration results in retarded combustion, and deceleration in early combustion. The figure shows the feedback system keeps much tighter control over CA50. The improved control over CA50 results in tighter HC emissions, plotted below, which are indicative of better fuel and combustion efficiency. The HC increase as increased fuel is used in accelerating. Note the time lag shown in the figure corresponds to the sampling length of the measuring equipment.

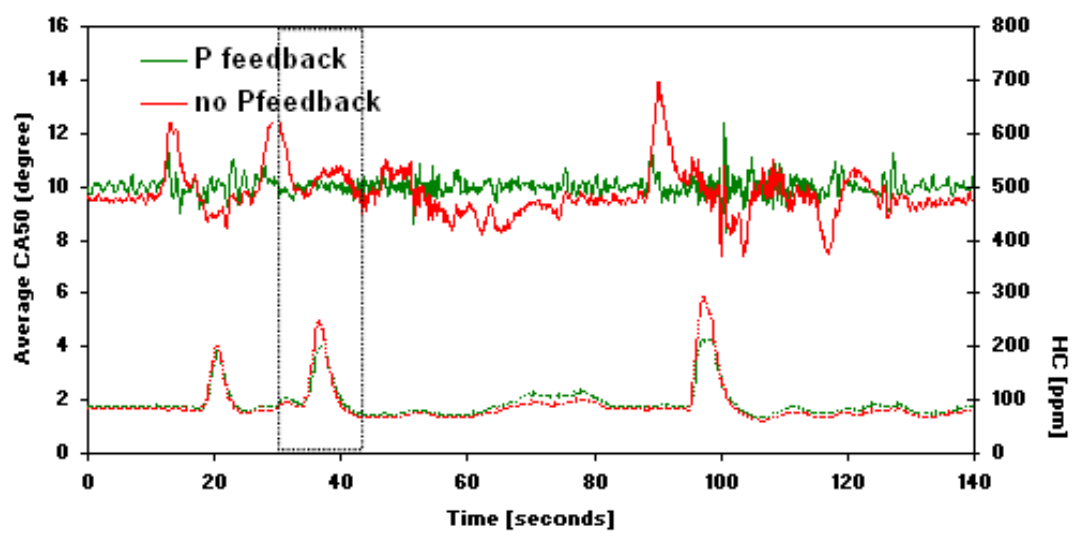

Figure 45 Effect of combustion phasing control on combustion efficiency

A further illustration of the effectiveness of the control and system coupled to combustion feedback is shown in Figure 46. The segment also captures the improved torque response due to better management over the air system and further reduction on the combustion efficiency as captured in the engine $\mathrm{HC}$ output. 

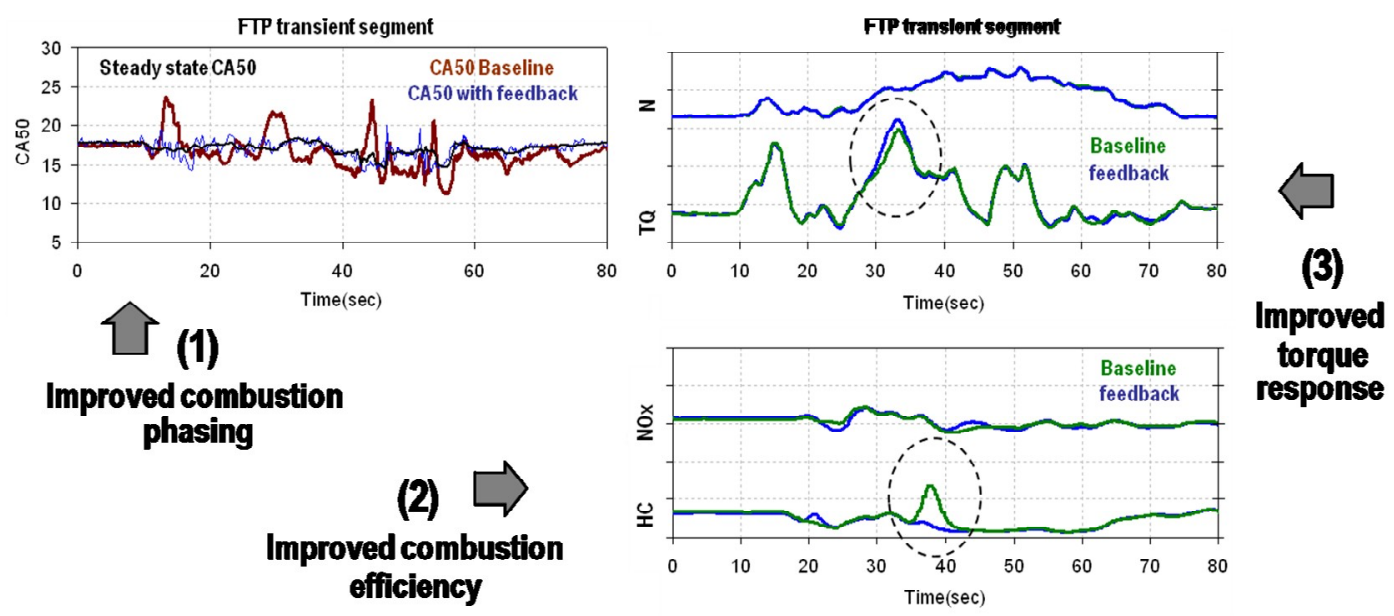

Figure 46 Combustion control on torque response and combustion efficiency

\subsection{Fuels Impact}

Extensive empirical work indicates that exhaust gas recirculation (EGR) is effective to lower the flame temperature and thus the oxides of nitrogen (NOx) production in-cylinder in diesel engines. Soot emissions are reduced in-cylinder by improved fuel/air mixing. As engine load increases, higher levels of intake boost and fuel injection pressure are required to suppress soot production. The high EGR and improved fuel/air mixing is then critical to enable low temperature combustion (LTC) processes. The final effort in the Navistar-DOE LTC project explored the properties of the Fuels for Advanced Combustion Engines (FACE), fuels statistically designed to examine fuel effects, across the full range of load, spanning up to 15 bar IMEP.

The work showed that the lower Cetane number $(\mathrm{CN})$ of the diesel fuel improved the mixing process by prolonging the ignition delay and the mixing duration leading to substantial reduction on soot at low to medium loads, improving the trade-off between NOx and soot. Low load performance, such as cycle-to-cycle variability, was worsened by less effective post flames and the less reactive nature of the mixture.

The higher volatility of the lower T90 fuels promoted the evaporation of the injected fuel spray, thereby accelerating the fuel/air mixing process and improving the homogeneity of cylinder charge. The T90 effect on ignition delay was minor, yet the improved vaporization and mixing translated in a noticeable soot reduction.

The higher aromatic contents in the diesel fuels prolonged the ignition delay. However, the soot emissions were not necessarily reduced according to the extended ignition delay. The soot trend competed with the aromatics, which are precursors of soot.

Fuels Matrix. A cubic design matrix described a high and low value for each parameter, and a center point of the cube. The range for Cetane was selected to be 30 to 55 Cetane numbers. The range for T90\% was chosen as 270 and $340{ }^{\circ} \mathrm{C}$. The range for aromatics was chosen to be 20 to $45 \%$ aromatics. These ranges stretch the typical ranges of US diesel fuel but encompass fuels which could be used in advanced combustion strategies. The properties of the 9 matrix fuels are shown in Table 8, and graphically presented in Figure 47. 
Results at low load. The EGR sweep were repeated for all fuels at an engine load of 5.5 bar. The emissions are plotted versus intake $\mathrm{O}_{2}$ concentration that represents the EGR dilution effect. The test results in Figure 48 show that NOx emissions are more dependent on the EGR ratio or the in-cylinder $\mathrm{O}_{2}$ concentration rather than the fuel properties. The effect is more noticeable at higher levels of NOx emissions. As EGR is increased, the NOx emissions of all 9 fuels are reduced below $0.2 \mathrm{~g} / \mathrm{kW}$-hr.

\section{Table 8: Properties of Fuels}

\begin{tabular}{|c|c|c|c|}
\hline Fuel \# & Cetane Number & Distillation T90 $\left[{ }^{\circ} \mathrm{C}\right]$ & Aromatic Volume [\%] \\
\hline 1 & 29.93 & 269.4 & 22.2 \\
\hline 2 & 28 & 336.1 & 19.4 \\
\hline 3 & 32.02 & 270.0 & 45 \\
\hline 4 & 28.44 & 337.2 & 46.6 \\
\hline 5 & 54.2 & 275.6 & 19.5 \\
\hline 6 & 53.3 & 341.1 & 21.3 \\
\hline 7 & 44.3 & 267.2 & 42.3 \\
\hline 8 & 50 & 342.2 & 43.3 \\
\hline 9 & 44.95 & 321.1 & 32.5 \\
\hline
\end{tabular}

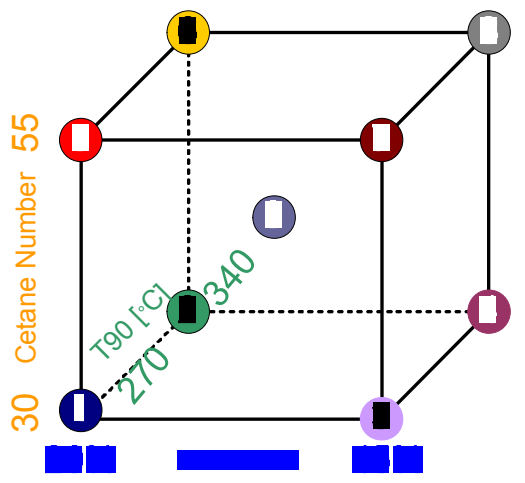

Figure 47 Fuel Property Cube

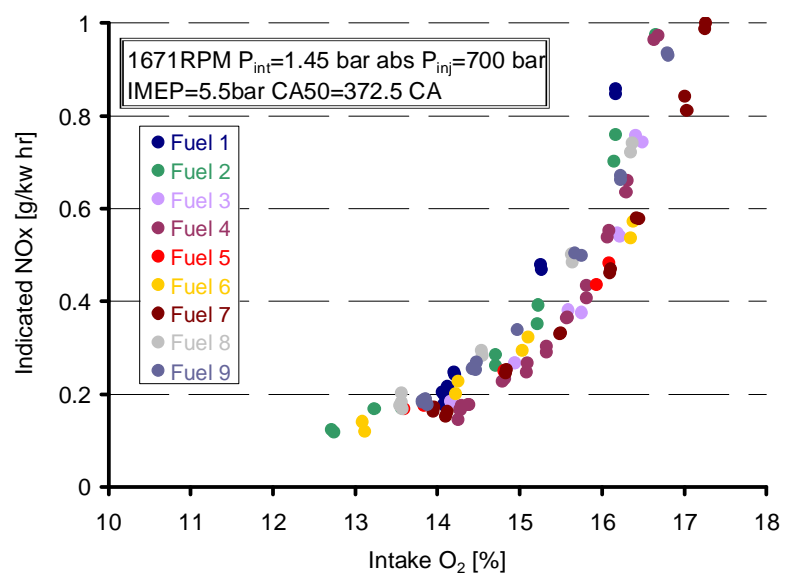

Figure 48 NOx Emissions of EGR Sweep at Low Load 
The soot emissions vary by several FSN points among the fuels, as shown in Figure 49. The soot trend correlates well with the CN. The highest soot emissions over the EGR sweep are observed for the high CN fuels, namely fuels 5,6 , and 8 . On the other hand, the soot emissions of the low CN fuels are below 0.5 FSN.

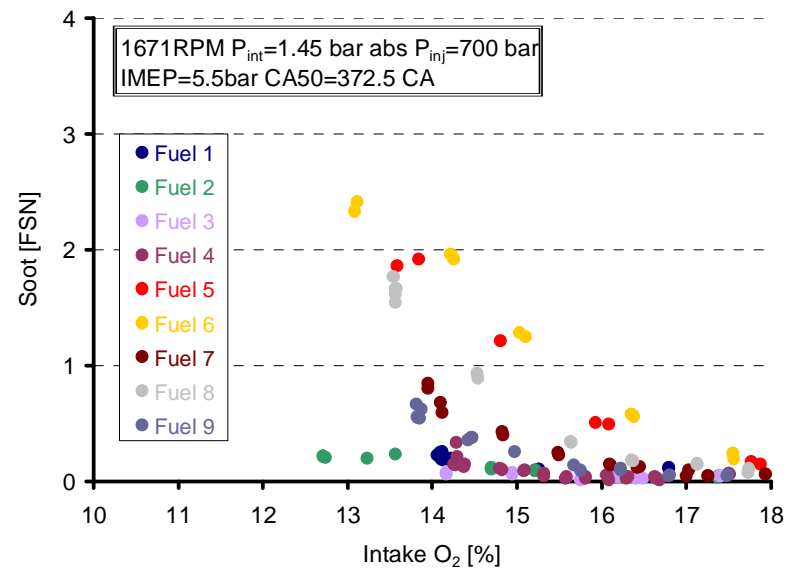

Figure 49 Soot Emissions of EGR Sweep at Low Load

The soot \& NOx trade-off was improved with the low CN fuels as shown in Figure 50. This improvement of the low $\mathrm{CN}$ fuels was achieved by the reduced soot emissions at low $\mathrm{O}_{2}$ levels because the $\mathrm{CN}$ has little direct impact on the NOx in the experiments (Figure 48).

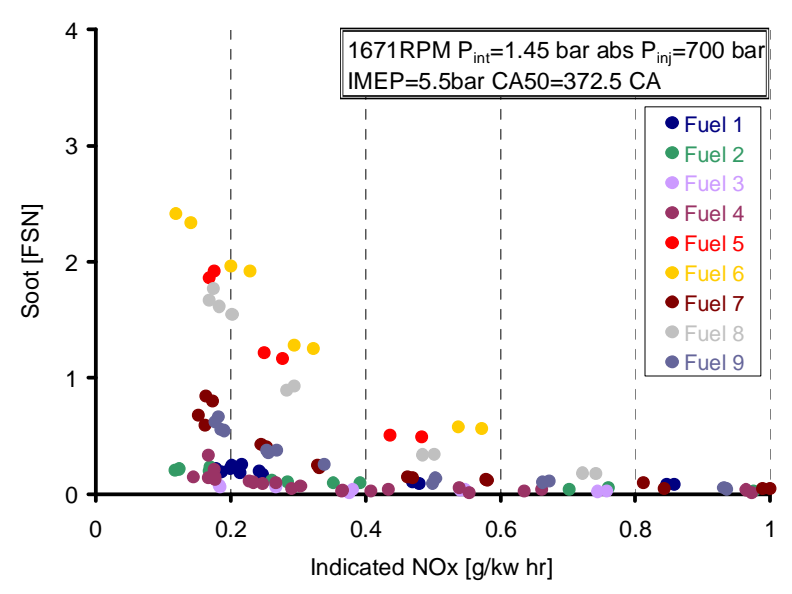

Figure 50: Soot \& NOx Trade-off at Low Load

Results at medium load. The soot \& NOx trade-off over the EGR sweep is plotted in Figure 51. The soot emissions of all the 9 fuels begin to climb when the indicated NOx emissions are lowered. The low CN fuels, within the range of T90 and aromatic content tested here, improve the NOx-soot tradeoff across the EGR sweep. The data forms two groups with low and high CN. At $0.2 \mathrm{gNOx}$ the FSN difference is as large- as 2 FSN. At medium load under the testing conditions, the CN is the most important factor of the three tested fuel properties with respect to the soot and NOx emissions. High $\mathrm{CN}$ fuels generate less THC emissions, but the reduction is not significant, because the overall THC emissions are below $200 \mathrm{ppm}$ at medium load. The $\mathrm{CO}$ emissions tend to overlap with each other. Less $\mathrm{CO}$ is produced by fuels with high CN, low T90, and low aromatic in general. 


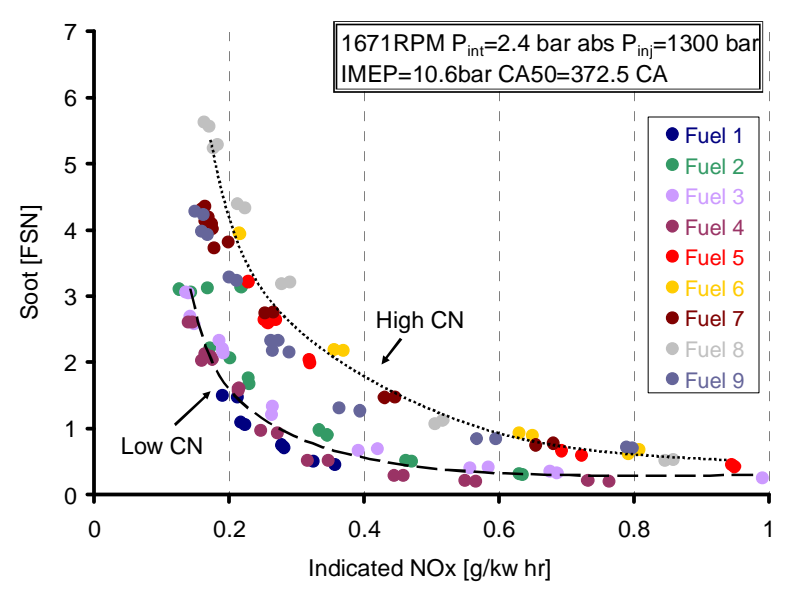

Figure 51 Soot \& NOx Trade-off at Medium Load

Results at high load. At an engine load of 14.6bar IMEP the EGR sweep was repeated. The NOx emissions of all 9 fuels overlap with each other and the overlap is greater than at lower loads. The three fuel properties showed insignificant impact on NOx emissions. On the soot emission side, the low CN fuels still generate less soot emissions, although the influence is weakened. At the high load of 14.6bar IMEP, the soot emissions exceed 3.5 FSN when the indicated NOx is pushed down to 0.2 $\mathrm{g} / \mathrm{kW}$-hr for all the fuels. The high $\mathrm{CN}$ fuels, such as fuel 6 , generate unacceptable high soot emissions of 5 to 6 FSN with heavy EGR. Data shows that the low CN fuels still outperform the high $\mathrm{CN}$ ones in the soot \& NOx trade-off. The THC emissions are reduced to below $100 \mathrm{ppm}$ level as the load is increased.

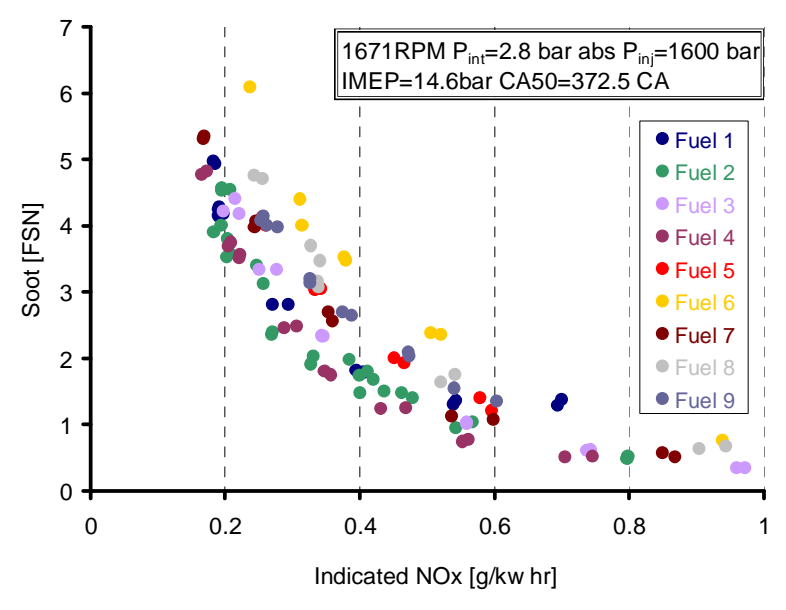

Figure 52 Soot \& NOx Trade-off at High Load

The work presented here utilized a single injection event with injection timing adjusted to yield a constant combustion phasing throughout the range of fuels and examined load conditions. The selection of a single injection event was made to streamline the experiments, while the constant combustion phasing preserved consistency to compare emissions. The authors propose to work on selecting the optimum fuel formulations and apply injection strategies and an optimum combustion chamber matching to further explore the capabilities of the fuel properties to yield clean and efficient combustion. Furthermore, the authors would collaborate with work presently carried out at the National Labs and other laboratories where the same fuels are being examined across a range of engine displacements. 


\section{Economic and Energy Impact}

The purpose of this study was to evaluate the costs and benefits associated with Low Temperature Combustion (LTC) technology developed by Navistar on the DOE LTC program. LTC technology proved to reduce fuel consumption by $5.5 \%$ while meeting 2010 emissions when compared to other technologies such as lean NOx trap (LNT) and selective catalytic reduction (SCR).

Economic models were developed as the framework for the cost vs. benefit analysis. Implementation of LTC technology would were compared to conventional EGR diesel, LNT and SCR technologies. The LTC, SCR and LNT technology being considered in this study are to be applied to the following truck classes and gross vehicle weight ratings (GVWR):

\begin{tabular}{|c|c|c|}
\hline Description & Class & GVWR \\
\hline Light duty pickup & Class 2A & $6000-8500 \mathrm{lbs}$ \\
\hline Heavy duty pickup & Class 2B & $8501-10000 \mathrm{lbs}$ \\
\hline Light duty truck & Classes 3 -5 & $10,001-19,500 \mathrm{lbs}$ \\
\hline Medium duty truck & Class 6-7 & $19501-33000 \mathrm{lbs}$ \\
\hline Heavy duty truck & Class 8 & $33,001 \mathrm{lbs}$ and over \\
\hline
\end{tabular}

\section{Market Growth Potential}

Class $2 b$ to 7 and class 8 vehicle sales are shown in the figure below [13]. Buses were assumed to be approximately 40,000 units per year due to their traditionally low volume. Assuming $1 \%$ market growth per year in all classes, the total truck vehicle sales are presented.

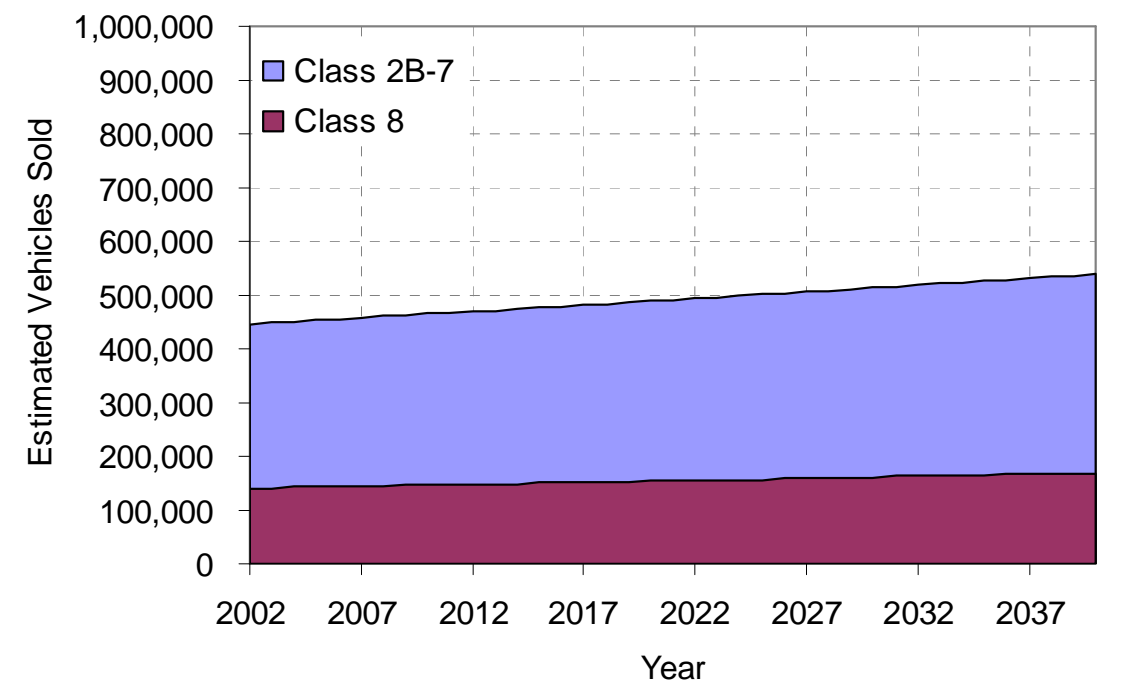

Figure 53 Actual and estimated truck vehicles sold from 2002 to 2040

The introduction of LTC technology to the marketplace can be compared to the introduction of electronic fuel injection technology to the car market and class 2A truck market. LTC technology could be implemented similar to EFI for class 2A because the complexity of the technology is fairly well understood. The figure below shows the assumption used in this study for LTC technology implementation for Class $2 \mathrm{~B}$ to 7 and for class 8 . Note that Class $2 \mathrm{~B}$ to 7 is assumed to attain full market penetration after 10 years of introduction whereas for the Class 8 market only $80 \%$ market penetration due to significant use of SCR technologies. Also Class 8 market introduction is assumed to begin 5 years after medium duty adaptation of the technology. LNT, $\mathrm{HCCl}$ and SCR technologies 
will all be assumed to have the same rate of market penetration for the purposes of this study. LTC truck sales are forecasted from 2010 to 2040.
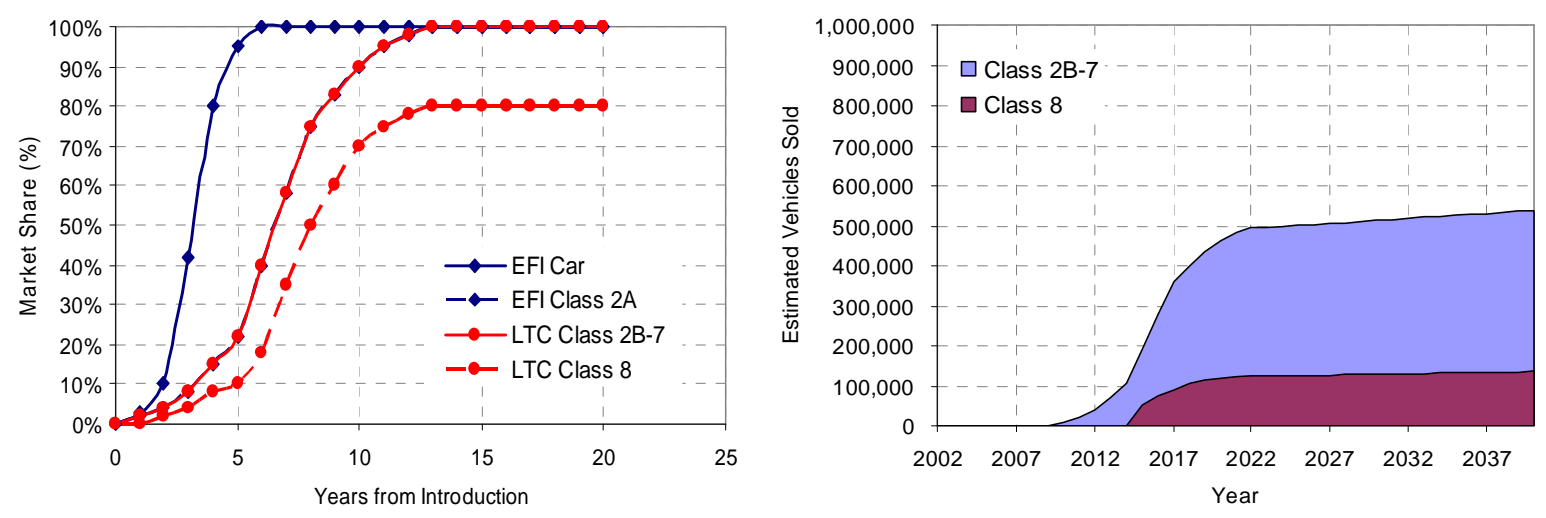

Figure 54 Market penetration of new technology (EFI, LTC)

\section{Oil Price Increase}

The historical price of oil was reviewed from 1987 to 2005 . Based on this historical data the price per barrel of oil for light crude is expected to follow a linear trend and reach $\$ 110$ per barrel of by the year 2040 as shown here.

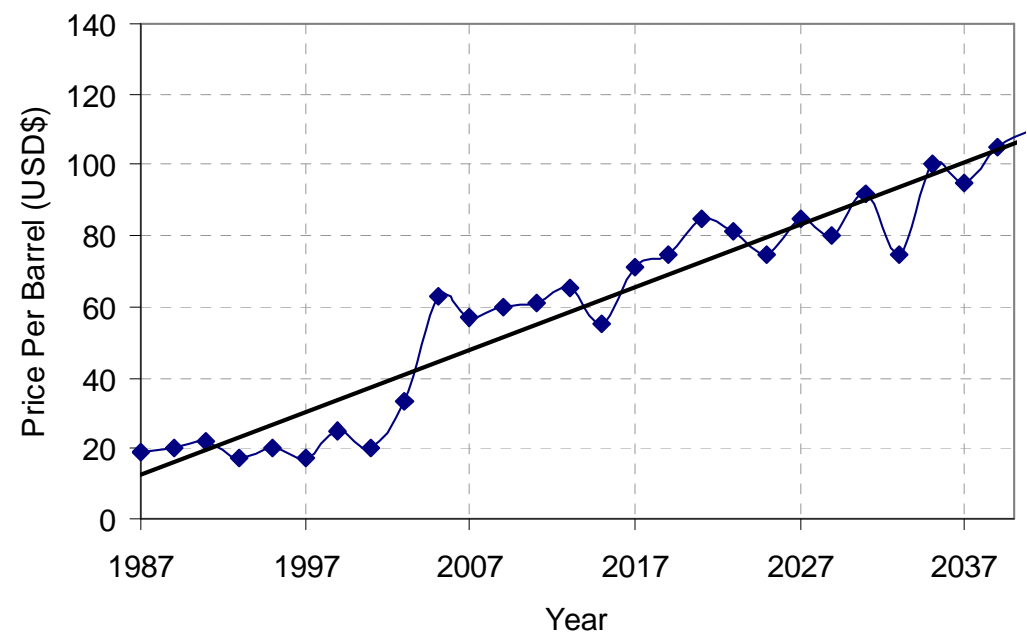

Figure 55 Price per barrel forecast of light crude oil

\section{Oil Savings}

The crude oil savings in million barrels per day was calculated by making several assumptions. Firstly the class 2B to 7 trucks were equipped with an Maxxforce 6.4L V8 and Class 8 engines were equipped with an Maxxforce 13L 16 big bore. The light duty engine is assumed to operate at full load for 3 hours a day and 240 days per year. The heavy duty engine is assumed to operate at full load for 8 hours a day 240 days per year. Also the efficiency advantage of the LTC showed in this work was $5.5 \%$. The conversion yield of light crude oil to diesel fuel was determined to be $34 \%$. The results of the crude oil savings per year are presented in figure below. 


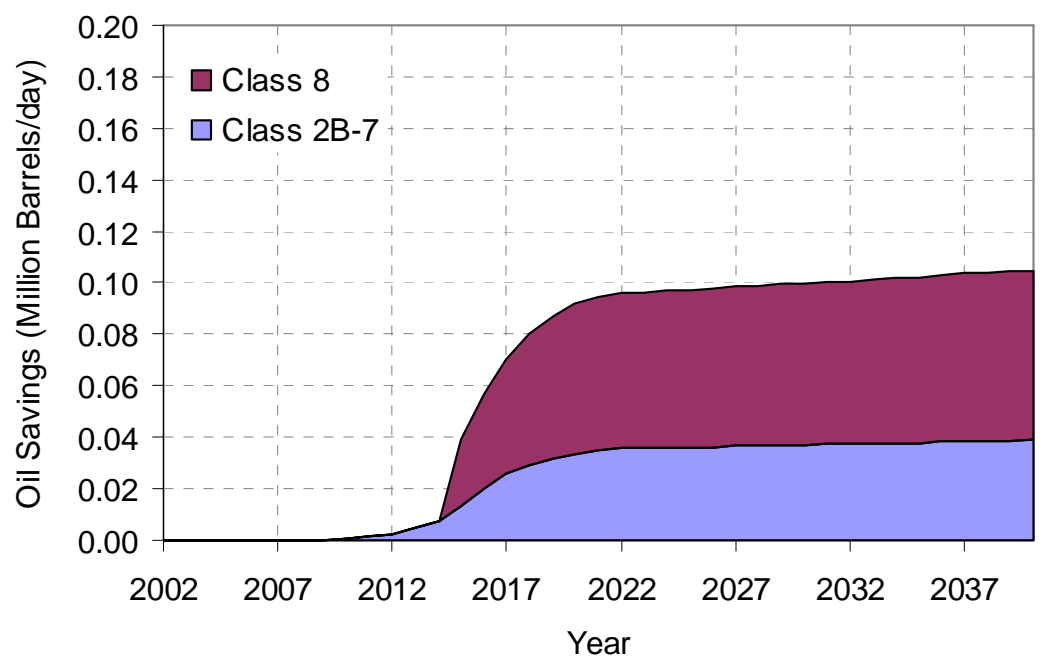

Figure 56 Crude oil savings with LTC technology.

\section{Engine Cost}

The breakdown of engine costs for both International $6.4 \mathrm{~L}$ V8 and the $13 \mathrm{~L} 16$ are presented in Table below. The addition of LTC technology for both $6.4 \mathrm{~L} \mathrm{V8}$ and $13 \mathrm{~L} 16$ engines was assumed to cost $\$ 500$ per engine on a volume of 400,000 units.

\begin{tabular}{|c|c|c|c|c|c|c|c|c|c|}
\hline \multirow{4}{*}{$\begin{array}{l}\text { Base Engine Price } \\
\text { Aftertreatment } \\
\text { LTC Technology }\end{array}$} & & \multicolumn{2}{|c|}{$\begin{array}{c}\text { US07 } \\
6.4 \text { L V8 }\end{array}$} & \multicolumn{2}{|c|}{$\begin{array}{c}\text { US10 } \\
6.4 \text { L V8 } \\
\text { LTC }\end{array}$} & \multicolumn{2}{|c|}{$\begin{array}{c}\text { US10 } \\
6.4 \text { L V8 } \\
\text { LNT }\end{array}$} & \multicolumn{2}{|c|}{$\begin{array}{l}\text { US10 } \\
6.4 \text { L V8 } \\
\text { SCR }\end{array}$} \\
\hline & $(\$)$ & \multicolumn{2}{|c|}{$\$ 6,787.00$} & $\$$ & $6,787.00$ & $\$$ & $6,787.00$ & $\$$ & $6,787.00$ \\
\hline & (\$) & $\$$ & 985.00 & & - & $\$$ & $1,500.00$ & $\$$ & $1,700.00$ \\
\hline & $(\$)$ & $\$$ & - & $\$$ & 500.00 & $\$$ & - & $\$$ & - \\
\hline Total & & $\$$ & $7,772.00$ & $\$$ & $7,287.00$ & $\$$ & $8,287.00$ & $\$$ & $8,487.00$ \\
\hline Savings (Penalty) & $(\$)$ & $\$$ & - & $\$$ & 485.00 & $\$$ & $(515.00)$ & $\$$ & $(715.00)$ \\
\hline & & & $\begin{array}{l}\text { USO7 } \\
13 \mathrm{~L} 16\end{array}$ & & $\begin{array}{l}\text { US10 } \\
13 \mathrm{~L} 16 \\
\text { LTC }\end{array}$ & & $\begin{array}{l}\text { US10 } \\
13 \mathrm{~L} 16 \\
\text { LNT }\end{array}$ & & $\begin{array}{l}\text { US10 } \\
13 \mathrm{~L} 16 \\
\text { SCR }\end{array}$ \\
\hline Base Engine Price & $(\$)$ & & $1,500.00$ & & $11,500.00$ & $\$$ & $11,500.00$ & $\$ 1$ & $11,500.00$ \\
\hline Aftertreatment & (\$) & & $1,700.00$ & & - & $\$$ & $2,000.00$ & $\$$ & $2,500.00$ \\
\hline LTC Technology & (\$) & $\$$ & - & $\$$ & 500.00 & $\$$ & - & $\$$ & - \\
\hline Total & & & $3,200.00$ & $\$$ & $12,000.00$ & $\$ 1$ & $13,500.00$ & $\$ 1$ & $14,000.00$ \\
\hline Savings (Penalty) [ & $(\$)$ & $\$$ & - & $\$$ & $1,200.00$ & $\$$ & $(300.00)$ & $\$$ & $(800.00)$ \\
\hline
\end{tabular}

\section{Future Savings with LTC Technology}

The cumulative future engine cost savings and fuel cost savings with implementation of LTC technology is presented in the figure below. The net present value of the savings was calculated based on an interest rate of $4 \%$. 
Program DE-FC26-05NT42413

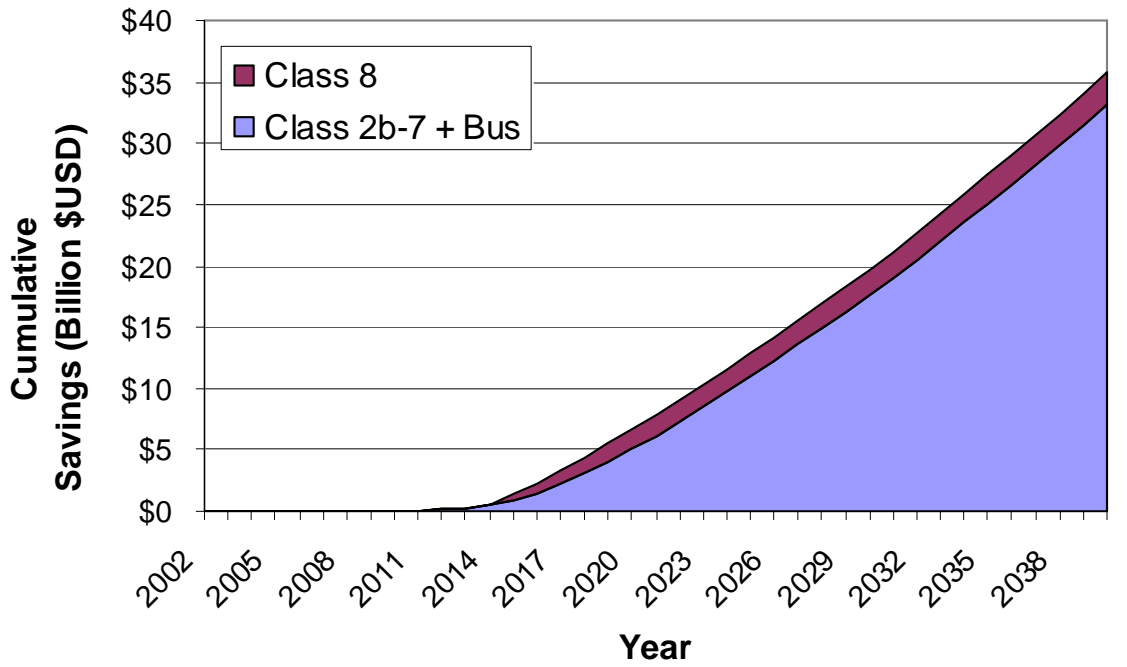

Figure 57 Cumulative savings due to implementation of LTC technology 


\section{Summary of Achievements}

This program applied the principles of Low Temperature Combustion (LTC) to the NAVISTAR 6.4L V8 medium duty Diesel engine to demonstrate EPA 2010 emissions without NOx after-treatment while attaining a 5\% BSFC improvement over the baseline product.

Project objectives were successfully attained by overcoming the combustion stability of LTC due to high EGR use. The project leveraged the modeling capabilities of LLNL and ConocoPhillips to overcome the lack of fundamental understanding of the LTC combustion process. Simultaneously, NAVISTAR developed new combustion diagnostics that are integrated onto its production ECU. Combustion feedback was integrated with the injection strategy and a newly developed variable valve actuation system.

\section{Application of PCCI.}

BSFC improvement of $2 \%$ was identified by Partially Premixed Compression Ignition Combustion $(\mathrm{PCCl})$. Here a portion of the fuel is injected early in the compression stroke to create a premixed charge. The amount and timing were optimized with the aid of cylinder pressure feedback control.

\section{Variable Valve Timing Technology.}

The project is the first successful demonstration of the application of VVA on a modern medium duty Diesel engine to successfully impact emissions and fuel economy. The system is simple and robust, provides fine intake valve closing resolution independently for each cylinder, and is capable of cycle to cycle adjustments.

\section{Fuel Economy and Emissions.}

The application of advanced EGR and air charge systems in conjunction with premixed fuel injection strategies $(\mathrm{PCCl})$ yielded a $4 \%$ better cycle averaged fuel consumption at $0.2 \mathrm{gNOx} / \mathrm{bhp}$-hr engine out. The use of VVA introduced an engineering margin for the $0.2 \mathrm{gNOx}$, while improving the average fuel consumption by $5.5 \%$ and reducing soot by $0.05 \mathrm{~g} / \mathrm{bhp}$-hr over the base engine.

\section{Publications:}

A list of publications documenting the program progress and final outcome is included here:

- Multicylinder Diesel Engine Design for $\mathrm{HCCl}$ operation, William de Ojeda, Alan Karkkainen, Diesel Engine Development, DEER 2006, August 20-24, Detroit, Michigan.

- Development of a Multi-Cylinder Diesel Engine for $\mathrm{HCCl}$ Operation, William de Ojeda, SAE Homogeneous Charge Compression Ignition Symposium 2006, Sep 25-26, San Ramon, California

- Multicylinder Diesel Engine Design for HCCl operation", William de Ojeda, Raj Kumar, Raul Espinosa, Phil Zoldak, Chunyi Xia, Diesel Engine Development, DEER 2007, August 12-16, Detroit Michigan 
- "Development of a Fuel Injection Strategy for LTC in a Diesel Engine", William de Ojeda, Phil Zoldak, Raul Espinosa, Raj Kumar, 2008-01-0057, SAE 2008 World Congress and Exhibition, Detroit.

- "Multicylinder Diesel Engine Design for LTC operation", William de Ojeda, Raj Kumar, Raul Espinosa, Phil Zoldak, Chunyi Xia, Dan Cornelius, Diesel Engine Development, DEER 2008, August 4-8, Auburn Hills, Michigan.

- "Development of a Fuel Injection Strategy for Partially Premixed Compression Ignition Combustion", William de Ojeda, Philip Zoldak, Raul Espinosa, Raj Kumar, 2009-01-1527, SAE 2009 World Congress and Exhibition.

- "Multicylinder Diesel Engine Design for LTC operation", William de Ojeda, Raj Kumar, Raul Espinosa, Phil Zoldak, Chunyi Xia, Dan Cornelius, Diesel Engine Development, DEER 2009, August 3-9, Dearborn, Michigan.

- "Effect of Variable Valve Timing on Low-Load Diesel Combustion Characteristics", William de Ojeda, Dan Cornelius, Raj Kumar, 2010-01-1124, SAE 2010 World Congress and Exhibition.

- "Impact of Variable Valve Timing on Low Temperature Combustion", William de Ojeda, Diesel Engine Development, DEER 2010, Detroit, Michigan.

- "The Impact of Fuel Properties on Diesel Low Temperature Combustion", Submitted to the 2011 SAE World Congress, William de Ojeda, Tytus Bulicz, Xiaoye Han, Ming Zheng, Fred Cornforth, 2011-11PFL-0922. 


\section{Extension of Program}

The present program has demonstrated the achievement of 2010 US NOx emission targets using incylinder combustion techniques. The next challenge is to improve the engine efficiency. To this effect, the following technology areas are seeing as enablers:

i. Use of ultra-high injection pressure. The present program used an injection system rated to 1600 bar. The impact of extending the injection pressure to 3000 bar or above would provide significant improvements in fuel - charge air homogenization and suppress soot formation. Recent systems are being proposed with injection pressure capability to $2200-2500$ bar for production.

The work proposed would entail a systematic study of the impact of injection pressure on emissions and performance. Ideally the study would extend to the use of high pressure with multiple-injection events.

ii. Fuel Properties. As new fuels are being considered, the ability to formulate specific properties can become a significant enabler to extend the LTC operation. Properties such as volatility and Cetane number can influence fuel and air homogenization and ignition delay control.

Navistar is currently testing the CRC FACE fuels in a SCTE platform. These fuels represent a fuel matrix of varying Cetane number, volatility and aromatic content. Preliminary tests, as reported here, show significant improvements can be attained in reducing soot and are likely to contribute to better fuel economy and simplified after-treatment systems.

iii. Improve Controls. Controls have proved to be a significant enabler to both improve the steady state optimization as well as to implement LTC transients. Future work is foreseen to take full advantage of the cylinder pressure information and feedback control towards developing more efficient combustion cycles.

iv. Reconsideration of VCR. The present program explored the VCR option but did not pursue its procurement. Present results have shown the benefit of variable compression ratios to accommodate the engine load range. The VCR may be able to extend the LTC range to 20 bar BMEP without fuel penalty.

A simplified version of the VCR could be pursued with a production intent design. 


\section{References}

1 Epsey C., and Dec J.E., "Diesel Engine Combustion Studies in a Newly Designed Optical-Access Engine Using High-Speed Visualization and 2-D Laser Imaging”, SAE 930971.

2 Murata, Y., Kusaka, J., Odaka, M., Daisho, Y., Kawano, D., Suzuki, H., Ishii, H., and Goto, Y., "Achievement of Medium Engine Speed and Load Premixed Diesel Combustion with Variable Valve Timing", SAE Paper 2006-01-0203.

3 Nevin R.M., Sun Y., Gonzalez M.A. and Reitz R.D., "PCCI Investigation Using Variable Intake Valve Closing in a Heavy Duty Diesel Engine", SAE Paper 2007-01-0903

4 Duffy K.., “Diesel HCCI Results at Caterpillar," DEER conference, August, 25-28, 2003.

5 Amsden A., KIVA-3V: A Block-Structured KIVA Program for Engines with Vertical or Canted Valves, Los Alamos Natl. Lab. Rep. LA-13313-MS, 1997.

6 Reitz, R.D., "Modeling Atomization Processes in High-Pressure Vaporizing Sprays," Atomization and Spray Technology, 3, 309, 1987.

7 Reitz, R. D. and Diwakar, R., "Structure of High-Pressure Fuel Sprays," SAE Paper No. 870598.

8 Patel A., Kong S.C., Reitz R.D., "Development and Validation of a Reduced Reaction Mechanism for Hcci Engine Simulations", SAE Paper No. 2004-01-0558.

9 Smith G.P., Golden D.M., Frenklach M., Moriarty N.W., Eiteneer B., Goldenberg M., Bowman C.T., Hanson R.K., Song S., Gardiner W.C., Lissianski V.V., and Qin Z., GRI-Mech 3.0, available from Web page http://www.me.berkeley.edu/gri mech/version30/text30.html:

10 Kong S.C., Sun Y., and Reitz R.D., "Modeling Diesel Spray Flame Lift-Off, Sooting Tendency and NOx Emissions Using Detailed Chemistry with Phenomenological Soot Model", ASME paper ICES2005-1009.

11 Hiroyasu H., and Kadota T., "Models for Combustion and Formation of Nitric Oxide and Soot in Direct Injection Diesel Engines", SAE Paper No. 760129.

12 Nagle, J., and Strickland-Constable R.F., "Oxidation of Carbon between 1000-200C". Proceedings of the Fifth Carbon Conference., Volume 1, Pergammon Press, 1962, pp.154-164.

13 http://www.wr4cleanair.org/Reports05/050205\%20Truck\%20Type\%20Appendix.pdf. Consensus Forecasts Inc. 2005. "September 2005 Oil Prices." Consensus Forecasts (September 12) p. 27. Hotelling, Harold. 1931. "The Economics of Exhaustible Resources." The Journal of Political Economy 39(2) (April) pp. 137-175. http://www.greencarcongress.com/2005/08/diesel_deficit_html 